\title{
Particulate Hot Gas Stream Cleanup Technical Issues
}

\author{
Annual Report \\ October 1994 - September 1995
}

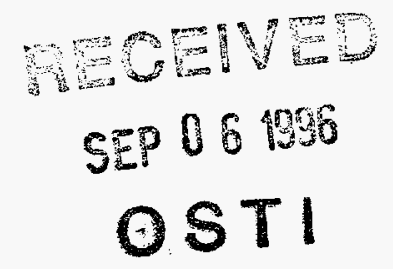

December 19, 1995

Work Performed Under Contract No.: DE-AC21-94MC31160

\section{For}

U.S. Department of Energy

Office of Fossil Energy

Morgantown Energy Technology Center

Morgantown, West Virginia

By

Southern Research Institute 2000 Ninth Avenue South

P.O. Box 55305

Birmingham, Alabama 35225-5305

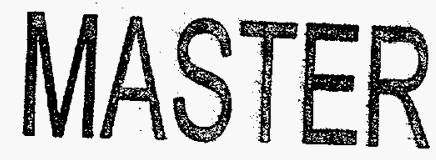

DSTHEUTION OF BHIS DOCWENT IS UNMTTED

a 


\section{DISCLAIMER}

This report was prepared as an account of work sponsored by an agency of the United States Government. Neither the United States Government nor any agency thereof, nor any of their employees, makes any warranty, express or implied, or assumes any legal liability or responsibility for the accuracy, completeness, or usefulness of any information, apparatus, product, or process disclosed, or represents that its use would not infringe privately owned rights. Reference herein to any specific commercial product, process, or service by trade name, trademark, manufacturer, or otherwise does not necessarily constitute or imply its endorsement, recommendation, or favoring by the United States Government or any agency thereof. The views and opinions of authors expressed herein do not necessarily state or reflect those of the United States Government or any agency thereof.

Available to the public from the National Technical Information Service, U.S. Department of Commerce, 5285 Port Royal Road, Springfield, VA 22161; phone orders accepted at (703) 487-4650. 


\section{DISCLAIMER}

Portions of this document may be illegible in electronic image products. Images are produced from the best available original document. 


\title{
Particulate Hot Gas Stream Cleanup Technical Issues
}

\author{
Annual Report \\ October 1994 - September 1995
}

Work Performed Under Contract No.: DE-AC21-94MC31160

\author{
For \\ U.S. Department of Energy \\ Office of Fossil Energy \\ Morgantown Energy Technology Center \\ P.O. Box 880 \\ Morgantown, West Virginia 26507-0880
}

Southern Research Institute

2000 Ninth Avenu South

P.O. Box 55305

Birmingham, Alabama 35255-5305

December 19, 1995 


\title{
PARTICULATE HOT GAS STREAM CLEANUP TECHNICAL ISSUES
}

\author{
ANNUAL REPORT \\ October 1994 - September 1995 \\ SRI-ENV-95-899-8484-A1
}

December 19, 1995

SOUTHERN RESEARCH INSTITUTE 2000 NINTH AVENUE SOUTH

Post Office Box 55305

BIRMINGHAM, ALABAMA 35255-5305

Principal Investigator: D. H. Pontius

\author{
for \\ UNITED STATES DEPARTMENT OF ENERGY \\ Morgantown Energy Technology Center \\ Post Office Box 880, 3610 Collins Ferry Road \\ Morgantown, West Virginia 26505
}

Contract No. DE-AC21-94MC31160

Project Manager: Thomas P. Dorchak 


\section{TABLE OF CONTENTS}

\section{PAGE}

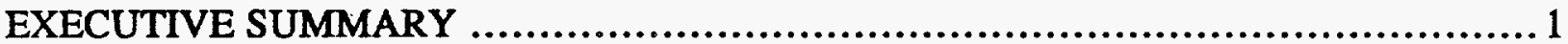

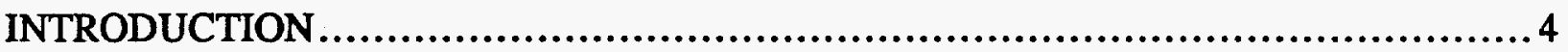

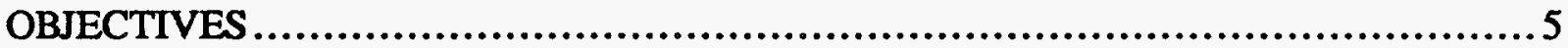

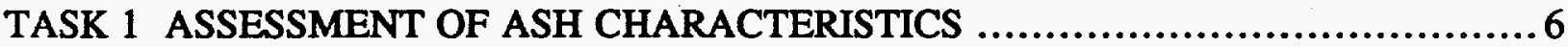

HGCU DATA BASE DEVELOPMENT ...............................................6

MODIFICATIONS TO THE EMPIRICAL PERMEABILITY MODEL ..................7 TRANSLATING LABORATORY PERMEABILITY DATA TO HGCU CONDITIONS...8 OPERATION AND PERFORMANCE OF THE TIDD APF ...........................9

Site Visits to Tidd ...................................................................... 11

Analyses of Tidd Ash Samples ..................................................... 14

Size Distribution .................................................................... 14

Chemical Analysis .............................................................. 17

Nodule Porosity, Uncompacted Bulk Porosity, and Specific Surface Area ............. 20

Scanning Electron Microscopy....................................................... 21

Laboratory Baking of Ash Nodules.................................................. 21

Mechanisms Controlling the Consolidation of Ash Deposits ........................... 31

Avoiding High-Strength PFBC Ash Deposits ......................................... 34

DESIGN OF A HIGH-TEMPERATURE UNCOMPACTED BULK POROSITY TEST DEVICE ...................................................................... 34

CHARACTERIZATION OF GASIFIER SAMPLES .................................... 35

TASK 2 FILTER MATERIAL CHARACTERIZATION ............................. 46

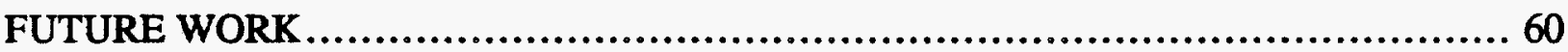

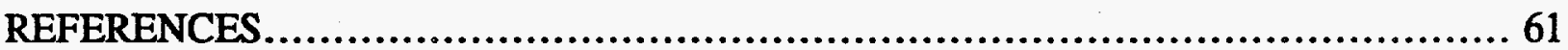

APPENDIX A ANALYTICAL METHODS USED TO CHARACTERIZE ASH...........A-1 


\section{EXECUTIVE SUMMARY}

This is the first annual report describing the activities performed under Contract No. DEAC21-94MC31160. The analyses of Hot Gas Stream Cleanup (HGCU) ashes and descriptions of filter performance studied under this contract are designed to address the problems with filter operation that are apparently linked to the characteristics of the collected ash. Task 1 is designed to generate a data base of the key characteristics of ashes collected from operating advanced particle filters (APFs) and to relate these ash properties to the operation and performance of these filters and their components. APF operations have also been limited by the strength and durability of the ceramic materials that have served as barrier filters for the capture of entrained HGCU ashes. Task 2 concerns testing and failure analyses of ceramic filter elements currently used in operating APFs and the characterization and evaluation of new ceramic materials.

Task 1 research activities during the past year included initial formatting of the data base and data entry, modification of the permeability model used to predict the filtering pressure drop associated with ashes in the data base, and initial design of a high-temperature test device for the measurement of the uncompacted bulk porosity of aggregates of ash formed at temperatures commonly encountered in operating APFs. (Uncompacted bulk porosity is a good indicator of the relative cohesivity of the ash, and also can be used to help estimate filter cake porosity and permeability.)

Two site visits were made to the American Electric Power's 70 MWe PFBC demonstration at the Tidd Plant located in Brilliant, Ohio. Observations of the condition of the Tidd APF and analyses of ash samples collected from the filter assembly during these two visits are summarized in this report. In general, analyses of the ash samples from the Tidd APF showed that the ash that collects at various places throughout the filter vessel initially forms loose, weak, uncompacted deposits that are 85 to $90 \%$ porous. (After the cyclone was completely bypassed, the ash formed deposits that were initially around $80 \%$ porous.) In almost all cases, the exposure of these deposits to the temperatures in the APF (1200 $1550^{\circ} \mathrm{F}$ ) caused them to gradually consolidate and transform into much stronger structures having porosities as low as $69 \%$. An excellent image generated with a Scanning Electron Microscope of a consolidated ash deposit collected from the APF was very enlightening as to the structure of the deposit. The tenacious ash deposits found in the APF appear as concretions composed of discrete fine particles almost completely embedded in a pervasive amorphous mass which apparently formed in the APF after the particles were initially collected. Various analyses and reviews of pertinent literature indicate that the mechanism responsible for the extreme consolidation of these ash deposits was a physical rearrangement of the ash particles due to the surface tension of melted or partially melted alkali-aluminosilicate eutectic mixture(s) formed at the contact points between adjacent particles after long-term exposure to the temperatures in the APF. This mechanism is discussed in more detail later in this report. 
Because of the mechanisms governing the consolidation of the ash deposits, it is doubtful that process changes such as slightly lowering the temperature in the APF, sorbent switching, or addition of a conditioning agent can be effective in inhibiting the formation of these eutectics and the subsequent consolidation and strengthening of the ash aggregates. The minimum operating temperature of the APF is strictly limited by the economics of the PFBC process. Past operation at reduced temperatures around $1250^{\circ} \mathrm{F}$ have not been able to prevent the formation of consolidated ash aggregates. Since magnesium and calcium are both excellent fluxing agents, altering the type of sorbent used in the PFBC process is not likely to alter the tendency for eutectic formation.

Therefore, the optimum solution to the problems caused by the ash aggregates that have been consolidated and strengthened by pervasive eutectic formation is the removal of ash aggregates from the APF before these eutectics have had enough time to develop. A large measure of success has been achieved by bypassing the cyclone upstream of the APF. This increases the size distribution of the particles forming the various ash deposits (filter cakes and passive deposits), thereby decreasing their inherent cohesivity. These agglomerates of lower cohesivity do not have sufficient strength to remain in the APF long enough to undergo consolidation. The effects of gravity and vibration cause them to fall off the surface on which they initially formed. We produced a special topical report entitled Analyses of Ashes from the Tidd PFBC Advanced Particulate Filter for the U.S. Department of Energy's Morgantown Energy Technology Center (DOE/METC) under Task 1 summarizing our observations, measurements, and conclusions regarding the operation and performance of the Tidd APF. An appendix covering this same material was also prepared for John Hoffman of American Electric Power for inclusion in his summary of Tidd operation.

We analyzed a sample of ash from the gasification facility located at DOE/METC and also performed additional analyses on gasifier ashes from tests carried out by M.W. Kellogg, Texaco, and KRW between 1988 and 1991. These additional analyses were intended to strengthen and clarify correlations that we have observed between specific surface area, uncompacted bulk porosity, specific gas flow resistance, drag-equivalent diameter, and tensile strength. Several of the gasifier ashes we analyzed exhibit very high resistances to filtering flow. We have related this characteristic to high proportions of ultrafine particles.

Task 1 Plans for the next year include completion of the design of the uncompacted bulk porosity test device described in this report and continued work on the interactive data base of HGCU ash characteristics. We are evaluating software that will be used to construct the data base. Additional samples solicited from various HGCU installations will be added to the HGCU data base and analyzed to assess their performance in high temperature filtration.

Task 2, which has been active for six months, focused on mechanical and thermal testing of various ceramic materials. Samples that have been analyzed include Dupont/Lanxide PRD-66, Dupont composite, 3M composite, IF and P Fibrosics, Refractron, and 
Schumacher ceramic materials. Analyses performed include hoop and axial tensile tests, composite and axial compression tests, axial thermal expansion tests, and creep evaluations. Specimens of recently received Schumacher filters are being machined in preparation for nondestructive density and ultrasonic velocity measurements. Following the completion of these measurements, mechanical and thermal testing of the new Schumacher material will commence. 


\section{INTRODUCTION}

This is the first annual report describing the activities performed under Contract No. DEAC21-94MC31160. Task 1 of this contract is concerned with the analyses of HGCU ashes and descriptions of filter performance and is designed to address the problems with filter operation that are apparently linked to the characteristics of the collected ash. Task 2 of this contract includes characterization of new and used filter elements. Some of the problems observed at the Tidd and Karhula PFBC facilities include excessive filtering pressure drop, the formation of large, tenacious ash deposits within the filter vessel, and bent or broken candle filter elements. In addition to these problems related to the characteristics of PFBC ashes and the ceramic materials used to construct candle filters, our previous laboratory characterizations of gasifier and carbonizer ashes have shown that these ashes also have characteristics that might negatively affect filtration.

Much of the work planned for Task 1 builds directly on work performed under a prior contract (No. DE-AC21-89MC26239). In order to identify which ash characteristics can lead to problems with filtration, we have assembled 235 ash samples from eleven facilities involved in METC's HGCU program. We have analyzed many of these ashes with a variety of laboratory tests. Physical attributes of the particles that we have examined include size distribution, specific surface area, particle morphology, and bulk ash cohesivity and permeability. We have also performed a range of chemical analyses on these ashes, as well as characterizations of agglomerates of ash removed from various places in the filter vessels at Tidd and Karhula. We are in the process of assembling the data obtained in these studies into an interactive data base which will help the manufacturers and operators of high-temperature barrier filters tailor their designs and operations to the specific characteristics of the ashes they are collecting.

During initial filter testing at various HGCU facilities, catastrophic failures of individual candle filter elements have prompted in-depth studies of the characteristics of the various ceramic materials used to produce these elements. HGCU filter temperatures have led to softening of the clay binders used to bond the granular ceramic materials together. Measurements have shown that many ceramic materials initially used in HGCU filters rapidly loose much of their strength when exposed to the environment within the APF. In addition, thermal shock resulting from the application of pulse air during cleaning has also apparently contributed to candle failures. Problems with the durability of the filter elements are being addressed by the development and evaluation of elements constructed from alternative ceramic materials. In order to understand the thermal and mechanical behavior of the various types of ceramic materials used in hot gas filtration, we have been performing hoop and axial tensile tests, thermal expansion, compression, and creep evaluations of these materials at temperatures up to $1800^{\circ} \mathrm{F}$. Nondestructive testing methods we perform on filter specimens include density and ultrasonic velocity. To date we have evaluated various characteristics of Dupont/Lanxide PRD-66, Dupont composite, 3M composite, IF and P Fibrosics, Refractron, and Schumacher materials. 


\section{OBJECTIVES}

Task 1 has two primary objectives. The first is to generate a readily accessible data base of the key characteristics of ashes collected from operating advanced particle filters. The second objective is to relate these ash properties and the contents of the data base to the operation and performance of the advanced particle filters and filter components. The first objective includes formatting the data base and collecting, analyzing, and maintaining ashes from operating HGCU facilities. The second objective of this task involves the collection of operating histories from advanced particle filters, correlating these histories with ash characteristics, interpreting these correlations, and communicating our conclusions in the various venues prescribed by DOE/METC.

The objective of Task 2 is to develop an overall understanding of the thermal and mechanical behavior of hot gas filter materials. This objective includes the creation of a materials property data base which will allow the prediction of the behavior of these materials in hot gas cleanup environments. Pertinent tests will be carried out on specimens of unused filter material and also on filter elements that have been exposed in actual operating environments. Nondestructive test techniques will be applied to filter elements to characterize the strength and durability of these elements without rendering them unusable. This task will also evaluate the adequacy and completeness of manufacturers' quality assurance/quality control plans for manufactured filter elements. 


\section{TASK 1 ASSESSMENT OF ASH CHARACTERISTICS}

This task has two primary objectives. The first is to generate a readily accessible data base of the key characteristics of ashes collected from operating advanced particle filters. The second objective is to relate these ash properties and the contents of the data base to the operation and performance of the advanced particle filters and filter components. The first objective includes formatting the data base and collecting, analyzing, and maintaining ashes from operating HGCU facilities. The second objective of this task involves the collection of operating histories from advanced particle filters, correlating these histories with ash characteristics, interpreting these correlations, and communicating our conclusions in the various venues prescribed by the U.S. Department of Energy's Morgantown Energy Technology Center (DOE/METC).

\section{HGCU DATA BASE DEVELOPMENT}

SRI currently maintains a collection of 235 ashes obtained from eleven facilities that are or have been involved in METC's HGCU program. An overview of the sources of these samples is presented in Table 1. Approximately half of these samples have been subjected to selected laboratory analyses. Brief descriptions of the various analytical methods we have used to analyze ashes in the HGCU data base are presented in Appendix A. All of the simple data (such as chemical analyses, specific surface area, uncompacted bulk porosity, etc.) have already been entered into a Microsoft Excel $^{\circledast}$ spreadsheet. There are a number of analyses and tests we have performed for a very limited number of samples of special interest that may be difficult to present in a conventional data base. Examples of these kinds of data include SEM photographs, SEM analyses (elemental and X-ray mapping) of individual ash particles, and baking and consolidation tests performed on bulk ash samples prepared in the laboratory. We have not yet decided how to include these types of specialized data in the data base. We are currently investigating structuring the HGCU data base in a Microsoft Access format. 
Table 1

Overview of Ash Samples in the HGCU Data Base

\begin{tabular}{|c|l|l|}
\hline \# of samples & \multicolumn{1}{|c|}{ source } & \multicolumn{1}{c|}{ process } \\
\hline 7 & New York Univ. & bubbling bed PFBC \\
\hline 8 & M.W. Kellogg & circulating PFBC \\
\hline 14 & M.W. Kellogg & gasification \\
\hline 2 & Texaco & gasification \\
\hline 11 & Grimethorpe & circulating PFBC \\
\hline 9 & KRW & gasification \\
\hline 2 & Allison & coal-fired combustion turbine \\
\hline 10 & Foster Wheeler & carbonizer \\
\hline 7 & Foster Wheeler & circulating PFBC \\
\hline 3 & Iowa State University & AFBC \\
\hline 45 & Karhula & circulating PFBC \\
\hline 116 & Tidd & bubbling bed PFBC \\
\hline 1 & DOE/METC & gasification \\
\hline
\end{tabular}

\section{MODIFICATIONS TO THE EMPIRICAL PERMEABILITY MODEL}

The mathematical permeability model Southern Research Institute developed in 1986 was based almost exclusively on empirical data measured for pulverized-coal ashes. One ash produced by atmospheric fluidized-bed combustion was also included in this modeling. This model, which relates the characteristic gas flow resistance of a porous bed of ash particles with the porosity of the bed, was based on the work of Kozeny ${ }^{1}$, Carman $^{2}$, Langmuir ${ }^{3}$, and Davies ${ }^{4}$.

We have used our model in our analyses of bulk samples of HGCU ashes to estimate the characteristic gas flow resistance of filter cakes formed from the ash being analyzed. Two key parameters determine this characteristic flow resistance: porosity and particle diameter. However, during the development of the model, we found that simple measurements of physical diameter obtained with various devices (Coulter Counter, Bahco Classifier, or Shimadzu centrifugally augmented sedigraph) do not correlate well enough with measured permeability data to accurately predict gas flow resistance. Therefore, we used our empirical permeability data to define the drag-equivalent diameter, a value we calculate for each ash tested, which accurately ranks the gas flow resistance of different ashes at equal filter cake porosities.

As our data base of HGCU ashes expanded, we found that the permeability data we measured for these ashes comprising small, irregular particles was not satisfactorily fit by the model developed in 1986 primarily for larger, spherical particles. In almost every case, the 1986 model would tend to overestimate the gas flow resistance values of uncompacted filter cakes. To correct these estimates, we used permeability data measured 
for 34 ashes composed of small, irregular particles to develop an adjusted permeability model. Most of these 34 ashes were generated at HGCU facilities. The new adjusted equation is presented below:

$\Delta p=\left(\mu U / D^{2}\right) \cdot(W / \rho) \cdot\left[111-211 \varepsilon+100 \varepsilon^{2}\right]^{2}$

where:

$\Delta \mathrm{p}=$ pressure drop across the porous bed, $\mu \mathrm{bar}$

$\mu=$ gas viscosity, poise

$\mathrm{U}=$ face velocity of the gas, $\mathrm{cm} / \mathrm{s}$

$\mathrm{D}=$ drag-equivalent diameter of the ash, $\mathrm{cm}$

$\mathrm{W}=$ areal mass loading of the porous bed, $\mathrm{g} / \mathrm{cm}^{2}$

$\rho=$ average true density of the ash particles, $\mathrm{g} / \mathrm{cm}^{3}$

$\varepsilon=$ porosity of the porous bed, dimensionless $(0<\varepsilon<1)$.

This new, adjusted form of our permeability model was then used to recalculate the dragequivalent diameters and relative gas flow resistances of all of the HGCU ashes for which we had measured permeability. These new values have been entered in the HGCU data base.

\section{TRANSLATING LABORATORY PERMEABILITY DATA TO HGCU CONDITIONS}

Measuring the permeability of simulated filter cakes formed from HGCU ashes is a key component of our ash characterizations. These permeability measurements are used to estimate or rank the on-line filtering pressure drop associated with actual filter cakes formed from these ashes. To generate reliable estimates from our laboratory measurements, it is crucial that the key characteristics of the filter cake and flue gas as they exist during high temperature filtration are accurately known.

As discussed in the preceding section, the permeability of the filter cakes depends in part on the morphology of the filter cake (expressed by the drag-equivalent diameter and the porosity of the cake). The amount (areal loading) of filter cake and the true density of the ash particles also influence the overall pressure drop associated with a given filter cake. The other factors that determine the pressure drop (face velocity and gas viscosity) are dependent on the characteristics of the flue gas. Our laboratory measurements of bulk ash permeability and the porosity of filter cakes removed from HGCU filters in combination with SEM observations of actual HGCU filter cakes have allowed us to accurately characterize the morphology of these cakes. Assessments of areal loading must be performed on site. True particle density has been accurately determined in the laboratory for many ash samples obtained from HGCU filters and is unchanged at HGCU flue gas conditions. Face velocity and flue gas viscosity are significantly different in HGCU filters than in the laboratory. However, the overall effect of increased temperature and pressure can be accurately estimated based on filtration theory and basic theories of fluid dynamics. 
Because we have accurate characterizations of the morphology of the filter cakes in operating HGCU filters, translating our laboratory permeability data (acquired at ambient temperature and pressure) to HGCU operating conditions is relatively simple. The increased temperature and increased pressure in the HGCU filter vessel cause changes in gas volume and gas viscosity. In turn, these two factors affect the filtering pressure drop. Based on the conditions included in Table 2, equation (2) demonstrates the translation from laboratory to HGCU conditions for a typical HGCU facility operating at 10 atmospheres and $1600^{\circ} \mathrm{F}$.

Table 2

Comparison of Laboratory with HGCU Filter Conditions

\begin{tabular}{|l|c|c|c|}
\hline \multicolumn{1}{|c|}{ condition } & Laboratory conditions & HGCU conditions & effect on pressure drop \\
\hline temperature, ${ }^{\circ} \mathrm{K}$ & 295 & 1144 & $\times 3.88$ \\
\hline gas viscosity, poise & 184 & $456^{*}$ & $\times 2.48$ \\
\hline pressure, Atm & 1.0 & 10 & X 0.1 \\
\hline
\end{tabular}

* These calculations use the values associated with air to approximate flue gas.

$\Delta \mathrm{p}(\mathrm{HGCU}$ conditions $)=\Delta \mathrm{p}$ (laboratory conditions) $\mathrm{X} 3.88 \times 2.48 \times 0.1$

Coincidentally, these multiplicative factors to combine to an overall factor of approximately 1.0. Therefore, when we measure the permeability of a simulated filter cake at laboratory conditions, the values we obtain apply directly to filter cakes in operating HGCU filters.

\section{OPERATION AND PERFORMANCE OF THE TIDD APF}

Tests of the APF at Tidd were conducted between October 1992 and the spring of 1995 to evaluate the ability of this filter system to efficiently and reliably remove entrained PFBC particles from flue gas at temperatures between 1200 and $1600^{\circ} \mathrm{F}$ and at pressures around 10 atmospheres. The Tidd APF was designed by the Westinghouse Science and Technology Center to perform as a barrier filter. The APF used periodic reverse pulses of high pressure air to remove ash from the filtering surface of the ceramic candle filter elements. A schematic diagram of the Tidd APF is shown in Figure 1. During its operation, the APF handled 1/7th of the process stream from the 70 MWe Tidd PFBC Demonstration Plant. In its initial configuration, the APF was preceded by a cyclone designed to capture most of the entrained particulate matter. The environment within the APF and specific characteristics of the PFBC ash presented unique challenges for this installation. As operating experience with the APF accumulated, the cyclone upstream of the APF was first derated, and then completely bypassed to increase the mean size of the ash particles entering the filter vessel. 


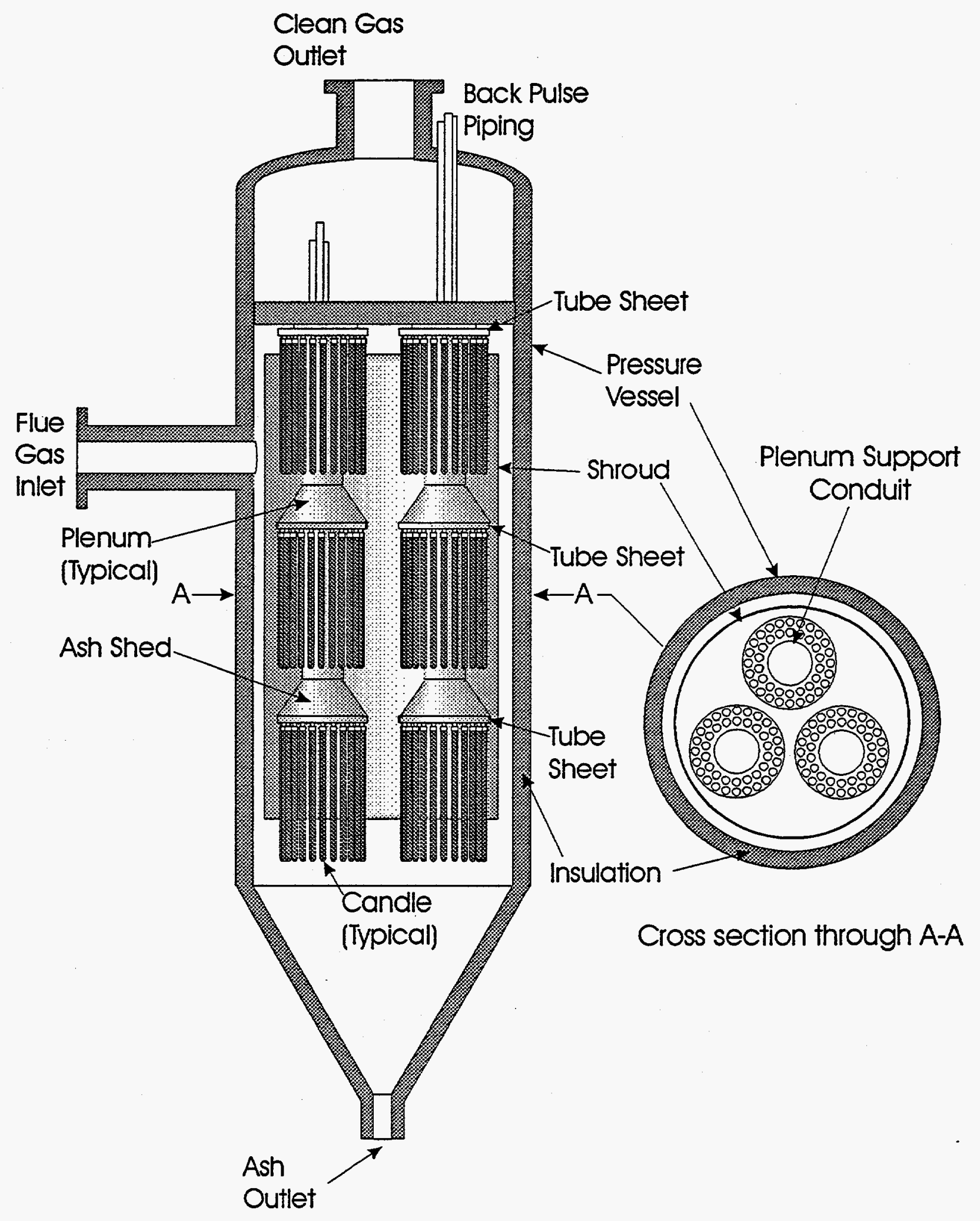

Figure 1. General features of the advanced HGCU system at the Tidd Demonstration Plant. 


\section{Site Visits to Tidd}

Southern Research Institute personnel made four site visits to the Tidd APF to inspect and document the condition of the filter vessel and to collect representative samples of the various deposits of ash found in the APF for analysis. The first two of these visits were made on an earlier contract (No. DE-AC21-89MC26239). (A topical report entitled Analyses of Ashes from the Tidd PFBC Advanced Particulate Filter summarizing our observations and the results of our ash analyses was submitted in August 1995 to DOE/METC.) The latter two site visits are discussed in the following paragraphs.

From May 1994 until the shutdown of the facility in the spring of 1995, operation of the APF focused on two separate approaches to eliminating the ash bridges previously formed between candle filter elements and nearby surfaces. The first approach involved increasing the mean size of the entrained particles entering the filter vessel by derating, and later bypassing, the cyclone located just upstream of the filter. The other approach was to remove the inner ring of candle filter elements from the top and middle plenum assemblies. Although this latter approach involved removing $25 \%$ of the ceramic candle filter elements, and consequently $25 \%$ of the active surface area, it was implemented to increase the separation between the candle filter elements and the ash sheds and plenum support conduits, reducing the likelihood that ash bridges would form at these locations.

When the APF was opened on October 27, 1994 a significant number of candle filter elements were broken, and ash deposits were present at various locations throughout the filter assembly. As observed in our two previous site visits, the region under each tube sheet where the candle filter elements were mounted was completely packed with ash deposits. Although the number of ash bridges adjacent to the filter elements was reduced compared to the two prior observations, there were still a few large ash bridges formed between the lower portion of filter elements in the top and middle plenum assemblies and the ash sheds and/or the plenum support conduits. In general, the filtering surfaces of the intact filter elements were relatively clean, except for regions of the candles just below the tube sheet deposits mentioned above. The surfaces of the plenum support conduits and the ash sheds were cleaner than previously observed; however, several thick ash deposits were present on portions of these surfaces. Bridging of ash between filter elements in the bottom plenums did not seem to be a serious problem. Following documentation of the condition of the APF, a suite of ash samples was collected for analysis. The ash samples we obtained from the Tidd APF are listed in Table 3. 
Table 3

Ash Samples Collected at Tidd on October 27, 1994

\begin{tabular}{|c|c|c|}
\hline ID \# & Location & Description/Comments \\
\hline 4096 & MP, PSC & \\
\hline 4097 & BP, TS & with agglomerates \\
\hline 4098 & FC from midway up BP & \\
\hline 4099 & FC from lowest 6 inches of BP & \\
\hline 4100 & ash from inner wall of pressure vessel & \\
\hline 4101 & $\mathrm{BP}, \mathrm{AB}$ & with agglomerates \\
\hline 4102 & BP, FC from inner candles & \\
\hline 4103 & $\begin{array}{l}\text { BP, FC from third ring of candles } \\
\text { (near center of plenum) }\end{array}$ & \\
\hline 4104 & TP, PSC/AS & $\begin{array}{l}\text { deposit near junction of PSC } \\
\text { and AS (with agglomerates) }\end{array}$ \\
\hline 4105 & TP, AS & $\begin{array}{l}\text { with agglomerates (deposit } \\
\text { about } 1 \text { inch thick) }\end{array}$ \\
\hline 4106 & TP, PSC & thin deposit halfway up PSC \\
\hline 4107 & TP, TS & some color variation \\
\hline 4108 & TP, TS & light brown ash from 4107 \\
\hline 4109 & MP, from inside of candle B-8 & \\
\hline 4110 & TP, FC from outer surface of candle & \\
\hline 4111 & MP, FC & \\
\hline 4112 & TP, FC from inner surface of candle & \\
\hline 4113 & $\mathbf{M P}, \mathbf{A B}$ & with agglomerates \\
\hline 4114 & MP, AS & large agglomerates \\
\hline 4115 & $\mathrm{TP}, \mathrm{AB}$ & large agglomerates \\
\hline 4116 & MP, AB & large agglomerates \\
\hline 4117 & APF outlet tube & deposited inside outlet tube \\
\hline $\begin{array}{l}\mathrm{AB}= \\
\mathrm{AS}= \\
\mathrm{PSC}= \\
\mathrm{FC}=\mathrm{I}\end{array}$ & $\begin{array}{l}\text { sh Bridge between Candles } \\
\text { sh Shedding Cone } \\
\text { Plenum Support Column/Conduit } \\
\text { ilter Cake Ash from Candle Surface }\end{array}$ & $\begin{array}{l}\text { TP = Top Plenum } \\
\text { MP = Middle Plenum } \\
\text { BP = Bottom Plenum } \\
\text { TS = Underside of Tube sheet }\end{array}$ \\
\hline
\end{tabular}

At the request of DOE/METC, we sent a portion of all the ash samples we collected to Dr. T.K. Chiang at DOE/METC and Dr. John Hurley at the University of North Dakota's Energy and Environmental Research Center. (There was not enough of sample ID \# 4117 [APF outlet tube] to split. Therefore Southern Research Institute has retained all of this particular sample.) 
The APF was opened once more on May 11, 1995 after the final shutdown of the Tidd Demonstration Plant. During this last operating period, the cyclone upstream of the APF was entirely bypassed to get as many relatively large particles into the filter vessel as possible. In general, the filter assembly was quite clean. The only significant deposits of ash were on the underside of the tube sheets, much like the deposits found in these locations during prior inspections. Most of the broken candle filter elements were of a particular experimental design. Most of the other filter elements were intact. As was done in October 1994, a suite of ash samples was obtained for analysis. These samples are listed in Table 4.

Table 4

Ash Samples Collected at Tidd on May 11, 1995

\begin{tabular}{|c|c|c|}
\hline ID \# & Location & Description/Comments \\
\hline 4142 & TP, A, TS & \\
\hline 4143 & TP, A, FC & central section of candle (nodules $0.25^{\prime \prime}$ thick) \\
\hline 4144 & TP, C, FC & clumps about $0.4^{\prime \prime}$ thick; bottom of viropore candles \\
\hline 4145 & TP, C, FC & \\
\hline 4146 & TP, B, FC & \\
\hline 4147 & TP, C, CSC/AS & from junction between CSC and AS \\
\hline 4148 & TP, C, AS & \\
\hline 4149 & TP, A, CSC & flaky deposits from CSC \\
\hline 4150 & TP, A, TS & flaky deposits from outer edge of tube sheet \\
\hline 4151 & MP, A, TS & very fluffy deposits \\
\hline 4152 & MP, A, FC & $0.06^{\prime \prime}$ thick, brushes off easily \\
\hline 4153 & MP, A, CSC & flaky deposits from CSC \\
\hline 4154 & MP, A, AS & \\
\hline 4155 & MP, A, CSC/AS & from junction between $\mathrm{CSC}$ and $\mathrm{AS}$ \\
\hline 4156 & MP, C, FC & \\
\hline 4157 & BP, A, TS & not as fluffy as ID \# 4151 \\
\hline 4158* & $\mathrm{BP}, \mathrm{A}, \mathrm{FC}$ & bottom section fairly thin, upper portion knobby \\
\hline 4159 & BP, B, FC & knobby deposits up to $0.4^{n}$ thick \\
\hline $4160^{*}$ & BP, A, FC & from inner ( $3 \mathrm{rd}$ and 4 th from outside) rings of candles \\
\hline 4161 & $\mathrm{BP}, \mathrm{C}, \mathrm{FC}$ & fresh cake fluffy, older portion firmly atte \\
\hline
\end{tabular}

TP $=$ Top Plenum $\quad A=$ Array A $\quad$ CSC $=$ Center Support Column

MP $=$ Middle Plenum $B=$ Array $B \quad A S=$ Ash Shed

BP $=$ Bottom Plenum $\quad C=$ Array C $\quad F C=$ Filter Cake Ash from Candle Surface

TS $=$ Underside of Tube sheet (region of attachment of candles)

* Portions of these samples were sent to Dr. T.K. Chiang at DOE/METC. 
Analyses of Tidd Ash Samples

The ash samples collected during our last two site visits included large pieces of the various types of deposits present throughout the filter vessel, as well as samples of loose ash that were found at several places in the APF. Analyses performed on ash deposits included SEM examinations of their structure and chemical composition, and direct measurements of their porosity. Measurements on loose bulk ash or deagglomerated (broken up) deposits included size distribution, chemical composition, specific surface area, uncompacted bulk porosity, and SEM photographs to assess particle morphology. We also studied the effects that baking at $1550^{\circ} \mathrm{F}$ had on ash nodules and cups of loose, sifted ash. The results of our analyses are summarized below.

\section{Size Distribution}

In order to fully assess to what extent derating and bypassing the cyclone upstream of the APF had on the inclusion of relatively large particles in the ash deposits in the filter vessel, we performed additional limited analyses on the three samples listed in Table 5 as well as on samples we obtained in our last two site visits.

Table 5

Samples Obtained from Tidd under Prior Contract No. DE-AC21-89MC26239

\begin{tabular}{|c|c|c|}
\hline ID \# & Date Obtained & Location in Filter Vessel \\
\hline 2998 & $9 / 30 / 93$ & MP, AS \\
\hline 4079 & $5 / 5 / 94$ & MP, FC \\
\hline 4084 & $5 / 5 / 94$ & TP, AS \\
\hline
\end{tabular}

We performed sedigraphic analyses of several of the samples we obtained from the Tidd APF. In each case, the ash size distribution was distinctly bimodal. However, the relative scarcity of large particles in these samples did not allow the sedigraph to yield a reliable determination of the size distributions for particles larger than about 20 to $40 \mu \mathrm{m}$. (To introduce more large particles into the measuring cell for analysis, an excessive amount of fine particles would be included also. The sedigraphic analysis cannot be performed if the concentration of the suspension is too high.) Therefore, the most enlightening descriptions of size distributions were obtained with a combination of sieving and sedigraphic analyses.

In Table 6, the mass mean diameters (MMDs) of various Tidd ashes are shown for the finer portion of the overall particle size range. To characterize the coarser portion of selected Tidd ashes, sieve analyses were performed on samples collected in October 1994, after derated cyclone operation, and May 1995, after operation with the cyclone completely bypassed. The sieving process we used separated a portion of the original ashes into three size fractions: particle diameters $>45 \mu \mathrm{m}$, particle diameters $>15 \mu \mathrm{m}$, but smaller than $45 \mu \mathrm{m}$, and ash particles with diameters $<15 \mu \mathrm{m}$. (The sieving process caused this last, 
smallest fraction to be discarded along with the isopropanol used to wash the particles through the $45 \mu \mathrm{m}$ and $15 \mu \mathrm{m}$ sieves.) The data in Table 7 show that bypassing the cyclone between October 1994 and May 1995 significantly increased the size distributions of ash collected in the APF.

Table 6

MMDs of Ashes Collected from the Tidd APF

\begin{tabular}{|l|c|c|}
\hline \multicolumn{1}{|c|}{ ID \#, (location), date } & $\begin{array}{c}\text { size range measured, } \\
\mu \mathrm{m}\end{array}$ & $\begin{array}{c}\text { Stokes' MMD, } \\
\mu \mathrm{m}\end{array}$ \\
\hline ID \# 2998, (MP, AS), Sept. 1993 & $0.6-20$ & 2.0 \\
\hline ID \# 4079, (MP, FC), May 1994 & $0.6-20$ & 2.4 \\
\hline ID \# 4084, (TP, AS), May 1994 & $1.0-20$ & 3.8 \\
\hline ID \# 4097, (BP, TS), Oct. 1994 & $1.0-40$ & 7.0 \\
\hline ID \# 4103, (BP, FC), Oct. 1994 & $0.6-20$ & 2.9 \\
\hline ID \# 4109, (MP), Oct. 1994 & $1.6-20$ & 4.5 \\
\hline ID \# 4111, (MP, FC), Oct. 1994 & $1.0-20$ & 3.6 \\
\hline ID \# 4114, (MP, AS), Oct. 1994 & $1.0-40$ & 3.3 \\
\hline ID \# 4142, (TP, TS), May 1995 & $0.4-40$ & 17 \\
\hline ID \# 4144, (TP, FC), May 1995 & $0.6-40$ & 11 \\
\hline ID \# 4151, (MP, TS), May 1995 & $0.6-40$ & 16 \\
\hline
\end{tabular}

Table 7

Sieve Analyses of Tidd Ashes

\begin{tabular}{|c|c|c|c|}
\hline \multirow{2}{*}{ ID \#, (location), date } & \multicolumn{3}{|c|}{ \% weight } \\
\cline { 2 - 4 } & $\operatorname{diam}>45 \mu \mathrm{m}$ & $45 \mu \mathrm{m}>\operatorname{diam}>15 \mu \mathrm{m}$ & $\operatorname{diam}<15 \mu \mathrm{m}$ \\
\hline ID \# 4097, (BP, TS), Oct. 1994 & 4.03 & 17.3 & 78.6 \\
\hline ID \# 4114, (MP, AS), Oct. 1994 & 0.64 & 3.84 & 95.5 \\
\hline ID \# 4142, (TP, TS), May 1995 & 28.9 & 50.7 & 20.4 \\
\hline ID \# 4144, (TP, FC), May 1995 & 30.1 & 34.3 & 35.6 \\
\hline ID \# 4151, (MP, TS), May 1995 & 44.8 & 33.3 & 21.9 \\
\hline
\end{tabular}

In Figure 2, the size distribution data for the five samples we characterized with our sieve analyses have been combined with size distribution data obtained with our sedigraph. These combined data clearly show the increase in particle size induced by bypassing the cyclone.

One of the purposes of performing sieve analyses was to compare the population of large particles in the ash deposits found on the top of the ash shedding cone under the middle plenum with the deposit that formed under the tube sheet at the top of the bottom plenum. These two sample locations are physically close to one another. We performed 


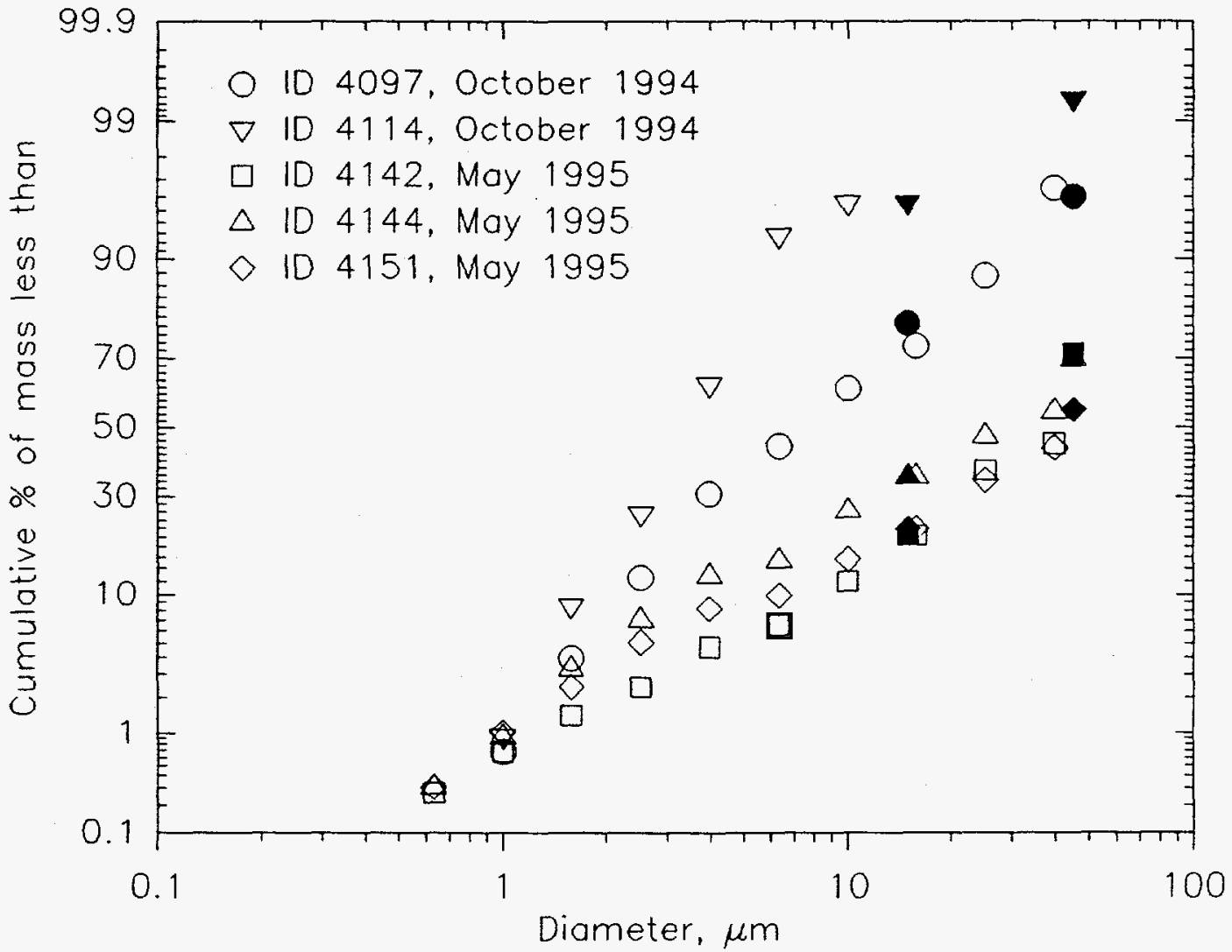

Figure 2. Cumulative size distribution data measured with a sedigraph and sieves for five ashes collected from the Tidd APF. The hollow data points represent sedigraphically obtained Stokes' diameters. The filled data points represent data obtained in the sieve analyses. 
measurements to determine if gravitational settling is the primary mechanism responsible for the presence of large particles in the ash deposits found at various locations in the filter vessel. If this were the case, we would expect that the sample taken from the ash shedding cone should have a significantly greater proportion of large particles than the sample from under the tube sheet. However, the sieve data measured for ID \# 4097 (BP, TS) and ID \# 4114 (MP, AS) do not confirm this hypothesis. Since there is no active mechanism such as gas flow through the filter cake to carry particles to the region under the tube sheet, the whole size range of particles found in the deposits from this location must have been transported to the deposit by eddy diffusion and/or Brownian movement. In fact, the sieve data for these two samples show that particles comprising the ash deposit formed on the ash shedding cone are significantly finer than those from the deposit underneath the tube sheet. We have no explanation for this difference.

The ash sample we collected from the tube sheet in the middle plenum (ID \# 4151, MP, TS) behaved much more like a free flowing powder than the other samples collected on the same site visit. Based on our sieving measurements, this free flowing ash exhibited the largest particle size distribution of those ashes that were analyzed. When this ash was removed from the tube sheet, it was loose and fluffy, unlike the other ash samples that were consolidated into nodules and deposits. This type of difference is common with fine powders. Powders normally become more free flowing as their particle size distribution becomes coarser.

\section{Chemical Analysis}

Chemical analyses of the free flowing ash (ID \# 4151, MP, TS) described above, and one of the nodular filter cake ashes (ID \# 4144, TP, FC) were performed to determine if differences other than particle size might account for the tendency of the coarser ash to behave like a free flowing powder. Chemical analyses of these two ashes and the sizeseparated portions generated from them during sieving are summarized in Table 8. 
Table 8

Chemical Analyses of Tidd Ashes Collected in May, 1995, \% wt.

\begin{tabular}{|l|c|c|c|c|c|c|}
\hline \multirow{2}{*}{ constituent } & \multicolumn{3}{|c|}{ nodular ash (ID \# 4144, TP, FC) } & \multicolumn{3}{c|}{ free flowing ash (ID \# 4151, MP, TS) } \\
\cline { 2 - 7 } & $\begin{array}{c}\text { all } \\
\text { diameters }\end{array}$ & $\mathrm{d}>45 \mu \mathrm{m}$ & $\begin{array}{c}15 \mu \mathrm{m}<\mathrm{d}, \\
\mathrm{d}<45 \mu \mathrm{m}\end{array}$ & $\begin{array}{c}\text { all } \\
\text { djameters }\end{array}$ & $\mathrm{d}>45 \mu \mathrm{m}$ & $\begin{array}{c}15 \mu \mathrm{m}<\mathrm{d}, \\
\mathrm{d}<45 \mu \mathrm{m}\end{array}$ \\
\hline $\mathrm{Li}_{2} \mathrm{O}$ & 0.01 & 0.01 & 0.01 & 0.01 & 0.01 & 0.01 \\
\hline $\mathrm{Na}_{2} \mathrm{O}$ & 0.29 & 0.16 & 0.23 & 0.27 & 0.13 & 0.20 \\
\hline $\mathrm{K}_{2} \mathrm{O}$ & 1.3 & 0.83 & 1.3 & 1.2 & 0.77 & 1.1 \\
\hline $\mathrm{MgO}$ & 8.3 & 11.3 & 8.5 & 13.2 & 16.5 & 13.5 \\
\hline $\mathrm{CaO}$ & 14.1 & 18.1 & 15.0 & 20.5 & 24.7 & 21.0 \\
\hline $\mathrm{Fe}_{2} \mathrm{O}_{3}$ & 7.1 & 4.8 & 7.5 & 8.0 & 6.2 & 9.9 \\
\hline $\mathrm{Al}_{2} \mathrm{O}_{3}$ & 11.7 & 7.5 & 10.8 & 10.8 & 7.2 & 9.5 \\
\hline $\mathrm{SiO}_{2}$ & 26.1 & 17.6 & 26.0 & 25.1 & 19.6 & 25.6 \\
\hline $\mathrm{TiO}_{2}$ & 1.2 & 0.41 & 0.46 & 1.1 & 0.33 & 0.49 \\
\hline $\mathrm{P}_{2} \mathrm{O}_{5}$ & 0.15 & 0.12 & 0.14 & 0.14 & 0.10 & 0.14 \\
\hline $\mathrm{SO}_{3}$ & 30.1 & 38.5 & 28.5 & 19.5 & 22.9 & 17.4 \\
\hline $\mathrm{LOI}^{2}$ & 13.5 & 19.6 & 15.3 & 1.5 & 2.4 & 1.1 \\
\hline $\mathrm{soluble} \mathrm{SO}_{4}=$ & 29.7 & 36.0 & 29.8 & 22.4 & 26.3 & 20.6 \\
\hline
\end{tabular}

Like other Tidd ashes we analyzed, the primary elemental constituents of these samples were calcium, magnesium, aluminum, silicon and sulfur. These analyses demonstrated that the larger ash particles in both samples (ID \# 4144, TP, FC) and ID \# 4151, MP, TS) contain more $\mathrm{Mg}, \mathrm{Ca}, \mathrm{SO}_{3}$, and havive higher $\mathrm{LOI}$ values than the smaller particles. The smaller particles are richer in $\mathrm{Al}, \mathrm{Na}, \mathrm{K}, \mathrm{Fe}, \mathrm{Ti}$, and $\mathrm{Si}$. These results suggest that the larger ash particles are derived mainly from the sorbent used in the combustion process, while the smaller particles are derived mainly from the coal. This is supported by comparisons of the concentrations of calcium and magnesium in the two parent samples and their corresponding size fractions. The coarser tube sheet ash (ID \# 4151, MP, TS) contains about $50 \%$ more calcium and magnesium than the finer filter cake ash. The particles too large to pass through the $45 \mu \mathrm{m}$ sieve also had a different appearance than the finer particles. Whereas the finer particles all had the characteristic reddish-orange color associated with PFBC ashes, most of the larger particles were brown. A few of them were black or white. All of these differences suggest that the sorbent-derived ash particles were somewhat larger than the coal-derived ash particles in these samples.

Another interesting difference in ID \# 4144 and ID \# 4151 is evident in the acid/base ratios as defined in Table 9. We believe the differences in these ratios is due to the exposure of the filter cake ash (ID \# 4144, TP, FC) to much more flue gas than the ash obtained from the passive deposit under the tube sheet (ID \# 4151, MP, TS). As flue gas is filtered through the filter cake, additional $\mathrm{SO}_{2}$ in the flue gas is captured by calcium and/or magnesium still remaining in the ash. Although unreacted sorbent present in the passive ash deposits can still react with $\mathrm{SO}_{2}$ in the flue gas, the reaction is diminished because the 
flue gas in direct contact with the ash particles in the deposit is exchanged or refreshed relatively slowly. The comparisons discussed above suggest that it is possible that the increased flowability of the tube sheet ash (ID \# 4151, MP, TS) may be partially due to chemical differences as well as differences in size distribution.

Table 9

Acid/Base Ratios in Tidd Ashes

\begin{tabular}{|c|c|c|}
\hline ID \#, (location) & $\mathrm{SO}_{3} /(\mathrm{Ca}+\mathrm{Mg})$ & soluble $\mathrm{SO}_{4}{ }^{*} /(\mathrm{Ca}+\mathrm{Mg})$ \\
\hline ID \# 4144, (TP, FC) & 1.3 & 1.3 \\
\hline ID \# 4151, (MP, TS) & 0.58 & 0.66 \\
\hline
\end{tabular}

We also compared the chemistry of two ash samples that had been obtained from a wellconsolidated one inch-thick filter cake that had resided in the APF for an extended period with two APF hopper ashes from the same period of operation. (Hopper ash provides the best candidate for ash that has had minimal exposure to the conditions in the APF.) The mineral analyses of these four samples are presented in Table 10. (These comparisons were made in order to help determine the mechanism responsible for the consolidation of the ash deposits formed in the APF. The significance of these chemical analyses is discussed in the section entitled Mechanisms Controlling the Consolidation of Ash Deposits later in this report.)

Table 10

Chemical Characteristics of Tidd Hopper and Filter Cake Ashes, \% wt.

\begin{tabular}{|l|c|r|c|c|}
\hline constituent & \multicolumn{2}{|c|}{ hopper ashes } & \multicolumn{2}{c|}{ filter cake ashes } \\
\hline $\mathrm{Na}_{2} \mathrm{O}$ & 0.30 & 0.31 & 0.30 & 0.27 \\
\hline $\mathrm{K}_{2} \mathrm{O}$ & 1.6 & 1.42 & 1.73 & 1.77 \\
\hline $\mathrm{MgO}$ & 9.9 & 9.63 & 8.77 & 7.96 \\
\hline $\mathrm{CaO}$ & 15.3 & 15.48 & 14.16 & 13.67 \\
\hline $\mathrm{Fe}_{2} \mathrm{O}_{3}$ & 5.3 & 6.49 & 4.79 & 5.63 \\
\hline $\mathrm{Al}_{2} \mathrm{O}_{3}$ & 13.4 & 11.80 & 13.01 & 13.63 \\
\hline $\mathrm{SiO}_{2}$ & 19.2 & 21.29 & 23.03 & 22.89 \\
\hline $\mathrm{TiO}_{2}$ & 0.50 & 0.56 & 0.61 & 0.07 \\
\hline $\mathrm{P}_{2} \mathrm{O}_{5}$ & 0.08 & 0.12 & 0.11 & 0.10 \\
\hline $\mathrm{SO}_{3}$ & 33.6 & 31.10 & 31.06 & 31.38 \\
\hline $\mathrm{LOI}^{\text {Soluble } \mathrm{SO}_{4}}{ }^{2}$ & 1.5 & 2.96 & 1.45 & 1.84 \\
\hline
\end{tabular}




\section{Nodule Porosity, Uncompacted Bulk Porosity, and Specific Surface Area}

We encapsulated two nodules from sample ID \# 4097 (BP, TS) on October 27, 1994 before leaving the Tidd Demonstration Plant. While on site, we also measured the porosity of two nodules from sample ID \# 4114 (MP, AS) and two more nodules from sample ID \# 4116 (MP, AB) using the ethanol method described in Appendix A. The averaged data from these determinations are presented in Table 11. We also performed a variety of physical analyses of several of the ashes we collected during our May 1995 site visit to Tidd. The results of these analyses are included in Table 11.

Table 11

Physical Analyses of Tidd Ashes and Nodules

\begin{tabular}{|l|c|c|c|c|}
\hline \multicolumn{1}{|c|}{ ID \#, (location) } & $\begin{array}{c}\text { date } \\
\text { obtained }\end{array}$ & $\begin{array}{c}\text { nodule } \\
\text { porosity, \% }\end{array}$ & $\begin{array}{c}\text { uncompacted } \\
\text { bulk porosity, \% }\end{array}$ & $\begin{array}{c}\text { specific surface } \\
\text { area, } \mathrm{m}^{2} / \mathrm{g}\end{array}$ \\
\hline ID \# 4097, (BP, TS) & Oct. 1994 & 84.4 & 91 & \\
\hline ID \# 4114, (MP, AS) & Oct. 1994 & 84.0 & 92 & \\
\hline ID \# 4116, (MP, AB) & Oct. 1994 & 82.3 & & \\
\hline ID \# 4142, (TP, TS) & May 1995 & 73.2 & 80 & -- \\
\hline ID \# 4144, (TP, FC) & May 1995 & 69.5 & 84 & -- \\
\hline ID \# 4151, (MP, TS) & May 1995 & - & 81 & -- \\
\hline ID \# 4144A, (TP, FC) & May 1995 & -- & -- & 6.9 \\
\hline ID \# 4144B, (TP, FC) & May 1995 & - & - & 5.1 \\
\hline ID \# 4151A, (MP, TS) & May 1995 & -- & -- & 1.7 \\
\hline ID \# 4151B, (MP, TS) & May 1995 & -- & -- & 1.8 \\
\hline
\end{tabular}

ID \# 4144A: diameter $>45 \mu \mathrm{m}$

ID \# 4144B: $15 \mu \mathrm{m}<$ diameter $<45 \mu \mathrm{m}$

ID \# 4151A: diameter $>45 \mu \mathrm{m}$

ID \# 4151B: $15 \mu \mathrm{m}<$ diameter $<45 \mu \mathrm{m}$

The data in Table 11 show that the porosity of nodules formed in the APF was lower for samples obtained after the cyclone had been completely bypassed. This trend can also be seen in the uncompacted bulk porosity data in Table 11. Coupled with the apparent increase in the size distribution of ashes after the bypassing of the cyclone, these results support the contention that the cohesivity of the ash collected in the APF was significantly reduced by the inclusion of relatively large particles. This behavior is common with fine powders, and almost certainly a factor in the relative cleanliness of the filter vessel when it was opened in May 1995. (The implications of bypassing the cyclone are discussed further later in this report.) The relative coarseness of ID \# 4151 (MP, TS), as indicated by the sieve analyses discussed earlier, is also evident in the values of specific surface area data measured for samples 4144A (TP, FC) and 4151A (MP, TS). 
Scanning Electron Microscopy

As with other HGCU samples we have studied, visual examination of ash nodules and loose bulk ash samples with a SEM has proved very useful. SEM examinations of six of the samples obtained in May 1995 supported the sieve and BET data that correlated ash coarseness with the free-flowing behavior we noted for sample ID \# 4151 (MP, TS). These SEM photographs are presented in Figures 3 through 8.

We also performed a variety of SEM analyses on nodules and loose ash from sample ID \# 4114 (MP, AS). The most crucial objective of these analyses was the determination of the composition of the interparticle bonds in the ash deposits formed in the filtration assembly. However, because the primary particles are relatively small (around $2 \mu \mathrm{m}$ for the majority of particles), SEM EDX spectra and elemental maps do not have sufficient resolution to focus exclusively on the region of the interparticle bonds.

Figure 9 shows representative SEM photographs of loose ash particles from sample ID \# 4114 (MP, AS). As suggested by our sieve analyses, these pictures indicate that particles larger than $10 \mu \mathrm{m}$ diameter are the exception in this sample. The irregular shapes of the PFBC ash particles are apparent in these photographs. Figure 10 shows two views of an ash nodule that we have been examining with EDX spectra and elemental maps. So far these analyses have been inconclusive because of the resolution of the technique. The photographs illustrate the attachment of relatively small particles to larger structures within the nodule. It is not clear from these photographs if these larger structures are directly derived from relatively large particles or if these large structures are formed after particles are initially collected.

We also produced a pair of stereographic SEM photographs of a fresh fracture surface of a nodule taken from ID \# 4114 (MP, AS). The stereographic image was very enlightening as to the structure of the nodule. However, because a special apparatus is required to obtain a true stereographic image from the SEM photographs we produced, only one of the two images is reproduced in Figure 11. The nodule appears to be a concretion composed of discrete fine particles almost completely embedded in a pervasive amorphous mass. Since the large mass in which the particles are embedded is almost certainly too large to have been formed during combustion and transported intact to the APF, it must have formed within the APF.

\section{Laboratory Baking of Ash Nodules}

We also took a large nodule from sample ID \# 4097 (BP, AS) and broke it into three pieces. The porosity of the first fraction was measured with the ethanol method. The second piece was baked at $1550^{\circ} \mathrm{F}$ for 3 hours. The third piece was baked at $1550^{\circ} \mathrm{F}$ for three days. The porosities of the two baked nodules were also measured with the ethanol method. These data are summarized in Table 12. 


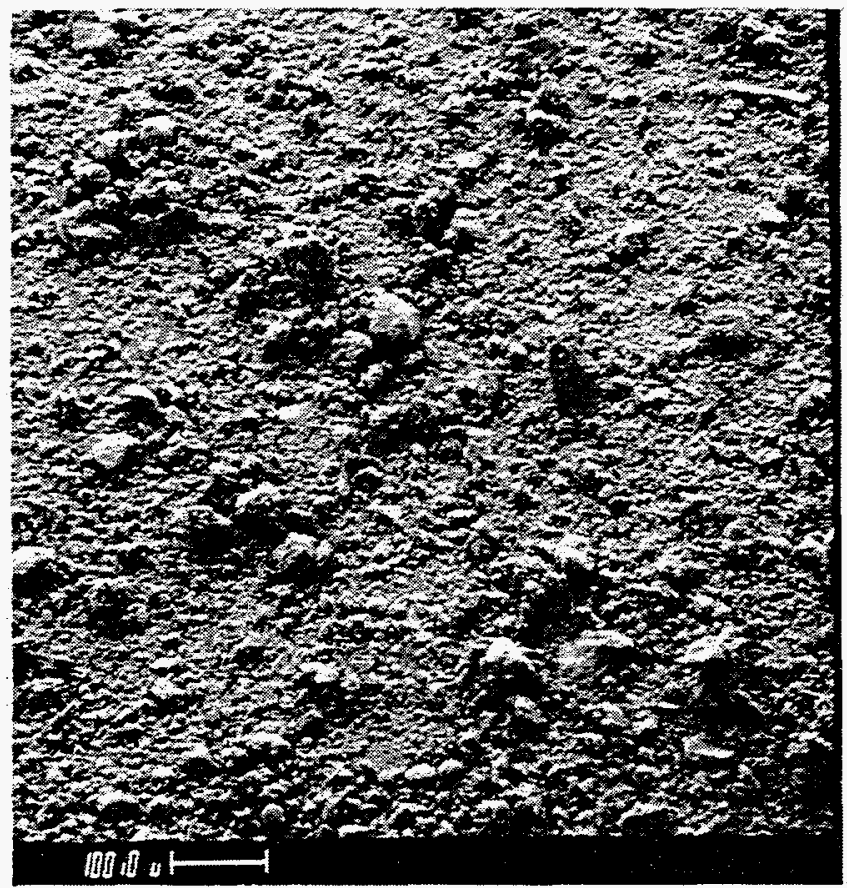

$\mathbf{a}$

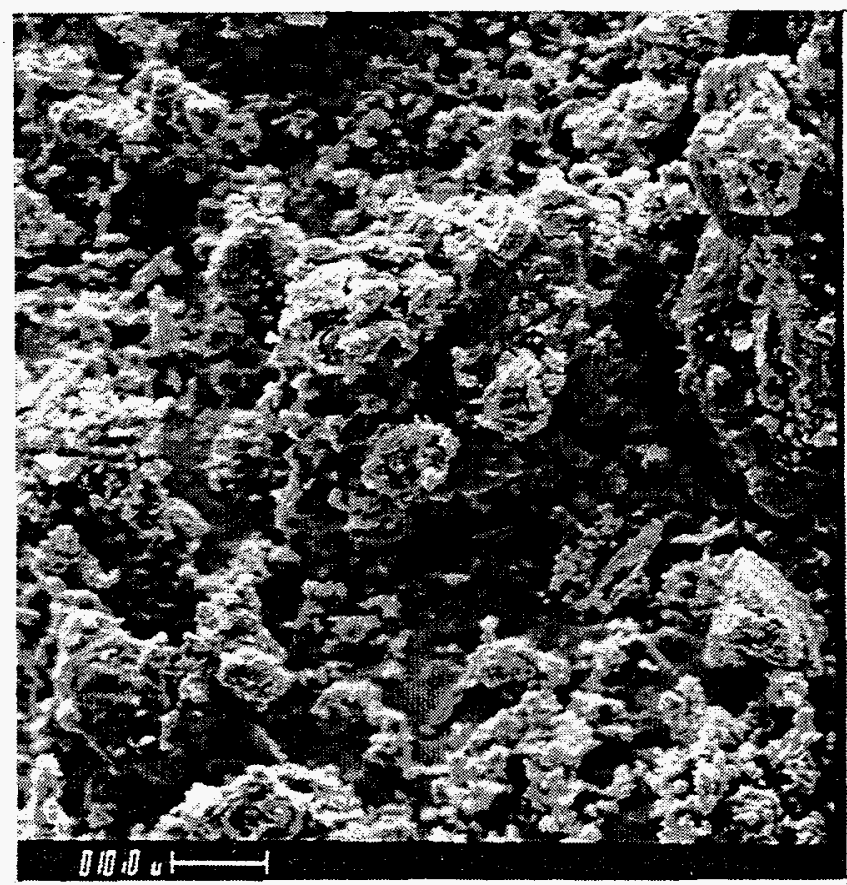

c

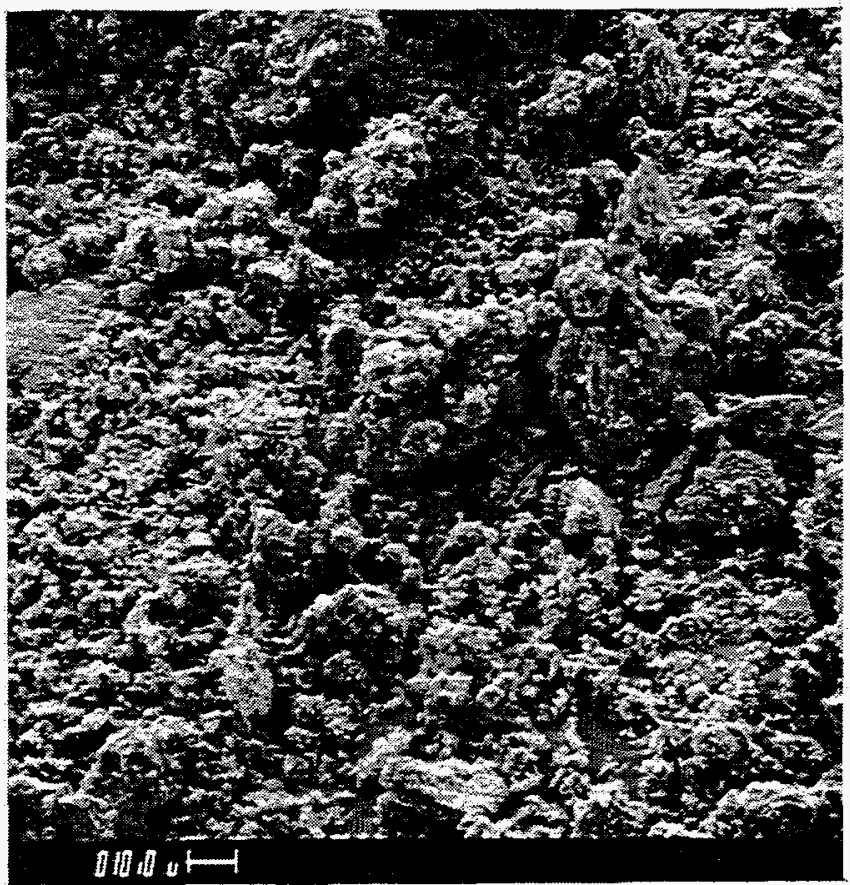

b

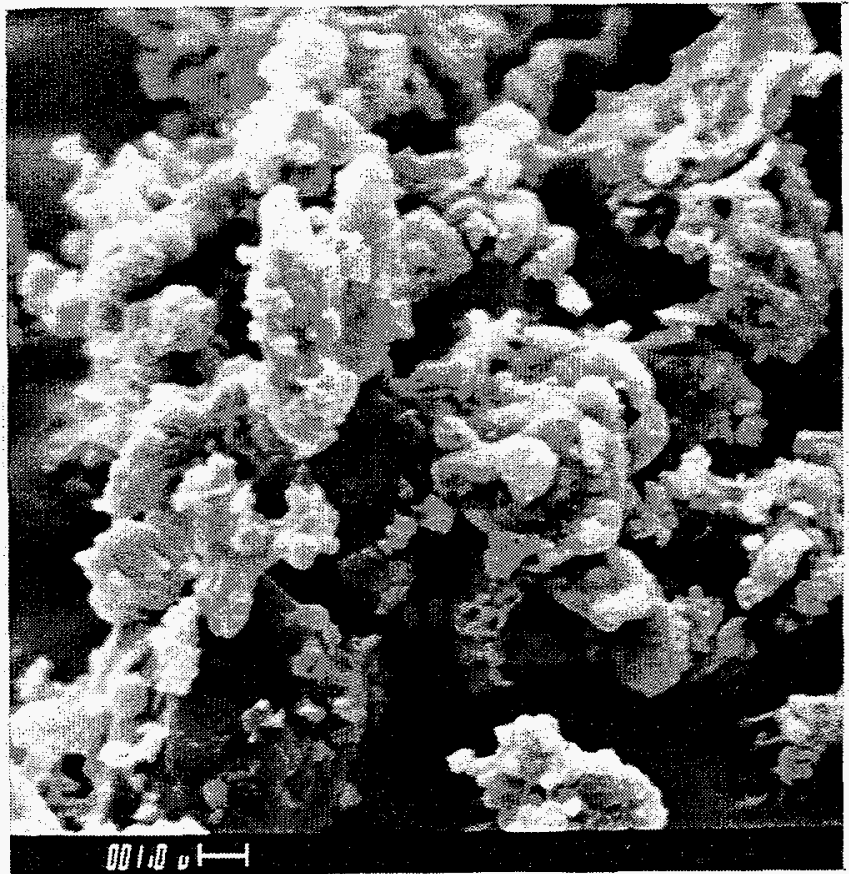

d

Figure 3. Representative SEM photographs of filter cake ash (ID \# 4144) removed from the top plenum at Tidd on May 11, 1995 taken at a) $100 \mathrm{X}$, b) $500 \mathrm{X}$, c) $1000 \mathrm{X}$, and d) $5000 \mathrm{x}$. 


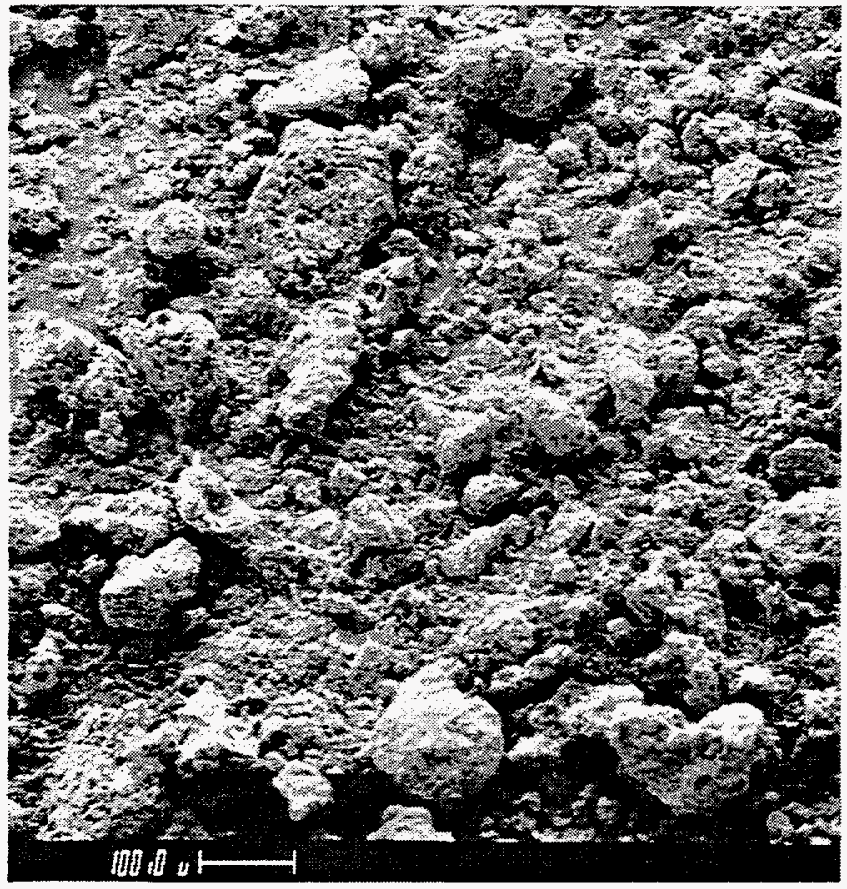

a

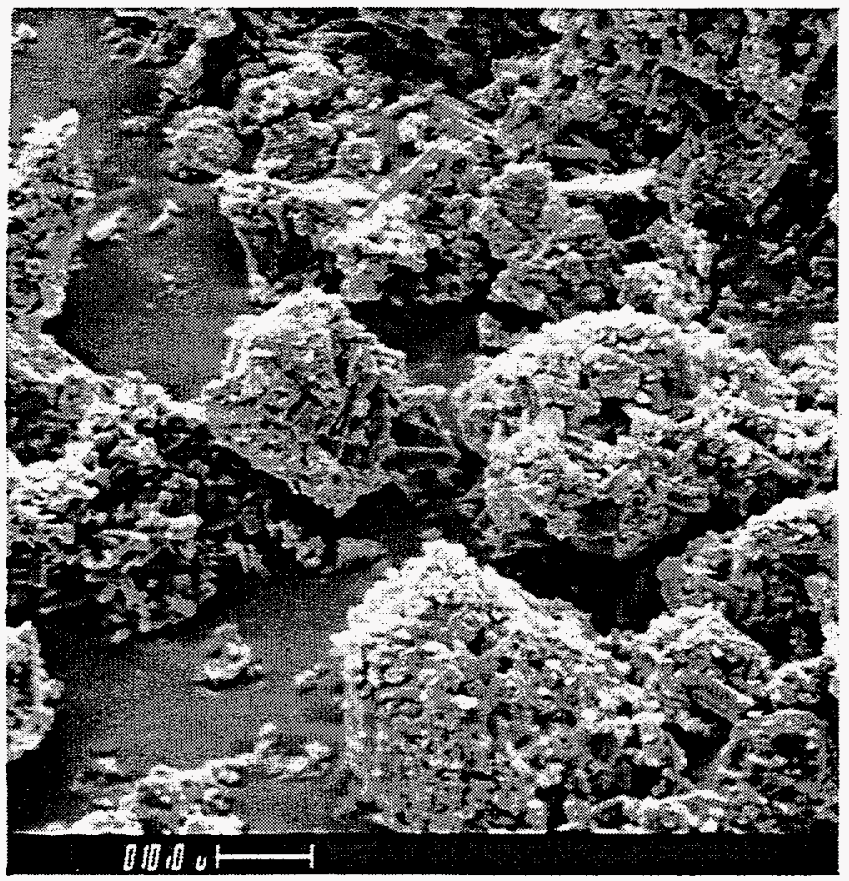

C

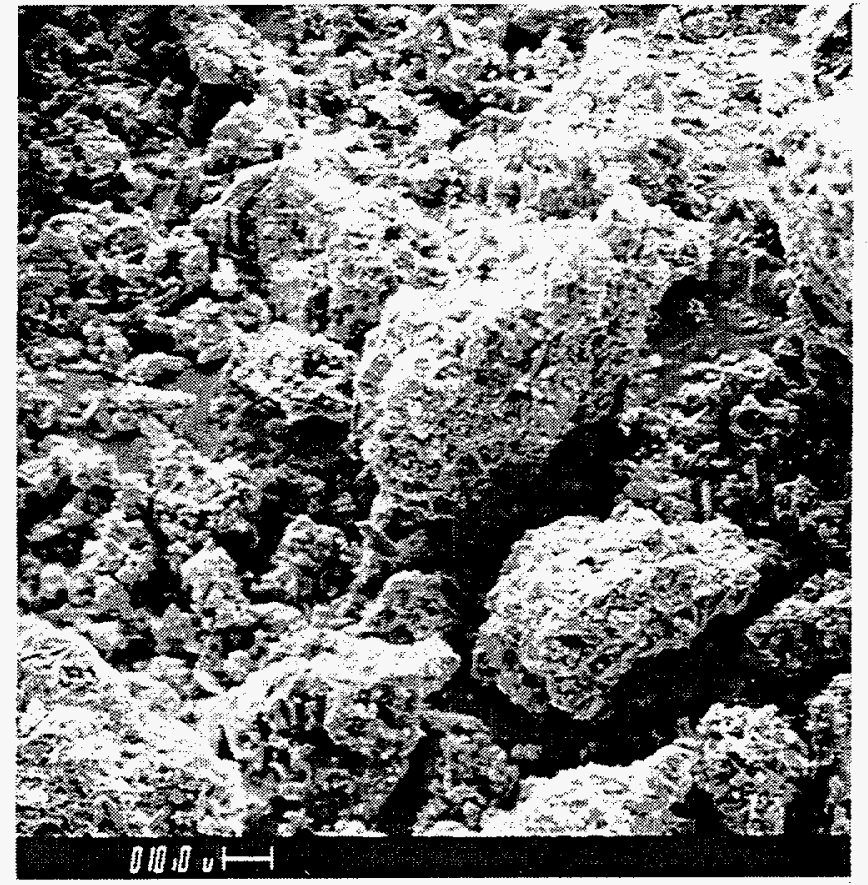

b

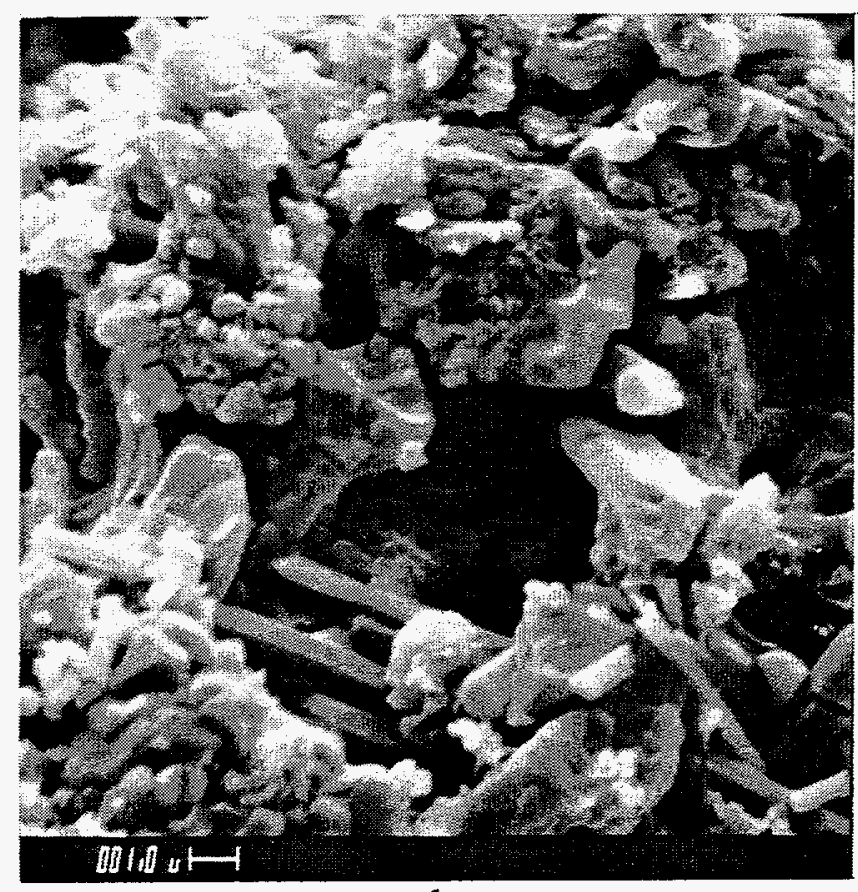

d

Figure 4. Representative SEM photographs of filter cake ash (ID \# 4144A) removed from the top plenum at Tidd on May 11, 1995 taken at a) $100 \mathrm{X}$, b) $500 \mathrm{X}$, c) $1000 \mathrm{X}$, and d) $5000 \mathrm{X}$. This ash sample contains only particles with diameters greater than $45 \mu \mathrm{m}$. 


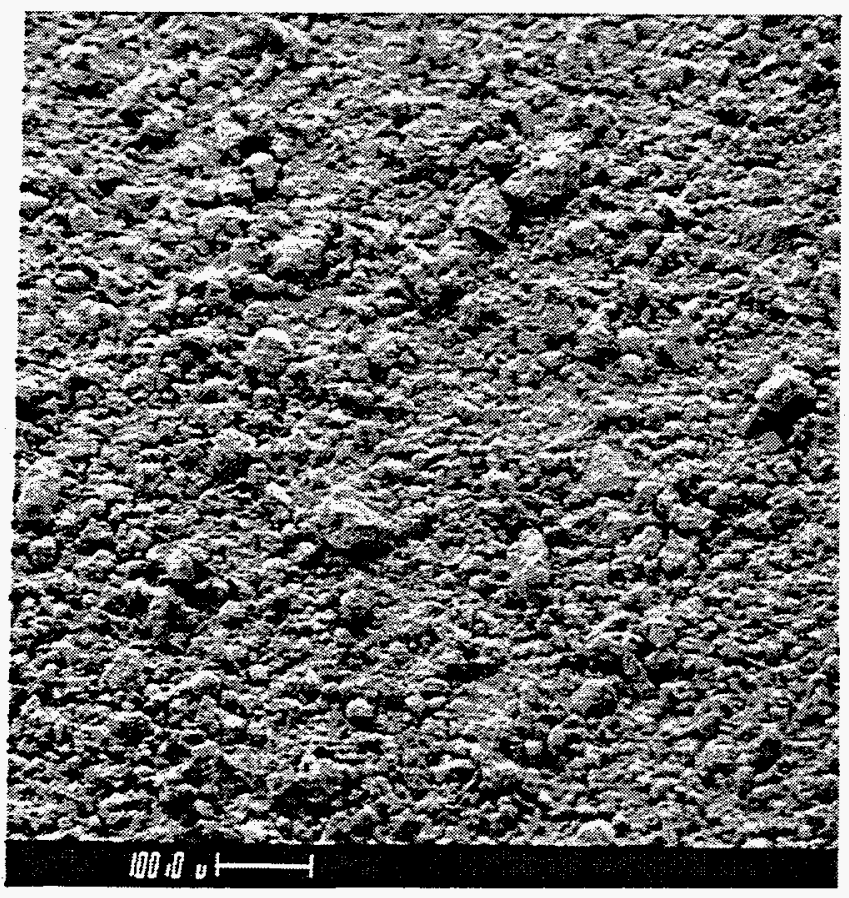

a

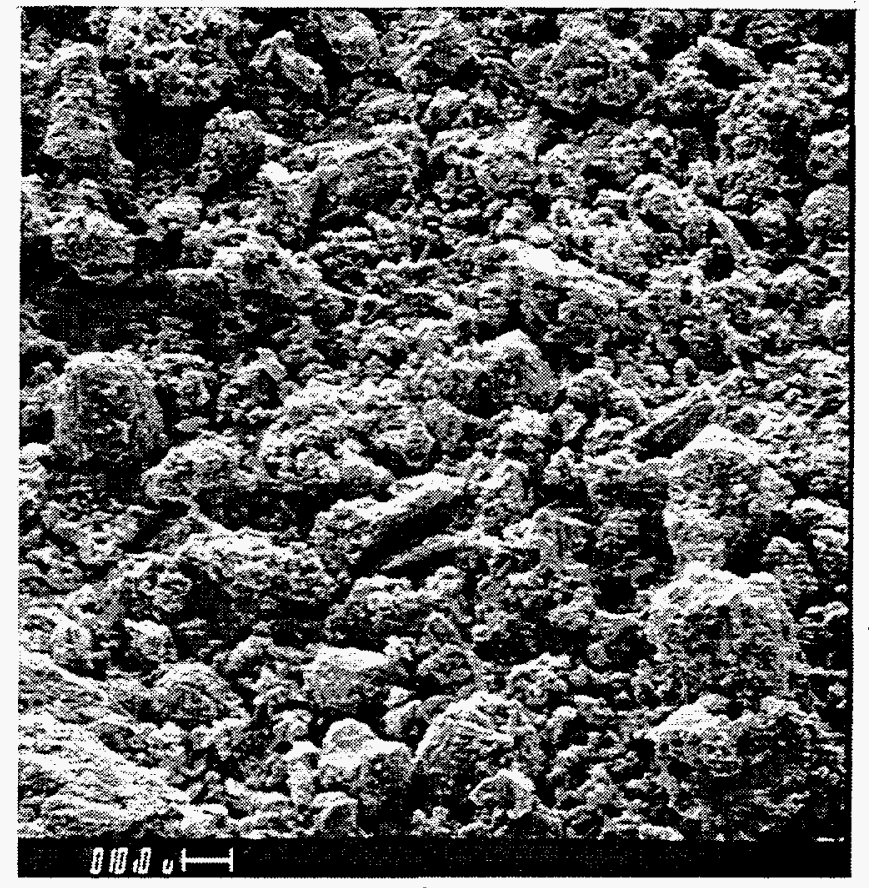

b

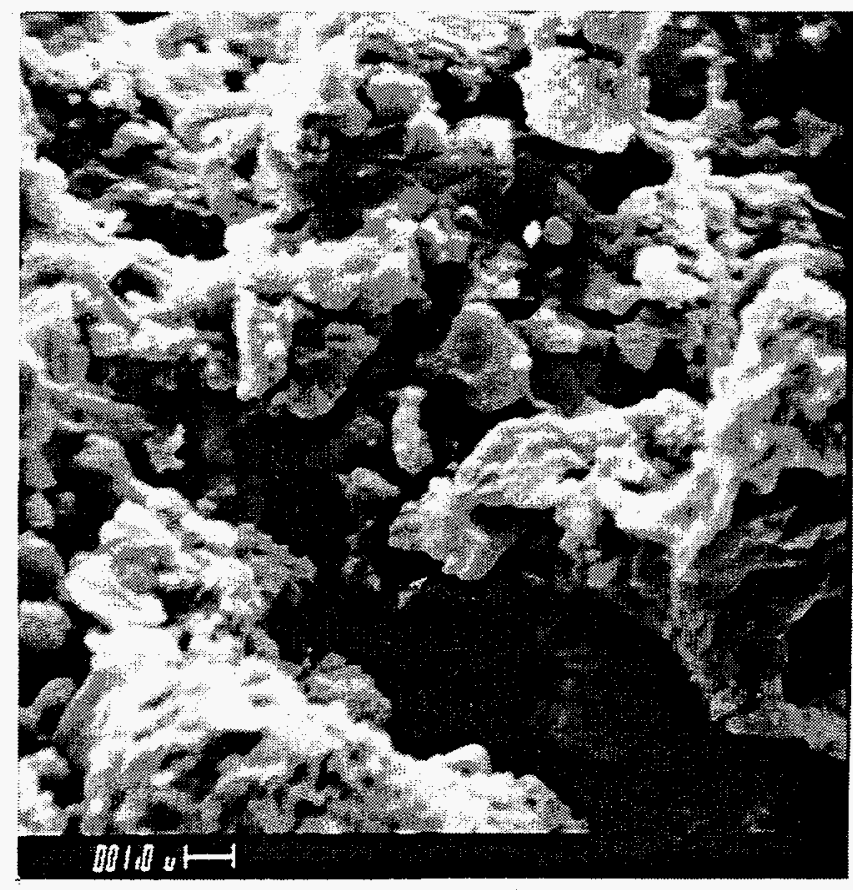

d

Figure 5. Representative SEM photographs of filter cake ash (ID \# 4144B) removed from the top plenum at Tidd on May 11, 1995 taken at a) $100 \mathrm{X}$, b) $500 \mathrm{X}$, c) $1000 \mathrm{X}$, and d) $5000 \mathrm{X}$. This ash sample contains only particles with diameters less than $45 \mu \mathrm{m}$ and greater than $15 \mu \mathrm{m}$. 


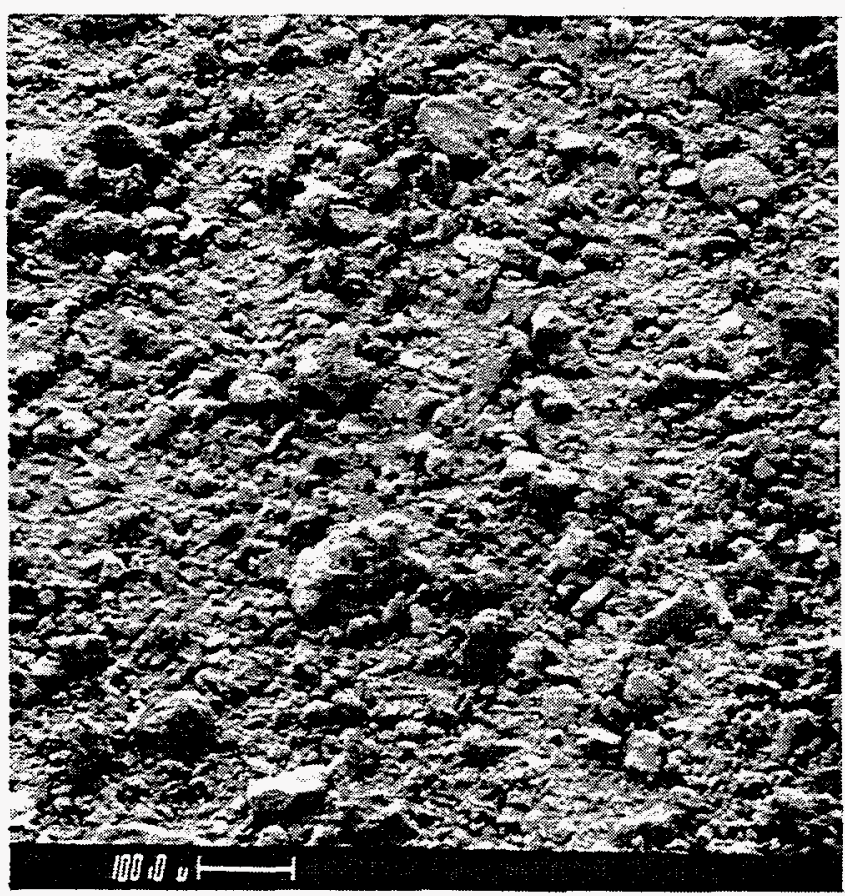

a

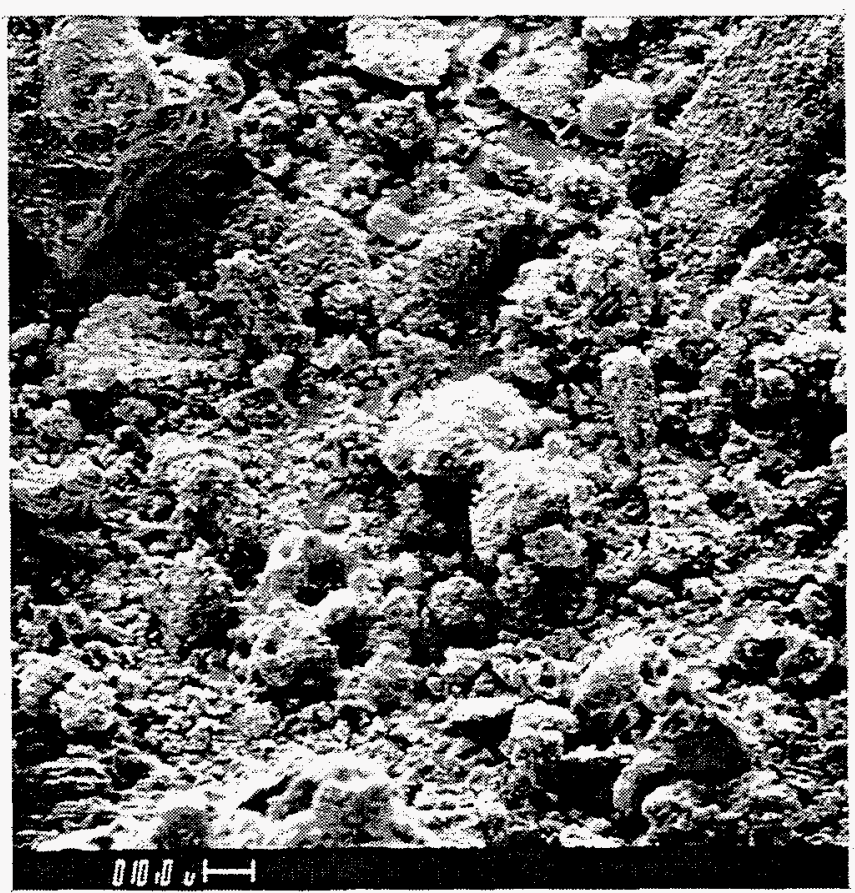

b

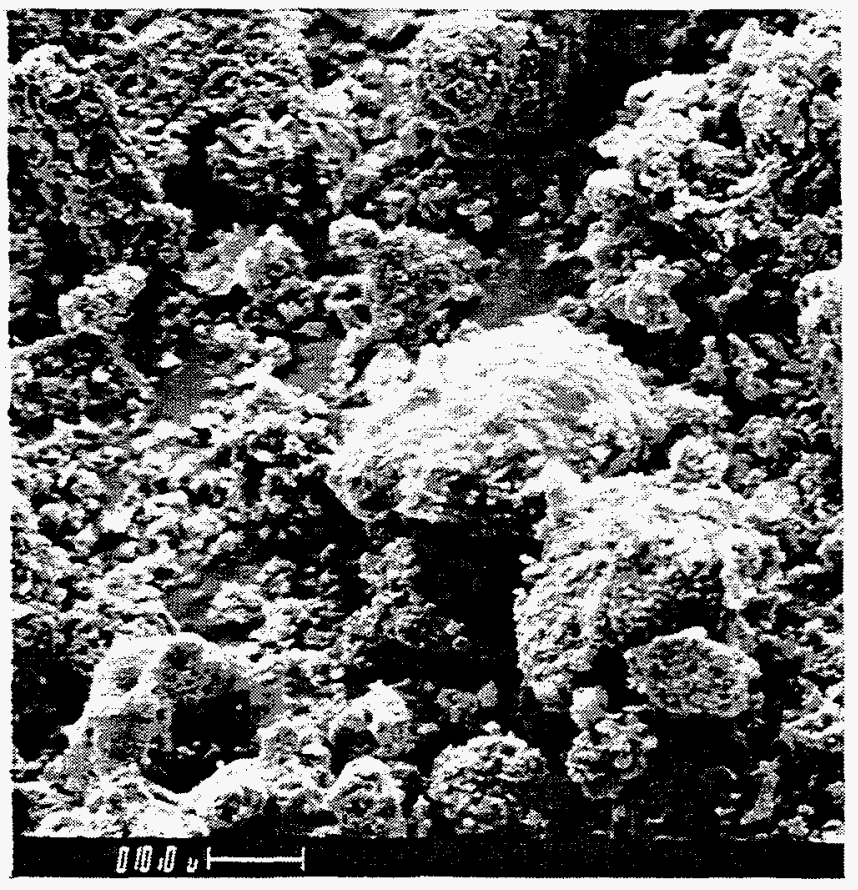

c

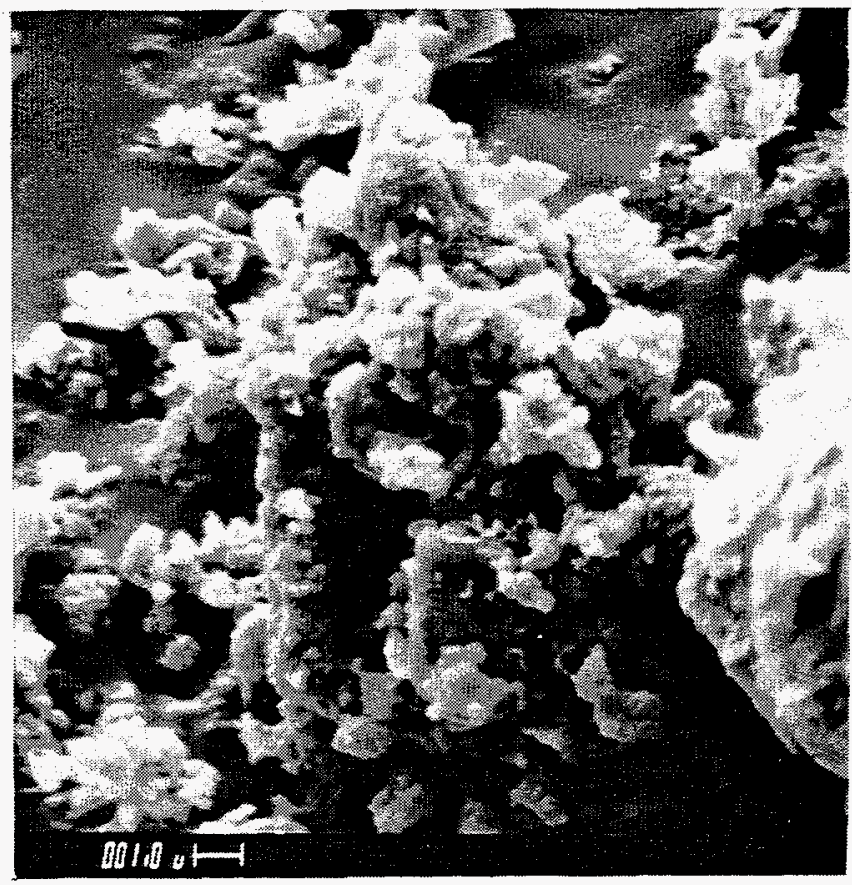

d

Figure 6. Representative SEM photographs of filter cake ash (ID \# 4151) removed from the top plenum at Tidd on May 11, 1995 taken at a) $100 \mathrm{X}$, b) $500 \mathrm{X}$, c) $1000 \mathrm{X}$, and d) $5000 \mathrm{x}$. 


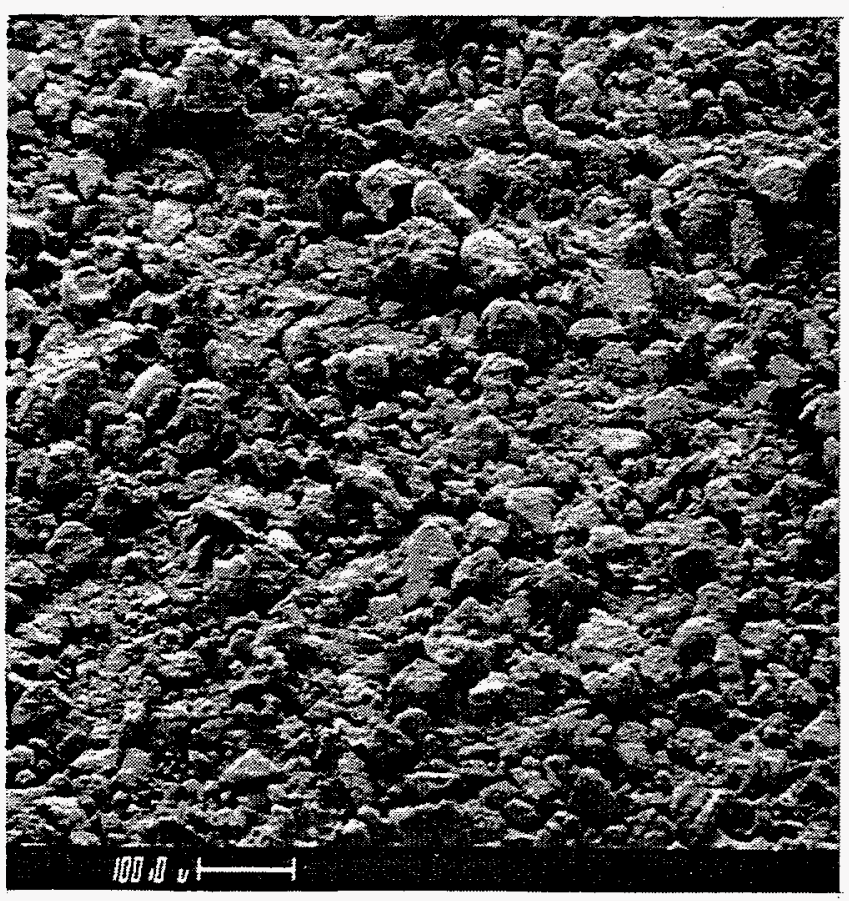

a

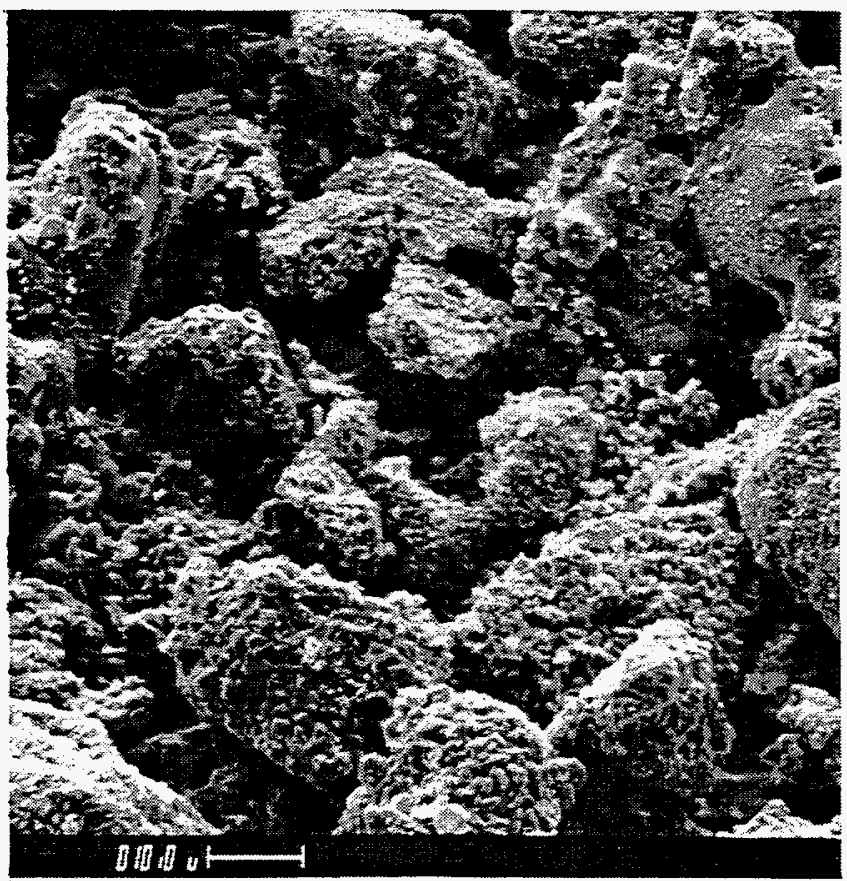

c

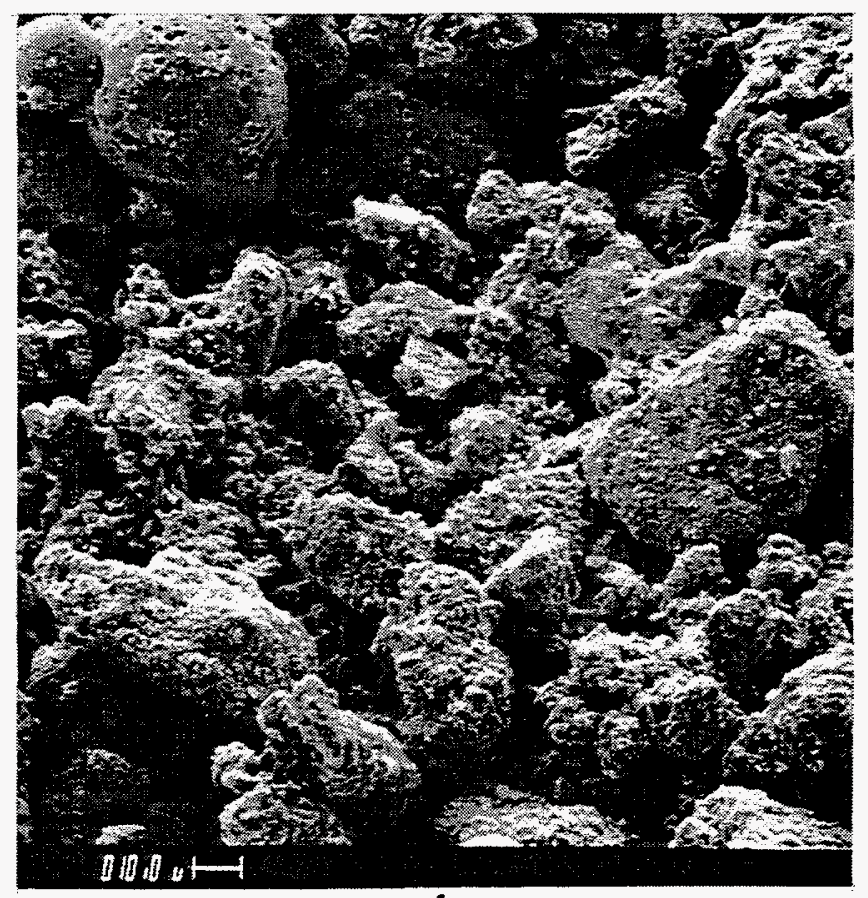

b

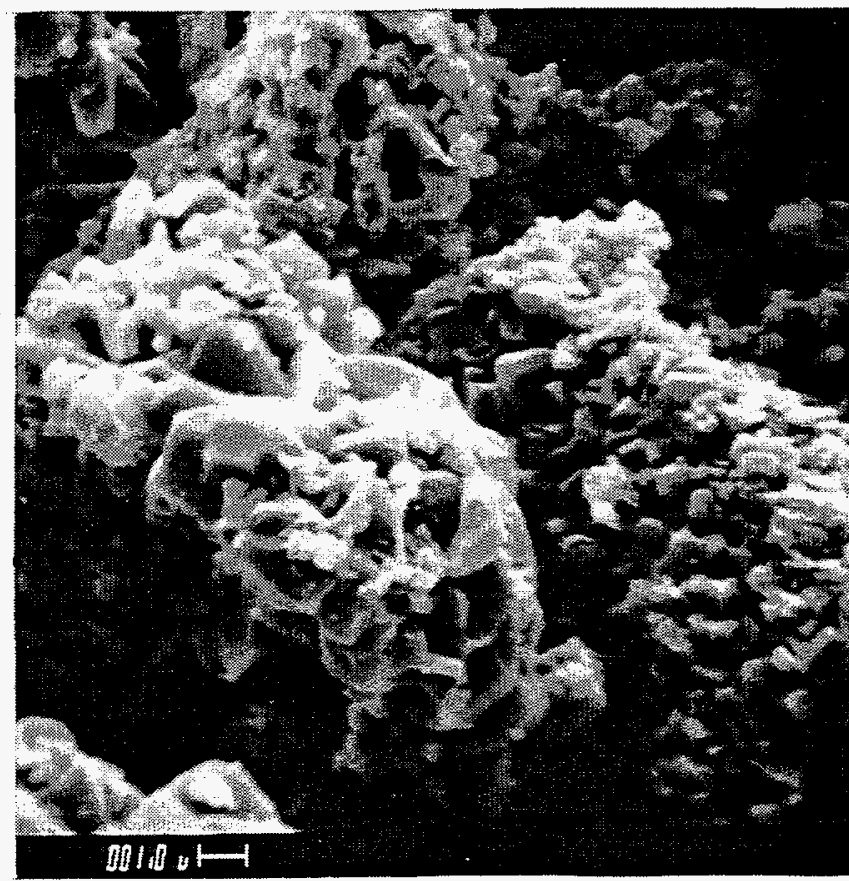

d

Figure 7. Representative SEM photographs of filter cake ash (ID \# 4151A) removed from the top plenum at Tidd on May 11, 1995 taken at a) $100 \mathrm{X}$, b) $500 \mathrm{X}$, c) $1000 \mathrm{X}$, and d) $5000 \mathrm{X}$. This ash sample contains only particles with diameters greater than $45 \mu \mathrm{m}$. 


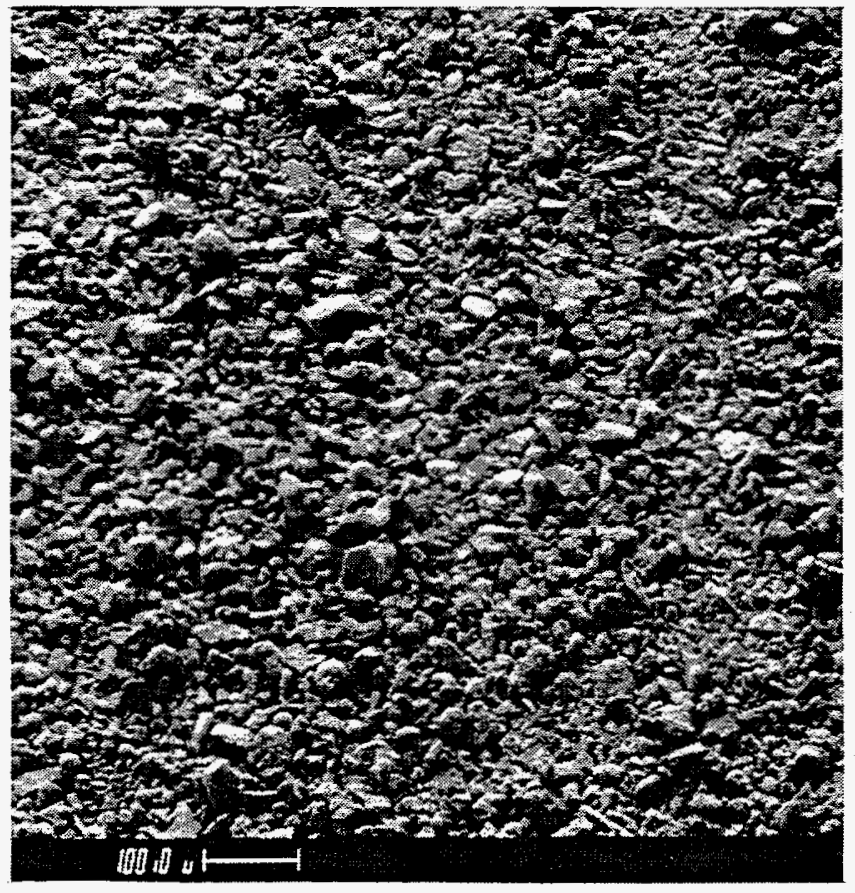

a

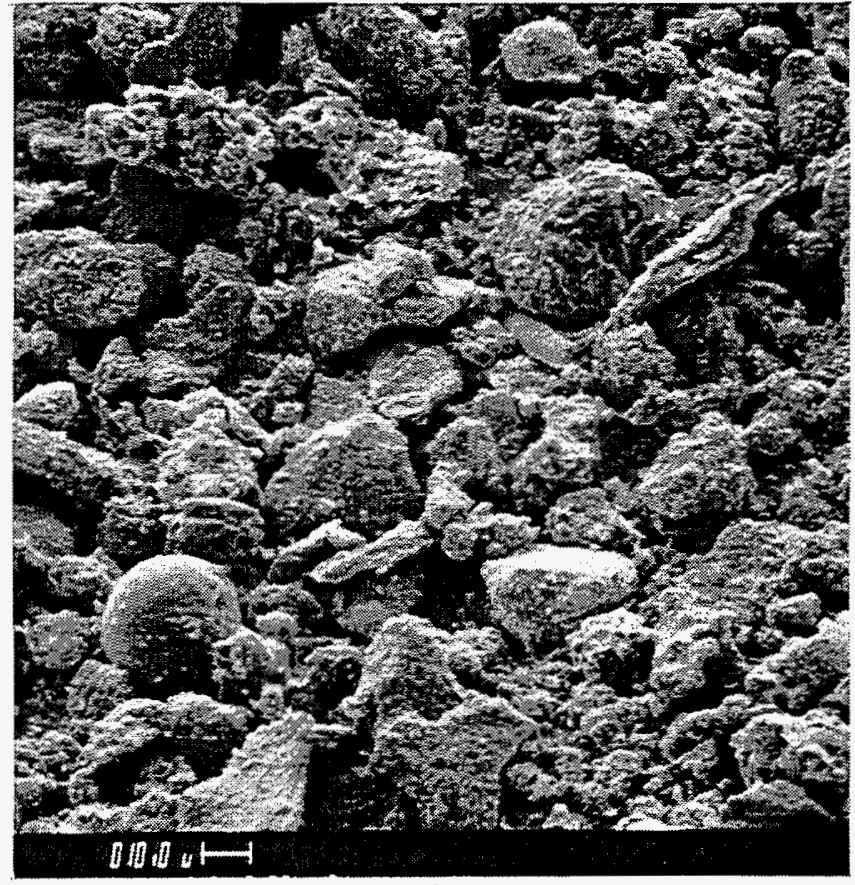

b

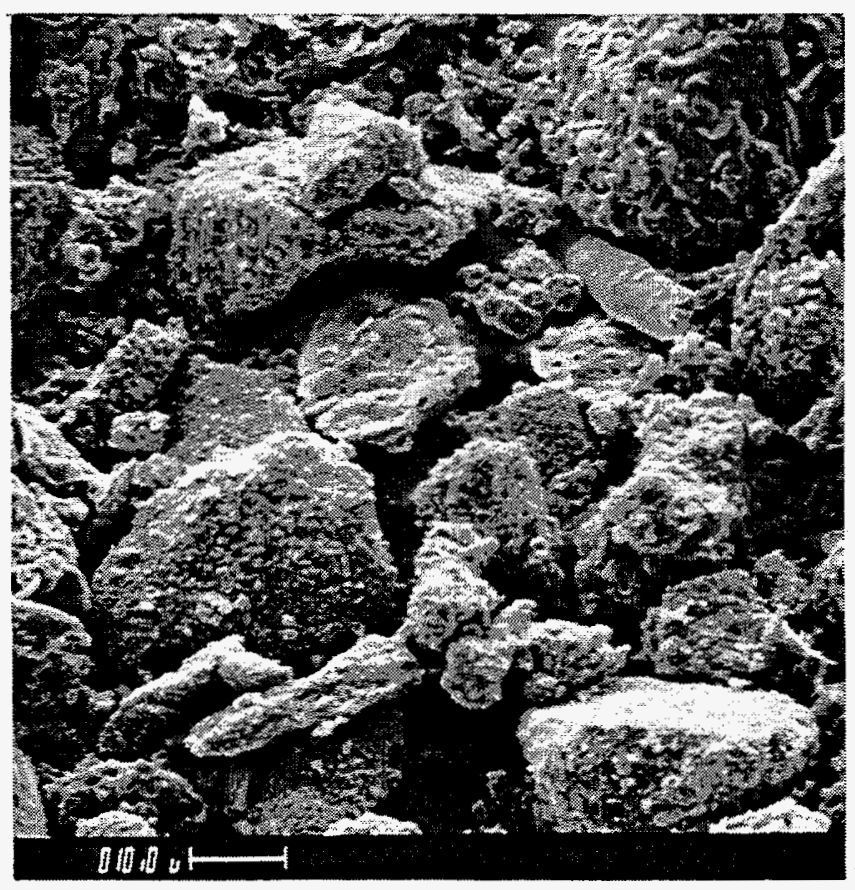

c

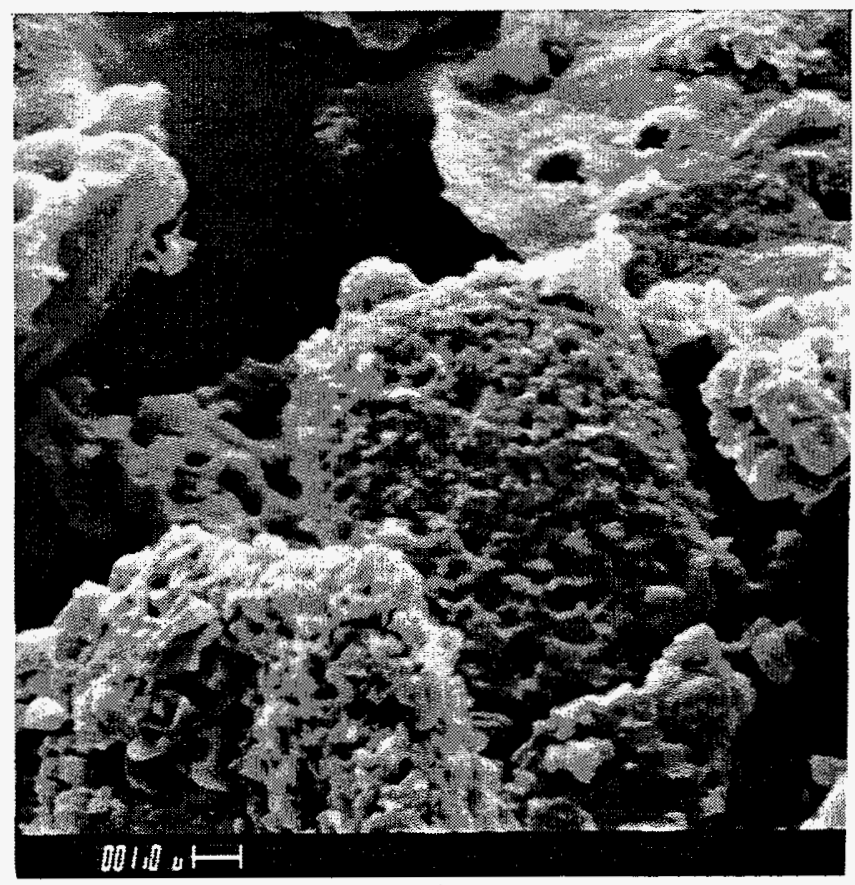

d

Figure 8. Representative SEM photographs of filter cake ash (ID \# 4151B) removed from the top plenum at Tidd on May 11, 1995 taken at a) $100 \mathrm{X}$, b) $500 \mathrm{X}$, c) $1000 \mathrm{X}$, and d) $5000 \mathrm{X}$. This ash sample contains only particles with diameters less than $45 \mu \mathrm{m}$ and greater than $15 \mu \mathrm{m}$. 


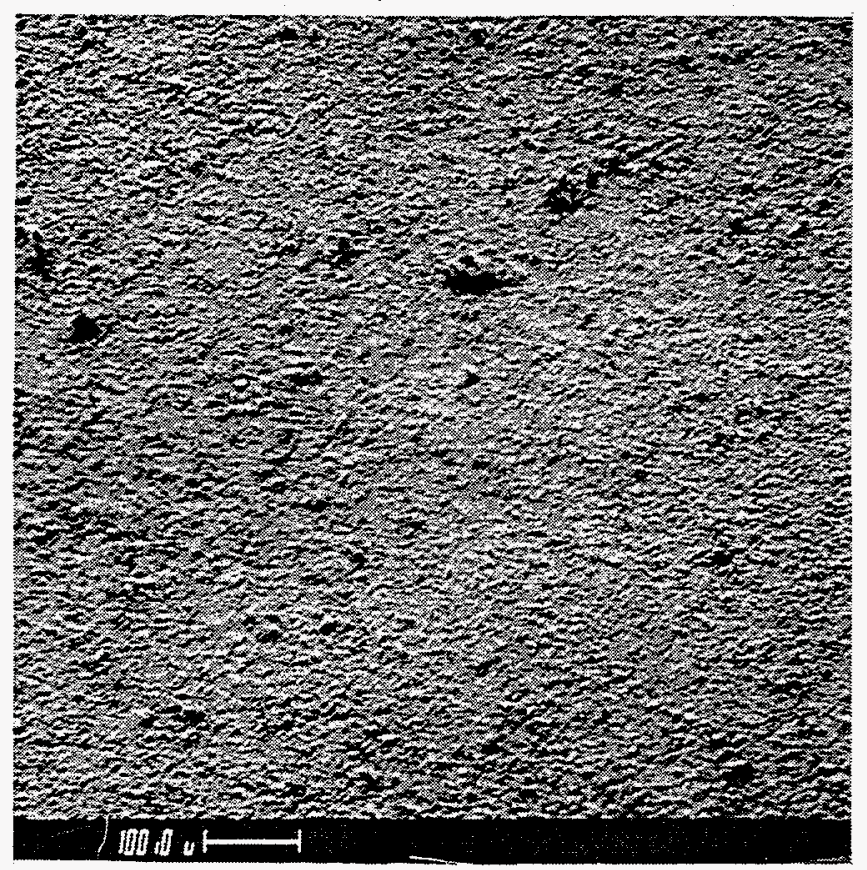

a

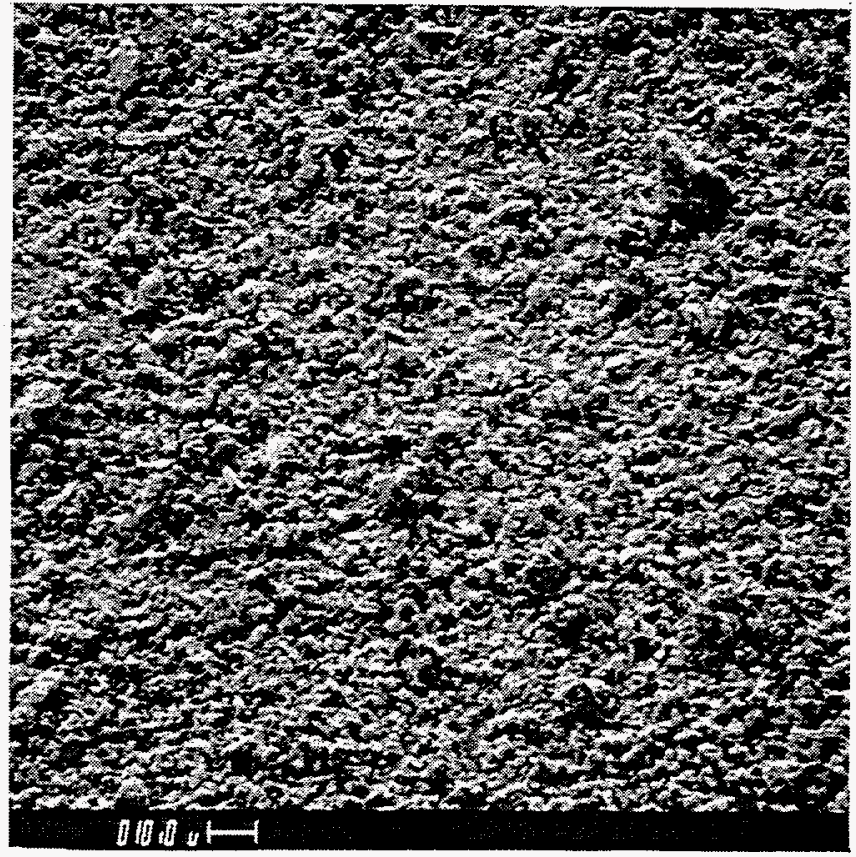

b

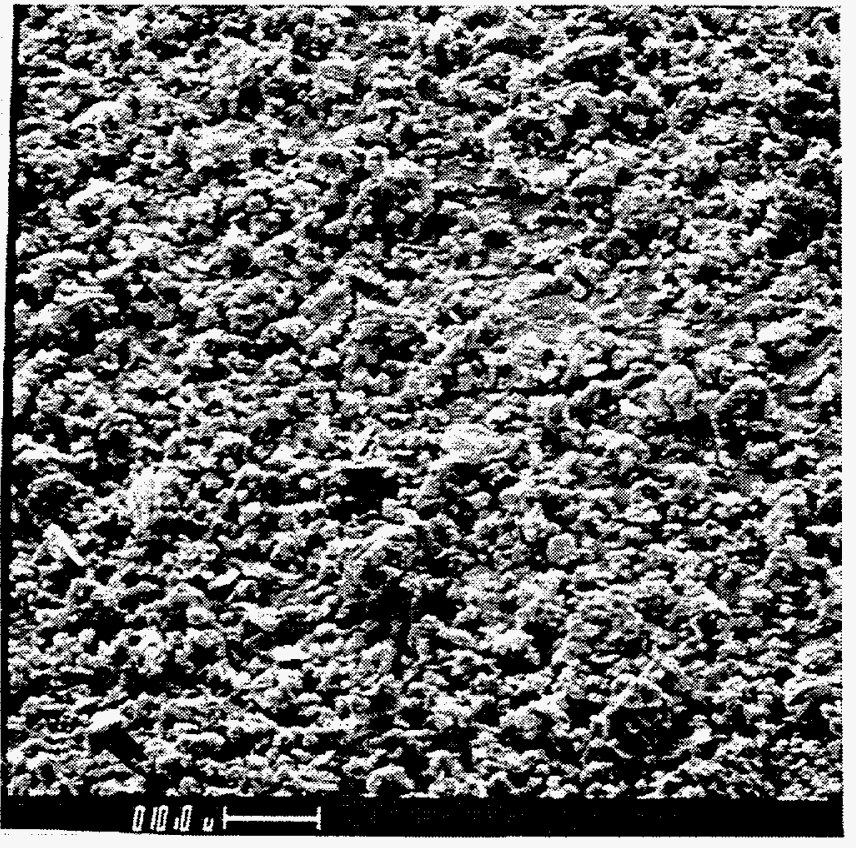

c

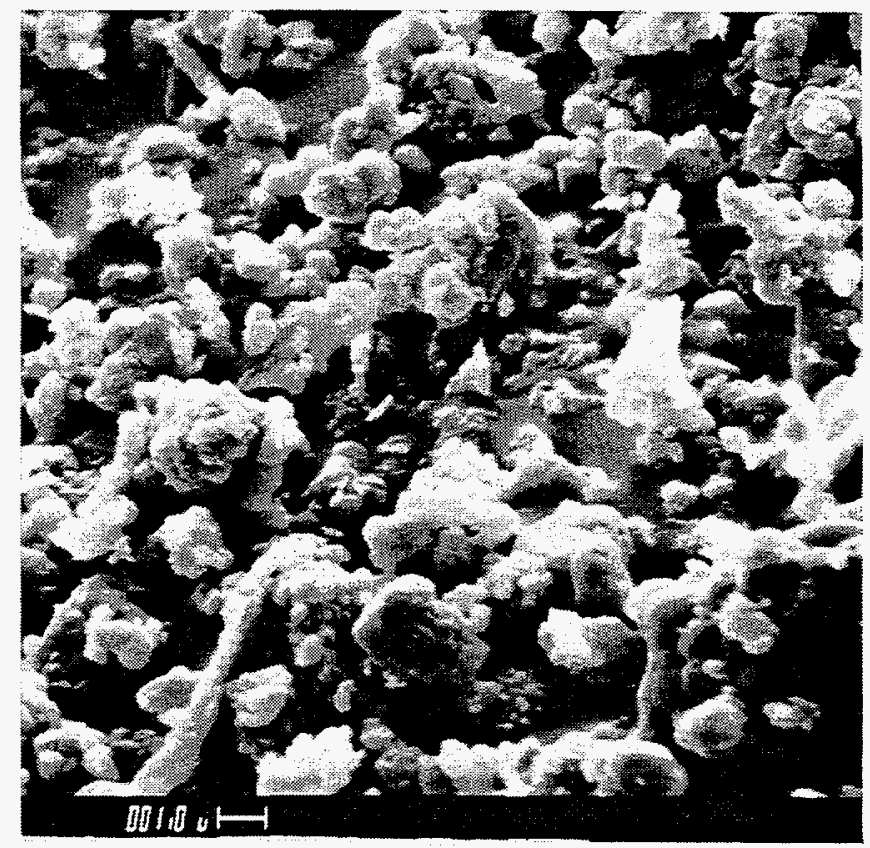

d

Figure 9. Representative SEM photographs of ID \# 4114 (MP, AS) ash taken at a) 100X, b) $500 \mathrm{X}$, c) $1000 \mathrm{X}$, and d) $5000 \mathrm{X}$. 


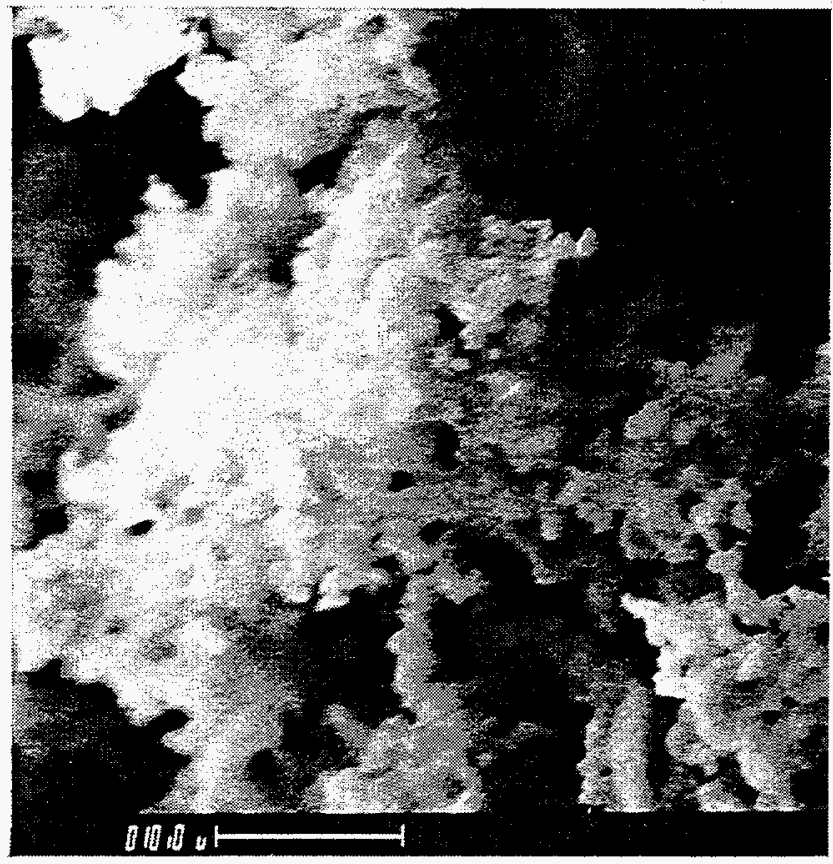

a

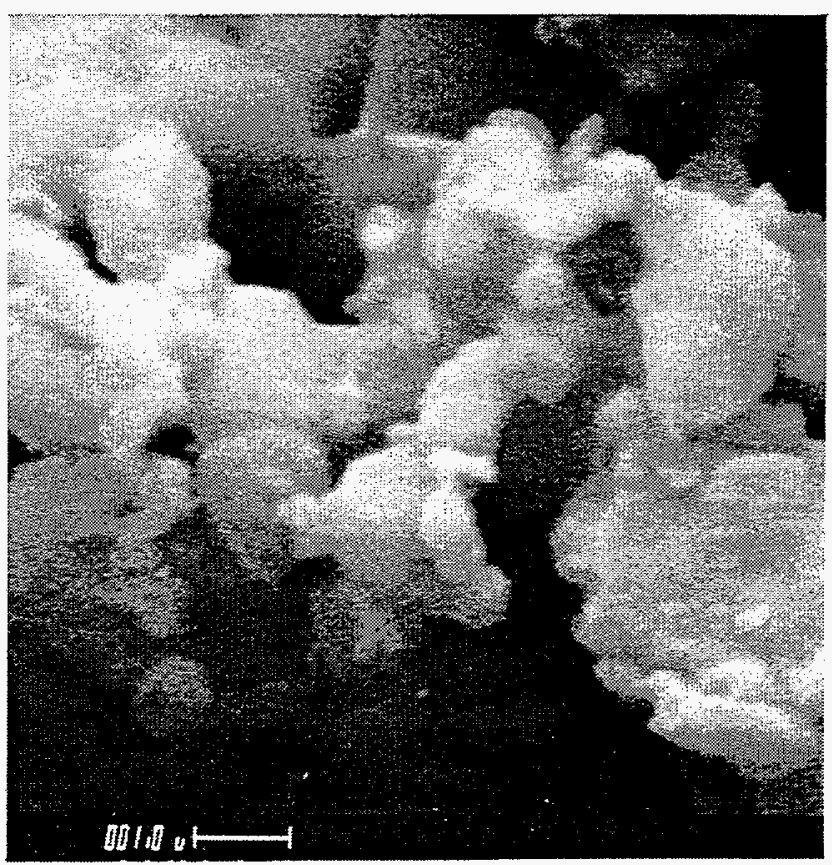

b

Figure 10. Two representative SEM photographs of an ash nodule from sample ID \# 4114 (MP, AS) ash taken at a) $2000 \mathrm{X}$ and b) $10,000 \mathrm{X}$. The primary particles that make up the agglomerate seem to be strongly bonded together. 


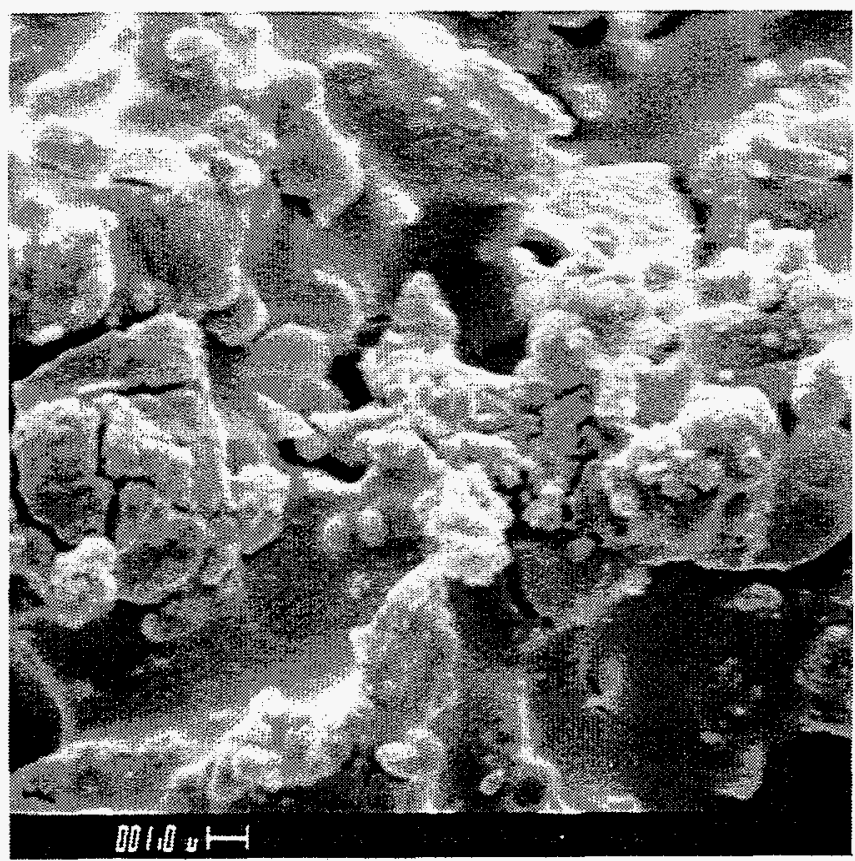

Figure 11. A representative SEM photograph of a fresh fracture surface of an ash agglomerate from sample ID \# 4114 (MP, AS). The nodule appears to be an concretion composed of discrete fine particles almost completely embedded in a pervasive amorphous mass. 
Table 12

Effects of Baking Duration at $1550{ }^{\circ} \mathrm{F}$ on the Porosity of ID \# 4097 Nodule (BP, TS)

\begin{tabular}{|c|c|}
\hline Duration, $\mathrm{hr}$ & Porosity, \% \\
\hline 0 & 81.4 \\
\hline 3 & 83.6 \\
\hline 72 & 86.3 \\
\hline
\end{tabular}

We are not certain what caused this apparent increase in porosity while the samples were being baked. Possibly the absorption and/or loss of water may account for these differences. Loose, sifted ash placed in the oven with these nodules consolidated slightly after 72 hours at $1550^{\circ} \mathrm{F}$ during this trial. We may perform additional baking tests to further investigate these effects.

\section{Mechanisms Controlling the Consolidation of Ash Deposits}

As can be seen in the SEM photograph of an aggregate of ash removed from the Tidd APF (Figure 11), the primary ash particles are nearly completely imbedded in a pervasive amorphous mass. The keys to determining the mechanism(s) responsible for the apparent consolidation of ash deposits into this type of amorphous mass lie in physical observations of the porosity of fresh and aged deposits, and in comparisons of the chemical composition of aged ash deposits with APF hopper ashes. (Hopper ashes are assumed to have experienced the least exposure to APF conditions than any other ash samples available for analysis.)

We consistently observed a difference between the porosity of newly-deposited regions of ash aggregates ( $85 \%$ or higher) and the porosity of portions of the aggregates that were exposed to the temperatures in the APF for extended periods (around $74 \%$ ). In other words, the newly-deposited regions of the agglomerates are no more than $15 \%$ solid, whereas the solid content of older portions is at least $26 \%$. This means that as the aggregates age in the APF, either the amount of mass has been nearly doubled from some source other than the primary particles (condensation or adsorption from the flue gas), or the primary particles have rearranged themselves to occupy about $58 \%$ of their original total volume. This difference in porosity has been observed for filter cakes and passively deposited ash agglomerates. The specific mechanisms involved in this type of transformation, referred to in this report as consolidation, have not been positively verified. However, different theories have been proposed, and a significant amount of circumstantial evidence exists that can be used to examine their validity.

The amorphous mass shown in Figure 11 may be composed of particles surrounded by some compound(s), such as alkali metals, that have condensed out of the flue gas. Another possibility is that unreacted calcium and/or magnesium present in the sorbent particles 
reacts with $\mathrm{SO}_{2}$ in the flue gas to form calcium and/or magnesium sulfates which form between the primary particles. Because the PFBC process captures only about $90 \%$ of the sulfur in the coal, a significant concentration of $\mathrm{SO}_{2}$ is present in the flue gas entering the APF. The ash that collects in the APF contains significant amounts of unreacted calcium and magnesium with which the $\mathrm{SO}_{2}$ can react. Calcium sulfate and magnesium sulfate are the compounds most likely to be formed as a result of the chemical adsorption of $\mathrm{SO}_{2}$ by ash particles. Since these alkali-sulfate salt molecules are physically larger than the original alkali molecules, the formation of these salts after the ash particles have been collected may result in lowered porosity, increased aggregate strength, and possibly the formation the type of concretion mentioned above. The other basic mechanism that may account for the consolidation of ash deposits is that eutectic mixtures are formed directly from the ash and sorbent particles in the deposit. In this mechanism, the ash particles soften significantly and gradually rearrange themselves into a more compact structure. Evidence supporting or refuting these three mechanisms is discussed in the following paragraphs.

For either condensed or adsorbed material to account for the apparent consolidation of ash deposits, a sufficient amount of material must be added to the deposit to yield the reductions in porosity (or increases in \% solid volume) that we have consistently observed. Since this material would have a different composition than the fly ash, and would be gradually added to ash deposits in the APF, aged deposits such as thick filter cakes would contain more of the adsorbed or condensed material than APF hopper ashes. The chemical compositions of these two types of Tidd ashes were presented in Table 10. Because the sulfur contents of hopper and filter cake ashes (expressed by measured $\mathrm{SO}_{3}$ and soluble sulfate levels presented in Table 10) are not significantly different, it is unlikely that enough $\mathrm{SO}_{2}$ becomes captured by the unreacted sorbent in the ash after an ash deposit is initially formed to account for the increased amount of solid material in consolidated ash deposits.

Another way to compare the chemistries of these two types of samples is to examine the relative concentrations of non-volatile components. If the flue gas contributed large amounts of mass to the aggregate through condensation or adsorption, the chemical constituents of this added mass would be limited to compounds that could exist as a vapor at the normal operating conditions of the APF. Although many compounds could satisfy these requirements, some of the major constituents found in the fly ash do not. Three major constituents that will not be found in a gaseous state in the APF are iron, aluminum and silicon. When we compare the mineral analyses of Tidd APF hopper ashes with mineral analyses of aged Tidd filter cake ashes, the iron, aluminum, and silicon contents of the two types of samples are very similar. Since the concentrations of these three nonvolatile elements are not significantly lower in filter cake ash than in hopper ash, it is apparent that essentially all of the mass of the filter cake is due to the original ash particles, and not to any significant deposition of gas-phase constituents from the flue gas. These results do not preclude formation of calcium and/or magnesium sulfate in the Tidd APF; 
however, the chemical analyses do not support the production of these compounds as the primary mechanism by which ash deposits consolidate.

Studies of the buildup of ash deposits on boiler tubes in conventional pulverized-coal fired boilers describe the formation of eutectics which may account for the apparent consolidation of the Tidd ash deposits. Many of the PFBC ash particles are derived directly from coal particles. These ash particles often contain a large percentage of aluminosilicate compounds. The other main source of ash particles collected in the filter vessel is the sorbent used in the PFBC process. Sorbent-derived ash particles contain relatively large amounts of calcium and/or magnesium. Once these two types of ash particles come in contact with each other in the agglomerates formed in the filter vessel, the aluminosilicate compounds in the coal fly ash tend to react with alkali and alkaline metals in the sorbent ash particles to form eutectics that melt at relatively low temperatures ${ }^{5}$. The progress of these reactions is supported by the intimate contact of the ash particles in the agglomerate and by long-term exposure of the ash particles to the temperatures in the filter vessel.

Most of the research into the formation of these eutectics has examined the formation of calcium aluminosilicate compounds (e.g. $2 \mathrm{Ca} \cdot \mathrm{Al}_{2} \mathrm{O}_{3} \cdot \mathrm{SiO}_{2}$ or $\mathrm{CaO} \cdot \mathrm{Al}_{2} \mathrm{O}_{3} \cdot 2 \mathrm{SiO}_{2}$ ). Although pure forms of these two compounds do not melt at the temperatures encountered in HGCU filter vessels (pure $2 \mathrm{Ca} \cdot \mathrm{Al}_{2} \mathrm{O}_{3} \cdot \mathrm{SiO}_{2}$ and $\mathrm{CaO} \cdot \mathrm{Al}_{2} \mathrm{O}_{3} \cdot 2 \mathrm{SiO}_{2}$ melt at around $2800{ }^{\circ} \mathrm{F}$ ), impurities that would almost certainly be present in these compounds due to the heterogeneous nature of coal fly ash particles would lower their melting points. It is likely that this reduction in melting points could combine with long-term exposure to the temperatures in the filter vessel to create relatively soft, sticky layers on the surfaces of the ash particles ${ }^{6,7}$. As the viscosity of the outer layer of the ash particles decreases, the bonds between the particles become stronger. Also, the surface tension of the liquid or nearliquid layer on the particles tends to pull adjacent ash particles closer together, thereby eventually consolidating the structure of the entire ash agglomerate. The same consolidating mechanism would apply to any eutectic mixture that melted or significantly softened at the temperatures within the filter vessel. Consolidation may be further enhanced by the relatively small size of the ash particles in the agglomerate.

The data show that the degree of consolidation of these agglomerates can not be accounted for by condensation and/or adsorption of materials from the flue gas. We believe the mechanism responsible for the extreme consolidation of these agglomerates of ash is a physical rearrangement of the ash particles due to the surface tension of melted or partially melted alkali-aluminosilicate eutectic mixture(s) that form at the contact points between adjacent particles after long-term exposure to the temperatures in the APF. This contention is supported by the similarities in the chemical composition of aged filter cake ashes and relatively fresh hopper ashes, and by the physical appearance of the amorphous mass between the primary particles. The amorphous material between the particles can best be described as a concretion formed from individual ash particles embedded in what appears to be a large, interconnected molten mass. 
Therefore we believe the amorphous mass in which the particles are embedded (as seen in Figure 11) is derived directly from the primary coal ash particles and sorbent particles originally deposited on the surface of the aggregate. The mechanism of eutectic formation is therefore responsible for the consolidation of ash deposits in the APF. The formation of calcium sulfate, magnesium sulfate and/or sodium sulfate on the surfaces of incompletely reacted sorbent particles in the agglomerate may contribute to eutectic formation. The melting points of these compounds in their pure state exceed the operating temperature of the APF. However, these compounds may become part of eutectic mixtures like the ones discussed above. In this way, adsorption of $\mathrm{SO}_{2}$ from the flue gas and its subsequent chemical reactions with alkali components of the ash may also play an important role in the consolidation of ash deposits.

\section{Avoiding High-Strength PFBC Ash Deposits}

It is doubtful that process changes such as slightly lowering the temperature in the APF, sorbent switching, or addition of a conditioning agent will be able to significantly affect the formation of these eutectics and the subsequent consolidation and strengthening of the ash aggregates. The minimum operating temperature of the APF is strictly limited by the economics of the PFBC process. Past operation at reduced temperatures around $1250^{\circ} \mathrm{F}$ have not been able to prevent the formation of consolidated ash aggregates. Since magnesium and calcium are both excellent fluxing agents, altering the type of sorbent used in the PFBC process is not likely to alter the tendency for eutectic formation. Finally, the addition of any conditioning agent to the eutectic system is only likely to lower its melting point even further. Therefore, the optimum solution to the problems caused by the ash aggregates that have been consolidated and strengthened by pervasive eutectic formation is the removal of ash aggregates from the APF before these eutectics have had enough time to develop. A large measure of success has been achieved by bypassing the cyclone upstream of the APF. This increases the size distribution of the particles forming the various ash deposits (filter cakes and passive deposits), thereby decreasing their inherent cohesivity. These agglomerates of lower cohesivity do not have sufficient strength to remain in the APF long enough to undergo consolidation. The effects of gravity and vibration cause them to fall off the surface on which they initially formed.

\section{DESIGN OF A HIGH-TEMPERATURE UNCOMPACTED BULK POROSITY TEST DEVICE}

As part of our effort to characterize HGCU ashes, we are designing a laboratory-test device that we will be able to use to form uncompacted beds of ash at temperatures up to $1700{ }^{\circ} \mathrm{F}$. Measurement of the uncompacted bulk porosity of the HGCU ashes is highly desirable for two reasons. Because the permeability of a filter cake is strongly dependent on its porosity, the influence of temperature on the porosity of HGCU aggregates will help predict and explain filtering pressure drop encountered in HGCU filters. Furthermore, the physical tensile strength of aggregates obtained from the Tidd APF is strongly correlated 
with aggregate porosity. As with permeability, it is crucial to determine the effects of temperature on the strength of ash deposits such as those found in operating APFs.

A sketch of our preliminary design is shown in Figure 12. The device basically consists of a heated tube, open at the top, with a porous disk forming the bottom of the tube. Ash is sifted or elutriated into the open top of the tube, and the particles are heated to $1700^{\circ} \mathrm{F}$ as they fall (or are transported by gas flow) through two heated zones of the tube and reach its bottom. After enough ash is sifted into the preheated device to fill and cover the quartz ring, a guillotine-type blade is slid across the top of the ring to isolate the amount of ash sample required to exactly fill the volume of the ring. After the blade is securely positioned over the top surface of the ring, the device is allowed to cool down. (For some tests, the isolated ash sample may be allowed to remain at the test temperature for extended periods to determine the relationship between the time of exposure to high temperatures and the porosity of the aggregate.) The device is then partially disassembled to allow the ash in the ring to be separately weighed. The sample is then examined to determine if it consolidated after being deposited within the volume of the ring. In the currently envisioned design, this device operates only at ambient pressures.

\section{CHARACTERIZATION OF GASIFIER SAMPLES}

In addition to these problems related to the characteristics of PFBC ashes, our laboratory characterizations of gasifier and carbonizer ashes have shown that these ashes also have characteristics that might negatively affect filtration. We analyzed a sample of ash from the gasification facility located at DOE/METC. The sample was provided by Richard Dennis of DOE/METC who requested a full analysis of this sample. We also performed additional analyses on gasifier ashes from tests carried out by M.W. Kellogg, Texaco, and KRW between 1988 and 1991 . These additional analyses were intended to strengthen and clarify correlations that we have observed between specific surface area, uncompacted bulk porosity, specific gas flow resistance, drag-equivalent diameter, and tensile strength. We planned to characterize the size distribution of several of these samples; however, the device we use to perform this measurement is down for repair. We expect to have the device repaired soon. The ash samples we studied during the past quarter are described in Table 13. 


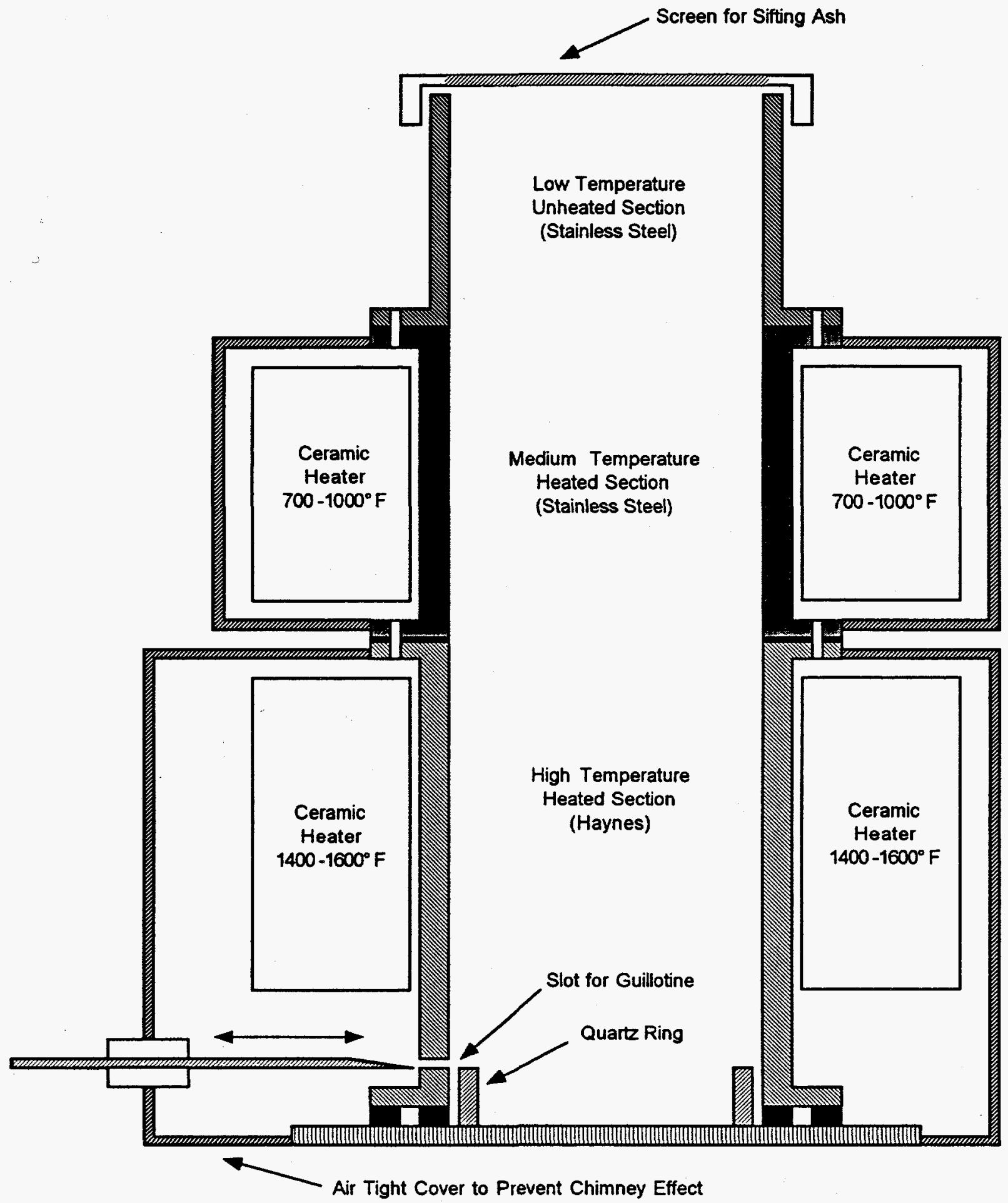

Figure 12. Preliminary conceptual design of the elevated temperature uncompacted bulk porosity test device. 
Table 13

Gasifier Ash Samples from the HGCU Data Base Characterized during the Past Quarter

\begin{tabular}{|l|l|l|}
\hline ID \# & \multicolumn{1}{|c|}{ Source } & \multicolumn{1}{c|}{ Brief description } \\
\hline 2800 & M. W. Kellogg & Transport Reactor Test Unit (TRTU) run G4 filter fines \\
\hline 2803 & M.W. Kellogg & TRTU run G101 filter fines \\
\hline 2832 & M. W. Kellogg & TRTU run H-1962-G3A filter fines \\
\hline 2834 & M. W. Kellogg & TRTU run H-1962-G5C filter fines \\
\hline 2838 & M. W. Kellogg & TRTU run H-1962-G7A filter fines \\
\hline 2840 & M. W. Kellogg & TRTU run H-1962-G8A filter fines \\
\hline 2678 & Texaco M.R.L. & run L8902-04 filter vessel ash pot solids \\
\hline 2550 & KRW & fluidized bed gasification char (82 \% carbon) \\
\hline 2556 & KRW & TP-037-9: C-110 outlet composite \\
\hline 2557 & KRW & TP-037-9: C-115 gasifier outlet composite \\
\hline 2558 & KRW & TP-037-9: C-120 outlet composite \\
\hline 2559 & KRW & TP-037-9: SC 41 hopper composite \\
\hline 2560 & KRW & TP-037-9: C-121 hopper (4/25/88) \\
\hline 2561 & KRW & TP-037-9: C-121 hopper (5/1/88) \\
\hline 2562 & KRW & TP-037-9: C-121 hopper (4/28/88) \\
\hline 4170 & DOE/METC & pilot-scale gasifier \\
\hline
\end{tabular}

Ashes generated during gasification processes differ significantly from ashes from PFBC and conventional pulverized-coal (PC) fired combustion facilities. The most distinctive chemical characteristic of most gasifier ashes is their high value of loss-on-ignition (LOI) due to the high carbon content remaining in the ash. The results of our mineral analysis of the DOE/METC gasifier ash sample (ID \# 4170) are presented in Table 14 along with results of mineral analyses we performed earlier on two ash samples from early gasification tests carried out at M.W. Kellogg's Transport Reactor Test Unit. Like ashes from other processes where sorbents are used for sulfur control, the addition of sorbents during the gasification process is reflected in relatively high concentrations of calcium and/or magnesium in the ash. Of the two M.W. Kellogg samples described in Table 14, ID \# 2800 was generated without added limestone, and limestone was added to the process during the generation of ID \# 2803. 
Table 14

Chemical Analyses of M.W. Kellogg and DOE/METC Gasification Ashes, \% wt.*

\begin{tabular}{|c|c|c|c|}
\hline constituent ID \# & 2800 & 2803 & 4170 \\
\hline $\mathrm{Li}_{2} \mathrm{O}$ & 0.02 & 0.02 & 0.02 \\
\hline $\mathrm{Na}_{2} \mathrm{O}$ & 0.59 & 0.51 & 0.59 \\
\hline $\mathrm{K}_{2} \mathrm{O}$ & 1.4 & 1.4 & 0.07 \\
\hline $\mathrm{MgO}$ & 0.53 & 1.3 & 10.9 \\
\hline $\mathrm{CaO}$ & 1.4 & 18.2 & 33.3 \\
\hline $\mathrm{Fe}_{2} \mathrm{O}_{3}$ & 5.8 & 4.6 & 1.17 \\
\hline $\mathrm{Al}_{2} \mathrm{O}_{3}$ & 58.9 & 42.3 & 17.4 \\
\hline $\mathrm{SiO}_{2}$ & 29.6 & 22.5 & 31.8 \\
\hline $\mathrm{TiO}_{2}$ & 0.67 & 0.5 & 1.49 \\
\hline $\mathrm{P}_{2} \mathrm{O}_{5}$ & 0.13 & 0.09 & 0.53 \\
\hline $\mathrm{SO}_{3}$ & 0.94 & 8.6 & 0.32 \\
\hline LOI & 47.2 & 40.7 & 35.9 \\
\hline soluble $\mathrm{SO}_{4}{ }^{=}$ & 0.36 & 3.5 & $<0.2$ \\
\hline Equilibrium $\mathrm{pH}^{* *}$ & 8.2 & 11.1 & 10.2 \\
\hline
\end{tabular}

* Quantities measured prior to the most recent reporting quarter are shaded. ** Equilibrium $\mathrm{pH}$ is dimensionless.

Physically, gasification ashes are also quite different than PC and PFBC ashes. Tables 15, 16 and 17 summarize the analyses we performed on gasifier ashes generated by M.W. Kellogg, KRW, Texaco, and DOE/METC.

Table 15

Physical Characteristics of M.W. Kellogg Gasification Ashes*

\begin{tabular}{|l|c|c|c|c|c|c|}
\hline \multicolumn{1}{|c|}{ quantity $\mathrm{ID} \#$} & 2800 & 2803 & 2832 & 2834 & 2838 & 2840 \\
\hline specific surface area, $\mathrm{m}^{2} / \mathrm{g}$ & 58 & 32 & 300 & 241 & 353 & 69 \\
\hline Stokes' $\mathrm{MMD}, \mu \mathrm{m}$ & 16 & 16 & 18 & 16 & 14 & 15 \\
\hline uncompacted bulk porosity, \% & 89 & 86 & 84 & 87 & 88 & 84 \\
\hline drag-equivalent diameter, $\mu \mathrm{m}$ & 1.58 & 1.65 & 1.34 & 1.51 & 1.30 & 2.14 \\
\hline $\begin{array}{l}\text { specific gas flow resistance, } \\
\text { in } \mathrm{H}_{2} \mathrm{O} \cdot \text { min } \mathrm{ft} / \mathrm{lb}\end{array}$ & 1.7 & 3.4 & 8.9 & 3.4 & 3.6 & 3.2 \\
\hline tensile strength, $\mathrm{N} / \mathrm{m}^{2}$ & 2.7 & 2.0 & 1.3 & 0.8 & 0.4 & 0.5 \\
\hline true particle density, $\mathrm{g} / \mathrm{cm}^{3}$ & 2.44 & 2.40 & 2.14 & 2.29 & 2.27 & 2.31 \\
\hline
\end{tabular}

* Quantities measured prior to the most recent reporting quarter are shaded. 
Table 16

Physical Characteristics of KRW Gasification Ashes*

\begin{tabular}{|l|c|c|c|c|c|c|c|c|}
\hline \multicolumn{1}{|c|}{ quantity \# } & 2550 & 2556 & 2557 & 2558 & 2559 & 2560 & 2561 & 2562 \\
\hline specific surface area, $\mathrm{m}^{2} / \mathrm{g}$ & 278 & 112 & 108 & 184 & 135 & 218 & 381 & 293 \\
\hline uncompacted bulk porosity, \% & 94 & 93 & 93 & 95 & 92 & 95 & 95 & 96 \\
\hline drag-equivalent diameter, $\mu \mathrm{m}$ & 0.14 & 0.99 & 0.93 & 0.28 & 0.95 & 0.26 & 0.26 & 0.25 \\
\hline $\begin{array}{l}\text { specific gas flow resistance, } \\
\text { in } \mathrm{H}_{2} \mathrm{O} \cdot \mathrm{min} \cdot \mathrm{ft} / \mathrm{lb}\end{array}$ & 45 & 1.3 & 1.5 & 6.4 & 2.0 & 7.4 & 7.8 & 4.5 \\
\hline tensile strength, $\mathrm{N} / \mathrm{m}^{2}$ & 3.5 & 0.3 & 0.3 & 2.5 & 0.3 & 3.0 & 1.8 & 1.1 \\
\hline true particle density, $\mathrm{g} / \mathrm{cm}^{3}$ & 2.17 & 2.11 & 2.08 & 2.14 & 2.18 & 2.12 & 2.12 & 2.17 \\
\hline
\end{tabular}

* Quantities measured prior to the most recent reporting quarter are shaded.

Table 17

Physical Characteristics of Texaco and DOE/METC Gasification Ashes*

\begin{tabular}{|l|c|c|}
\hline \multicolumn{1}{|c|}{ quantity $\mathrm{ID} \#$} & 2678 & 4170 \\
\hline specific surface area, $\mathrm{m}^{2} / \mathrm{g}$ & 88 & 140 \\
\hline uncompacted bulk porosity, \% & 92 & 94 \\
\hline drag-equivalent diameter, $\mu \mathrm{m}$ & 1.16 & 0.08 \\
\hline $\begin{array}{l}\text { specific gas flow resistance, } \\
\text { in } \mathrm{H}_{2} \mathrm{O} \cdot \text { min } \mathrm{ft} / \mathrm{lb}\end{array}$ & 1.1. & 101 \\
\hline tensile strength, $\mathrm{N} / \mathrm{m}^{2}$ & 0.6 & 0.6 \\
\hline true particle density, $\mathrm{g} / \mathrm{cm}^{3}$ & 2.62 & 2.87 \\
\hline
\end{tabular}

* Quantities measured prior to the most recent reporting quarter are shaded.

In general, the gasification ashes we have analyzed have very high specific surface areas. Because filtering drag is accumulated as the gas being filtered passes over the surfaces of the particles in the filter cake, high specific surface areas generally correlate with small values of drag-equivalent diameter. (Drag-equivalent diameter incorporates the effects of particle morphology on filtering drag. The effect of the structure of the filter cake on drag is determined by the filter cake porosity. Therefore, filtering drag is a function of the shape of the particles in the filter cake and the porosity of the cake.)

The relationships between the specific surface area data and drag-equivalent diameters measured for the various groups of gasification ashes listed in Table 13 are presented in Figure 13. Where sufficient data are available to identify a trend, the expected correlations between high specific surface areas and small values of drag-equivalent diameters can be seen. We believe that process differences cause each group of samples to exhibit a distinct relationship between these two variables. Differences in the way the particles were generated almost certainly caused the distribution of pore sizes on the surfaces of the 


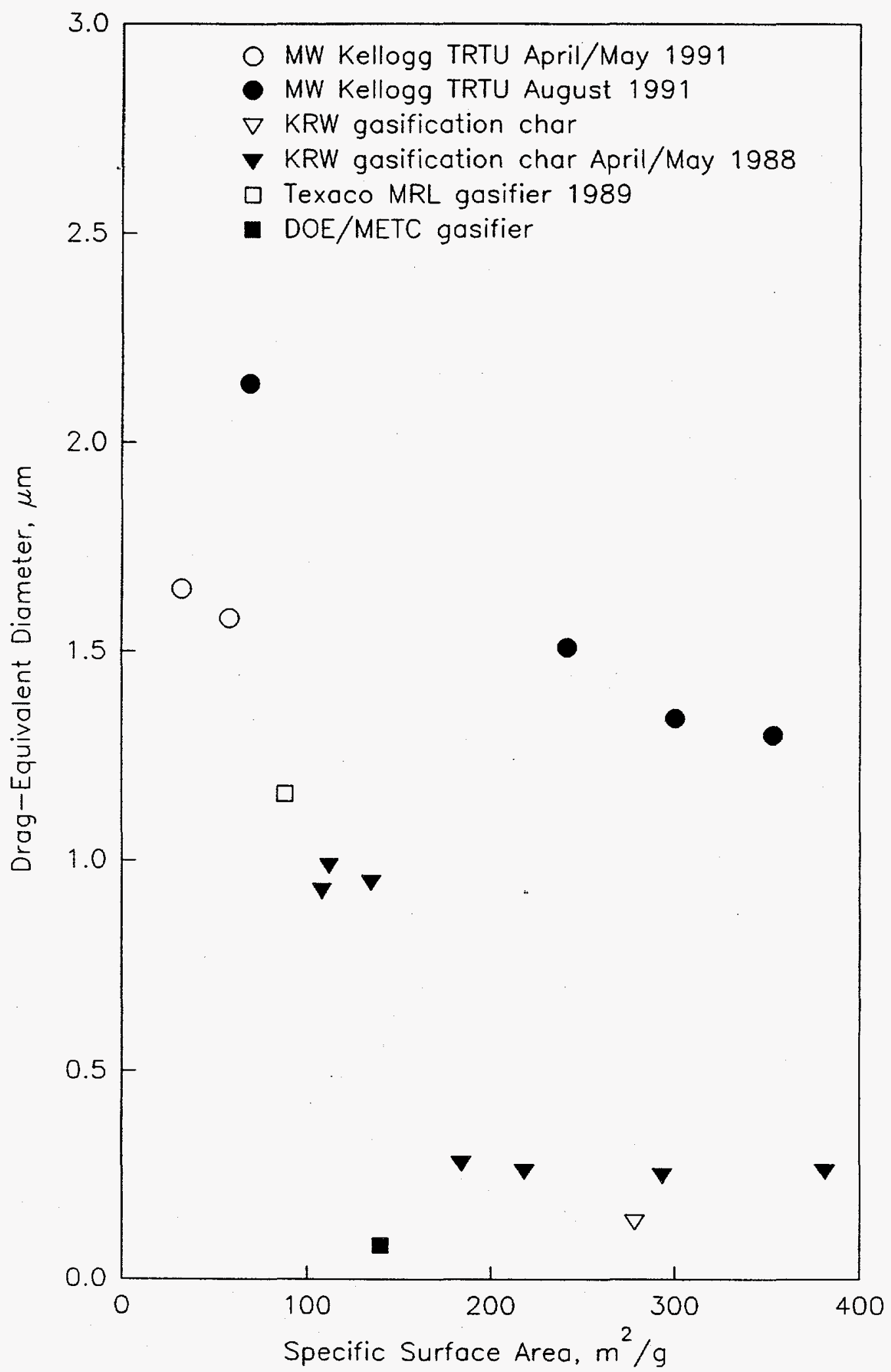

Figure 13. Relationship between specific surface area and drag-equivalent diameter for gasification ashes in the HGCU data base. 
particles to differ. Similarly, the proportion of the total surface area that is contained within the ash particles would be expected to differ according to the gasification process used. These two differences in the nature of the total surface area of the various ash samples affects the correlation between specific surface area and drag-equivalent diameter. First, the BET method for measuring surface area includes any surface area found in the interior of the particles. The vast majority of gas being passed through the simulated filter cake during the determination of drag-equivalent diameter (and flue gas passing through actual filter cakes) flows over the surfaces of the particles and not through them. Therefore the internal surface area measured by the BET method has little, if any, effect on filtering drag. In a similar manner, the BET method includes the surface area contained in very fine pores on the surfaces of the particles. However, gas flowing over the surfaces of the particles does not enter pores whose sizes are on the order of the mean free path of the gas molecules. This effect also causes the BET measurement to be more sensitive to surface area than the permeability method we use to measure the drag-equivalent diameter.

Of all the gasification ashes listed in Table 13, the two ashes exhibiting the lowest permeabilities to gas flow (or the highest specific gas flow resistances) were ID \# 2550 and ID \# 4170. Even though these ashes would be expected to form filter cakes with porosities on the order of $94 \%$ (the uncompacted bulk porosity value measured for each of these ashes), the morphologies of the particles in these two samples are the ultimate cause of their high resistance to filtering flow. Although other ashes listed in Table 13 have higher values of specific surface area than these two ashes, ID \# 2550 and ID \# 4170 exhibited the lowest values of drag equivalent diameter of all the gasification ashes we tested.

When these two ashes were examined with a scanning electron microscope (Figures 14 and $15)$, the fineness of their particle size distributions was readily apparent. Figure 14 demonstrates that, on a number basis, ID \# 2550 is composed predominantly of ultrafine particles having diameters less than $0.5 \mu \mathrm{m}$. The sample also contains a much smaller number of particles with diameters around 5 to $10 \mu \mathrm{m}$. (On a mass basis, these larger particles almost certainly dominate the size distribution of the ash, however, we have not yet been able to measure the size distribution of this ash because of the malfunction of our sedigraph.) In Figure 15 it is apparent that the size distribution of ID \# 4170 is much like that of ID \# 2550 , except that ID \# 4170 contains very few particles larger than $5 \mu \mathrm{m}$ diameter, and no particles with diameters larger than $10 \mu \mathrm{m}$.

The size distribution of ID \# 4170 was measured in a recent evaluation of a laser-based device to be used at the Power Systems Development Facility. The measured data, which are shown in Figure 16, show a distinctly bimodal distribution with a volumetric median diameter of $1.8 \mu \mathrm{m}$. Because of the appearance of the particles in ID \# 4170 in the SEM photographs shown in Figure 15, we are skeptical that the distribution shown in Figure 16 accurately represents the actual size distribution of this sample. We believe that the process used to prepare and deagglomerate the sample prior to its characterization by laserbased light scattering failed to fully separate the primary particles. In this process, a portion of the sample was suspended in a mixture of water and two types of surfactants and 


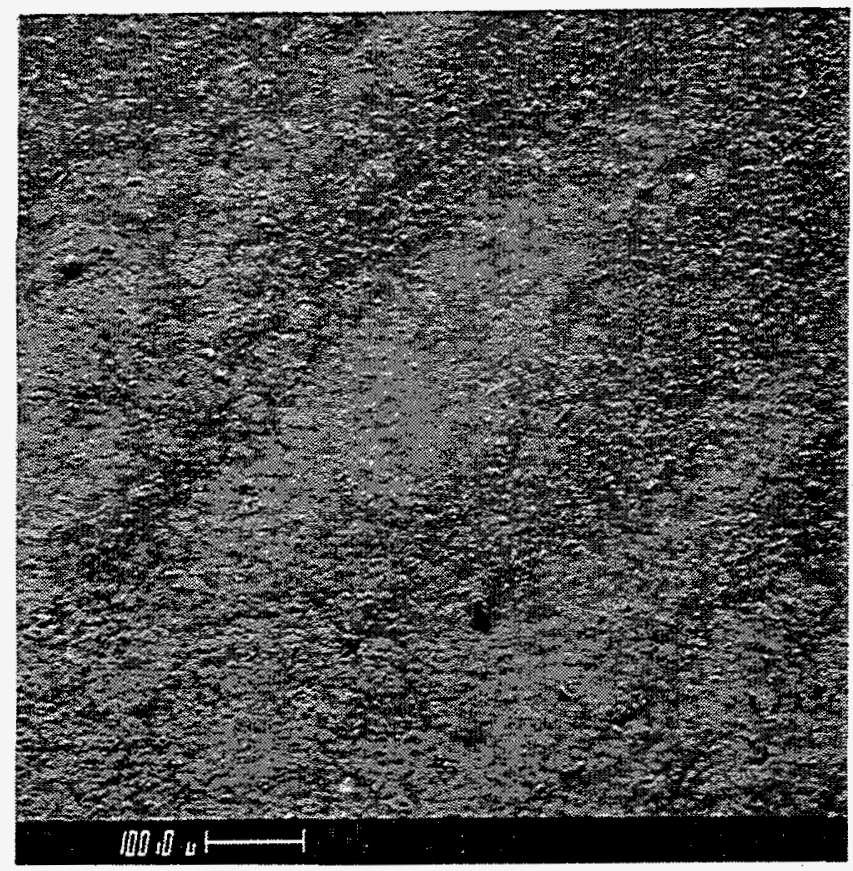

a

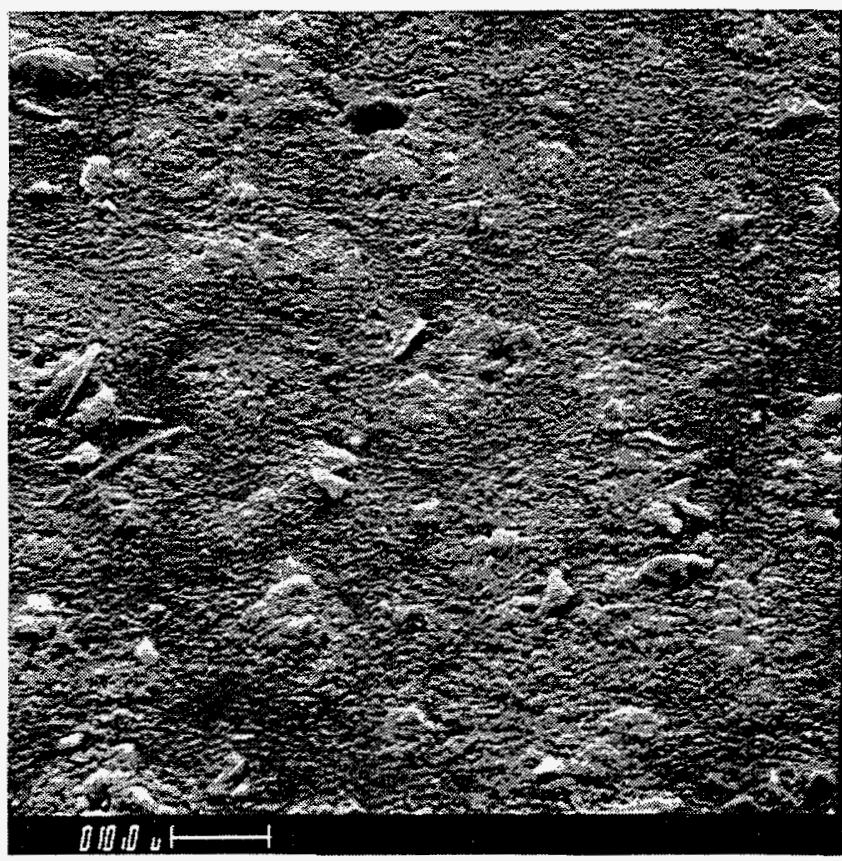

c

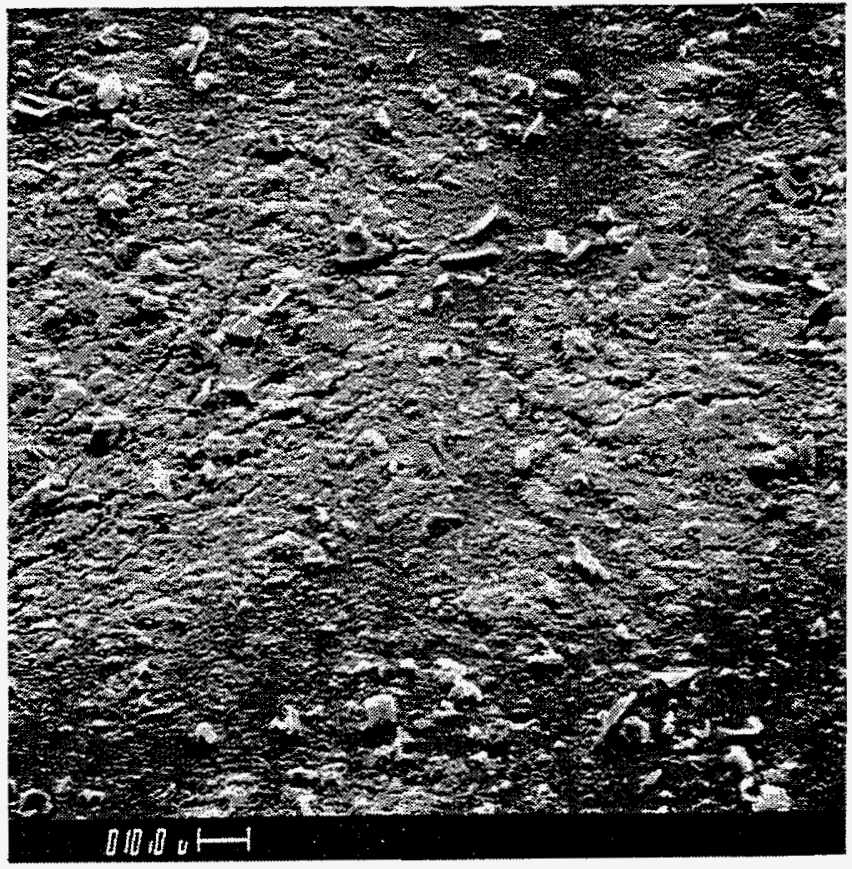

b

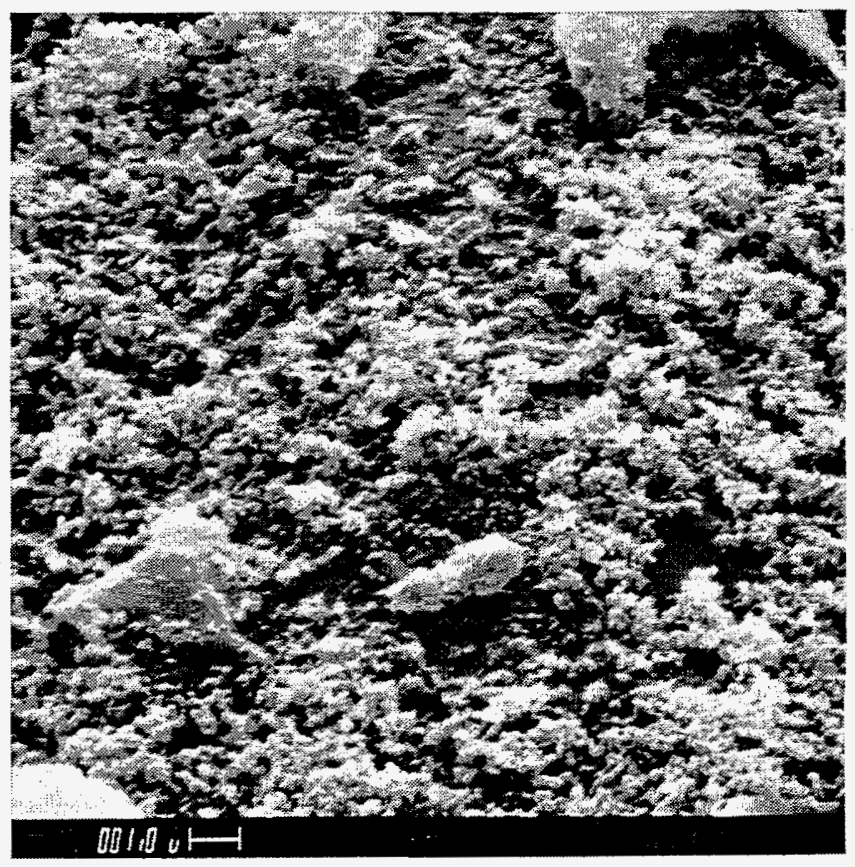

d

Figure 14. Representative SEM photographs of gasifier char (ID \# 2550) taken at a) $100 \mathrm{X}, \mathrm{b}) 500 \mathrm{X}$, c) $1000 \mathrm{X}$, and d) $5000 \mathrm{X}$. 


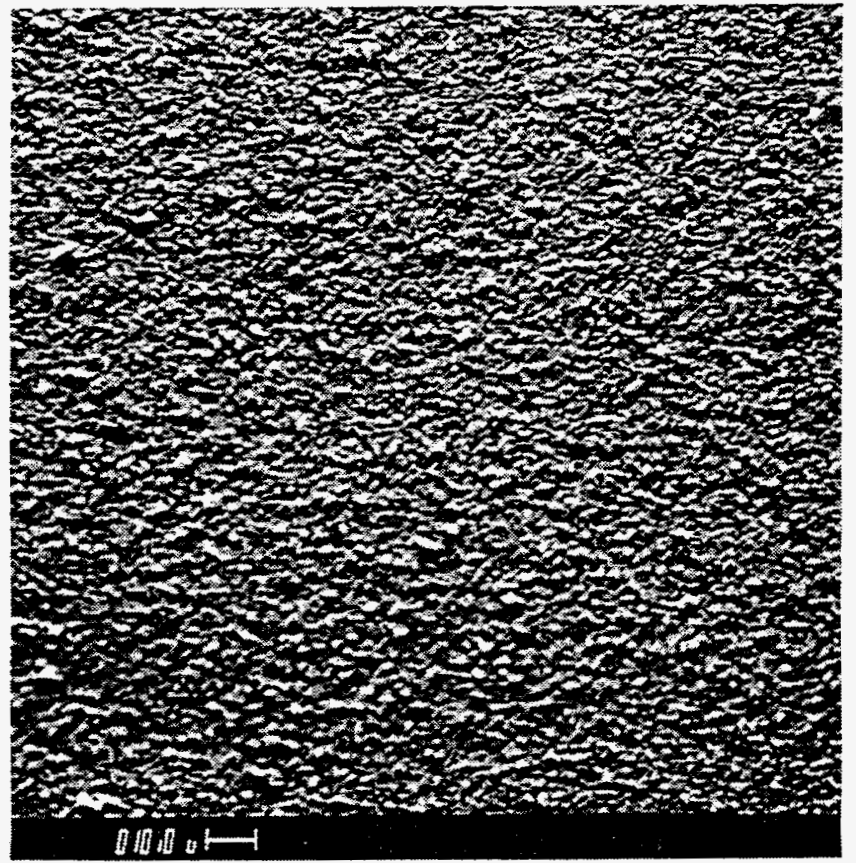

a

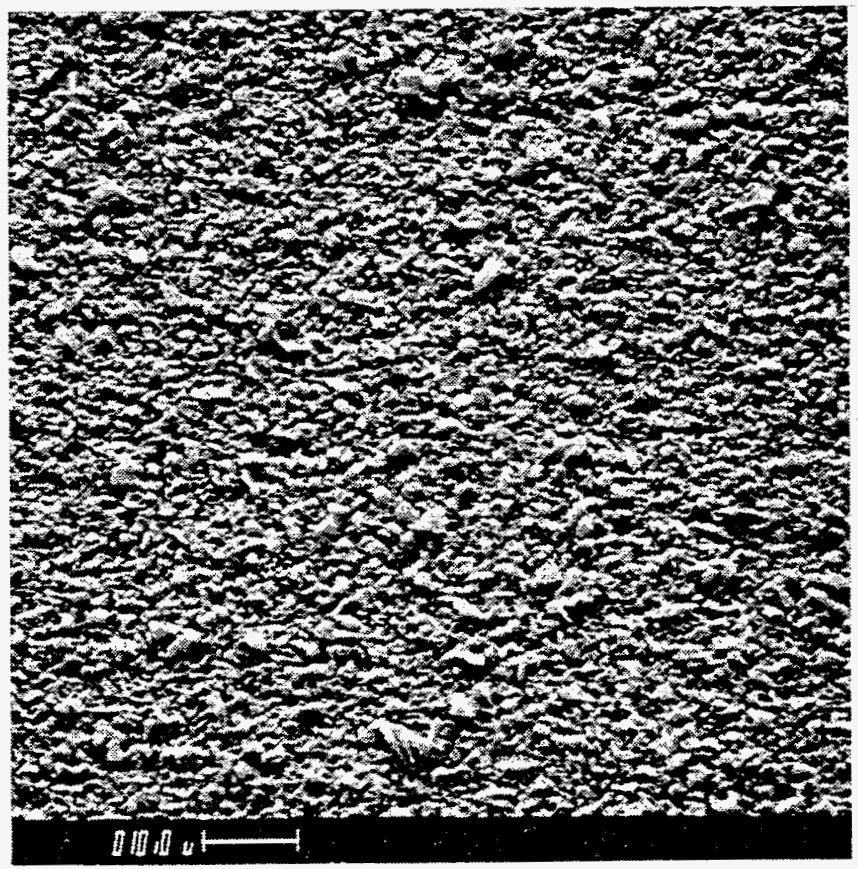

b

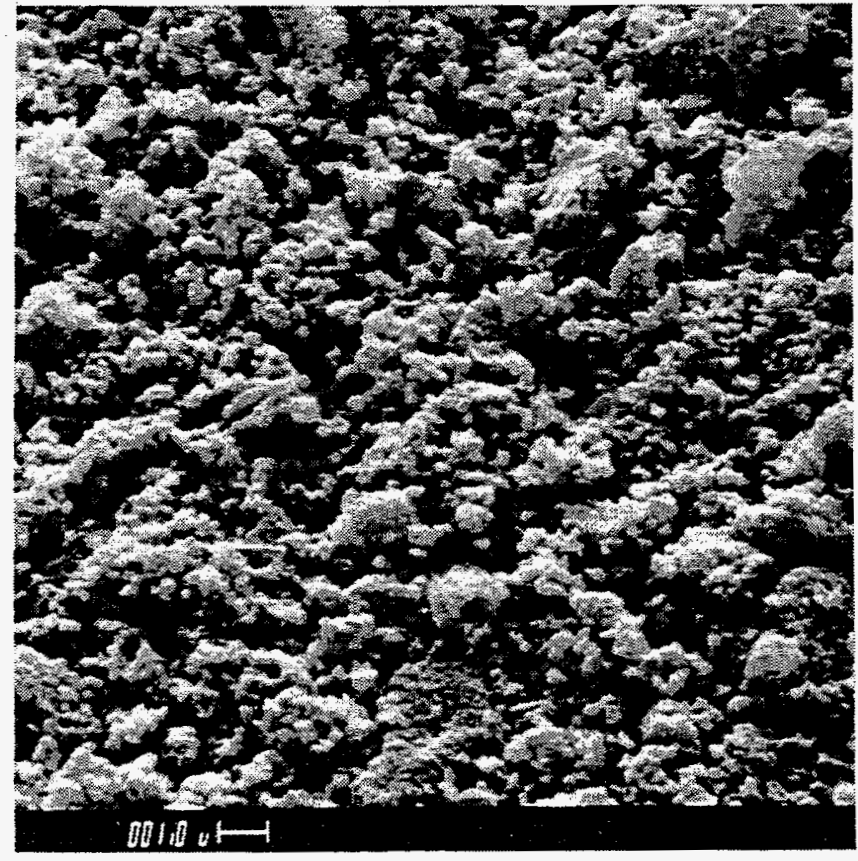

c

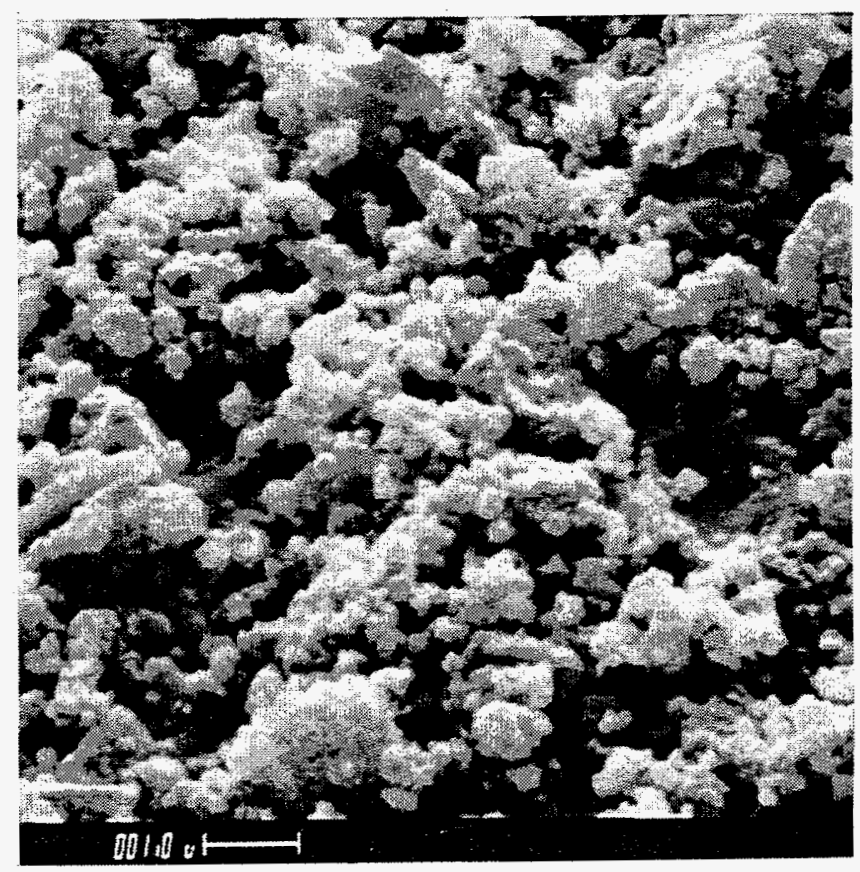

d

Figure 15. Representative SEM photographs of gasifier ash (ID \# 4170) taken at a) 500X, b) $1000 \mathrm{X}$, c) $5000 \mathrm{X}$, and d) $10000 \mathrm{X}$. 

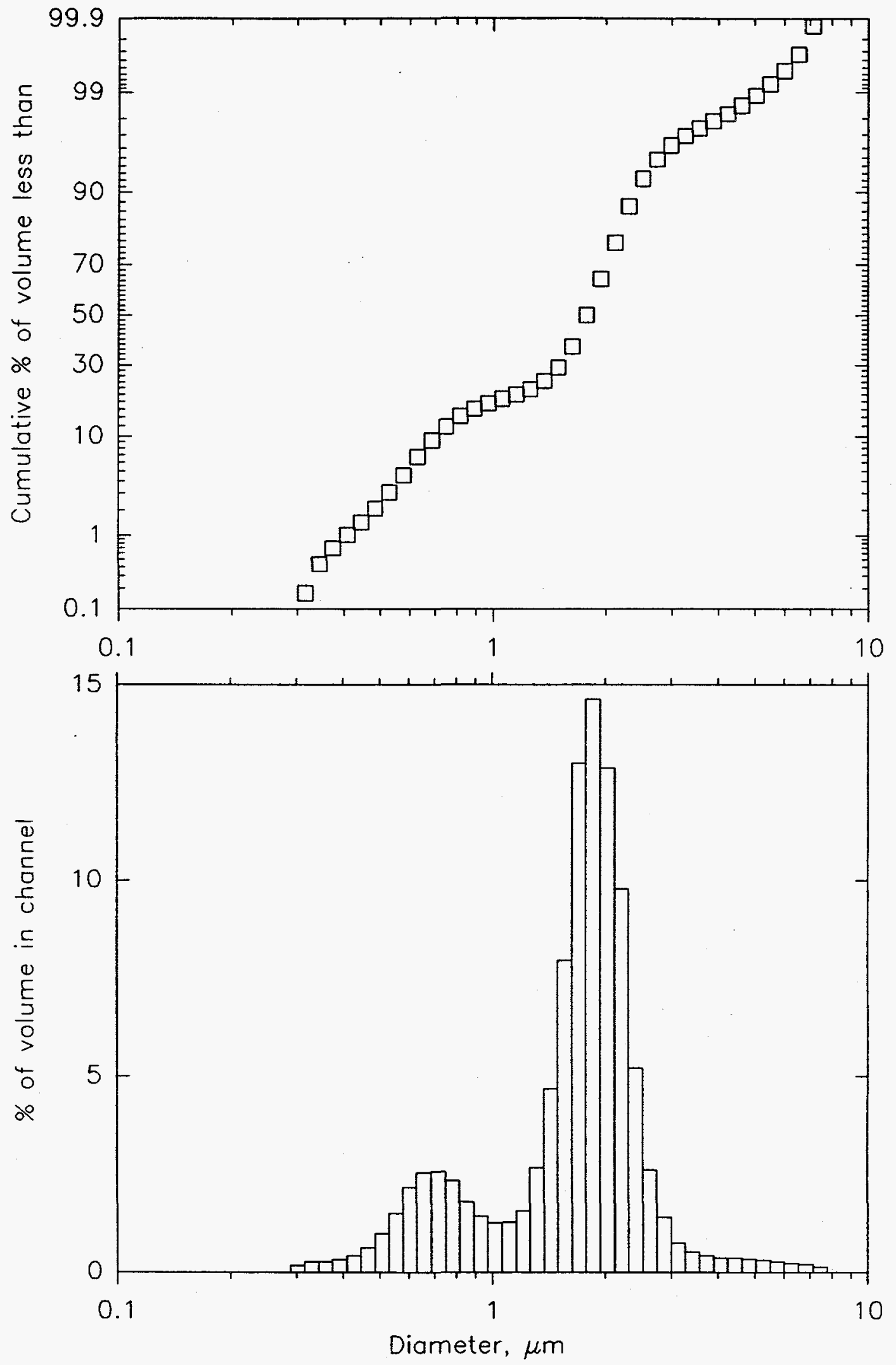

Figure 16. Cumulative and differential size distributions of ash from the DOE/METC gasifier (ID \# 4170) measured by a laser-based particle size analysis system and presented on the basis of assumed particle volume. 
the suspension was then agitated with an ultrasonic probe. This type of process is often used to successfully deagglomerate fine particles, however, it has also been known to cause primary particles to agglomerate. Based on our SEM observations of this sample and our experiences with ultrasonic agitation of dilute suspensions, we believe that the larger peak in the bimodal distribution shown in Figure 16 results from agglomerates of smaller primary particles. If this larger peak is discounted, the remaining size distribution has a volumetric median diameter around $0.7 \mu \mathrm{m}$ instead of the $1.8 \mu \mathrm{m}$ volumetric median diameter if the larger peak is included. In either case, the sample is composed of very fine particles, and $1.8 \mu \mathrm{m}$ serves as an upper bound of the volumetric median size of the particles.

Another factor which may lower the median diameter even lower than the $0.7 \mu \mathrm{m}$ value discussed above is the absence of any particles smaller than $0.29 \mu \mathrm{m}$ in the measured distribution even though the device is supposedly able to identify and account for particles as small as $0.12 \mu \mathrm{m}$. Once again, based on the SEM photographs in Figure 15, the sample does appear to contain a significant proportion of primary particles smaller than $0.29 \mu \mathrm{m}$. These experiences during the measurement of the size distribution of ID \# 4170 highlight some of the difficulties that are often encountered with samples containing a large proportion of ultrafine particles. (As with ID \#2550, we plan to quantify the size distribution of ID \# $\mathbf{4 1 7 0}$ with our sedigraph when it is repaired.)

Overall, these observations indicate that gasification ashes can exhibit extremely low permeabilities which can be traced to the presence of a high proportion of ultrafine particles. Consequently, it may be difficult to maintain a reasonable pressure drop in the filtration of these gasification ashes.

In general, the gasification ashes we tested exhibit very high uncompacted bulk porosities, which indicates that they are highly cohesive. (High uncompacted bulk porosities are generally associated with ashes having fine size distributions and/or irregular particle shapes. Gasification and PFBC ashes often have both of these characteristics.) However, these gasification ashes also generally exhibit relatively low tensile strengths. Normally, we would expect that highly cohesive ashes would also have high tensile strengths. We are not yet certain what causes this anomaly with gasification ashes. The low tensile strengths we have measured for gasification ash samples may indicate that ash dislodged from filter elements during pulse cleaning cycles may break up into very small agglomerates. If this type of breakup occurs, reentrainment of previously collected ash may pose a significant problem. 


\section{TASK 2 FILTER MATERIAL CHARACTERIZATION}

Mechanical and thermal testing of Dupont/Lanxide PRD-66, Dupont composite, 3M composite, and IF and P Fibrosics is continuing. A test matrix for these materials is shown in Table 18. Hoop tensile strengths for PRD-66, Dupont composite, and 3M composite and axial compressive results for IF and P Fibrosics have been reported in a separate sub-task report. Thermal expansion values measured at $1500^{\circ} \mathrm{F}$ are presented in Table 19. Thermal expansion values for the complete temperature range measured are shown in Figure 17.

Table 18

Preliminary Screening Test Matrix for Dupont PRD-66, Dupont Composite, $3 \mathrm{M}$ Composite, and IF and P Fibrosics Materials

\begin{tabular}{|l|l|c|l|}
\hline \multicolumn{1}{|c|}{ Material } & \multicolumn{1}{|c|}{ Test/Property } & Orientation & \multicolumn{2}{|c|}{ Temperature, ${ }^{\circ} \mathrm{F}$} \\
\hline $\begin{array}{l}\text { PRD-66, Dupont } \\
\text { composite, and 3M } \\
\text { composite }\end{array}$ & tension & hoop & $50^{*}$ \\
\hline $\begin{array}{l}\text { PRD-66, Dupont } \\
\text { composite, and 3M } \\
\text { composite }\end{array}$ & $\begin{array}{l}\text { tension after } 100 \mathrm{hr} . \\
\text { heat soak at } 1700^{\circ} \mathrm{F}\end{array}$ & hoop & $5 *$ \\
\hline $\begin{array}{l}\text { PRD-66, Dupont } \\
\text { composite, and 3M } \\
\text { composite }\end{array}$ & thermal expansion & hoop & $2-$ \\
\hline IF and P Fibrosics & compression & axial & 3 \\
\hline IF and P Fibrosics & thermal expansion & axial & $2-\cdots-{ }^{2}$ \\
\hline
\end{tabular}

* Three replicates for $3 \mathrm{M}$ composite

Table 19

Measured Thermal Expansion Values

\begin{tabular}{|c|c|c|}
\hline Material & Orientation & Thermal Expansion at $1500^{\circ} \mathrm{F}$ \\
\hline IF and P & axial & 0.0047 in./in. \\
\hline PRD-66 & diametral & 0.0033 in./in. \\
\hline 3M composite & diametral & 0.0025 in./in. \\
\hline
\end{tabular}

Testing of new Refractron and Schumacher candle filter materials is also in progress. A test matrix for these materials is shown in Table 20. Cutting plans are shown in Figures 18 through 20. Hoop tensile results are shown in Table 21 for Refractron and Table 22 for Schumacher. Creep testing of Refractron is now in progress. No creep was detected after $\sim 150$ hours at $1550{ }^{\circ} \mathrm{F}$ and creep testing is proceeding at $1600^{\circ} \mathrm{F}$. Schumacher creep 


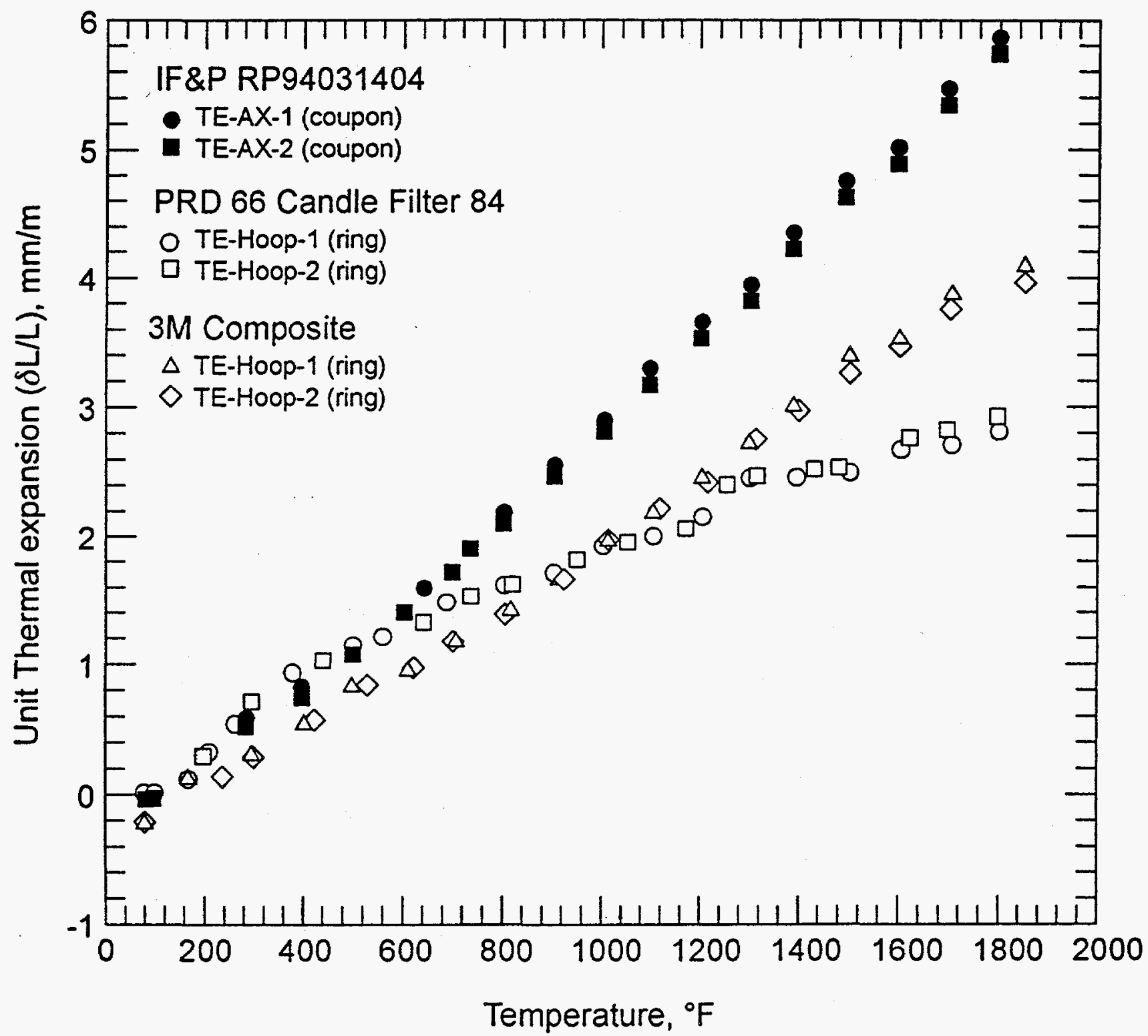

Figure 17. Thermal expansion of IF and P Fibrosics, Dupont PRD-66, and 3M composite materials. 

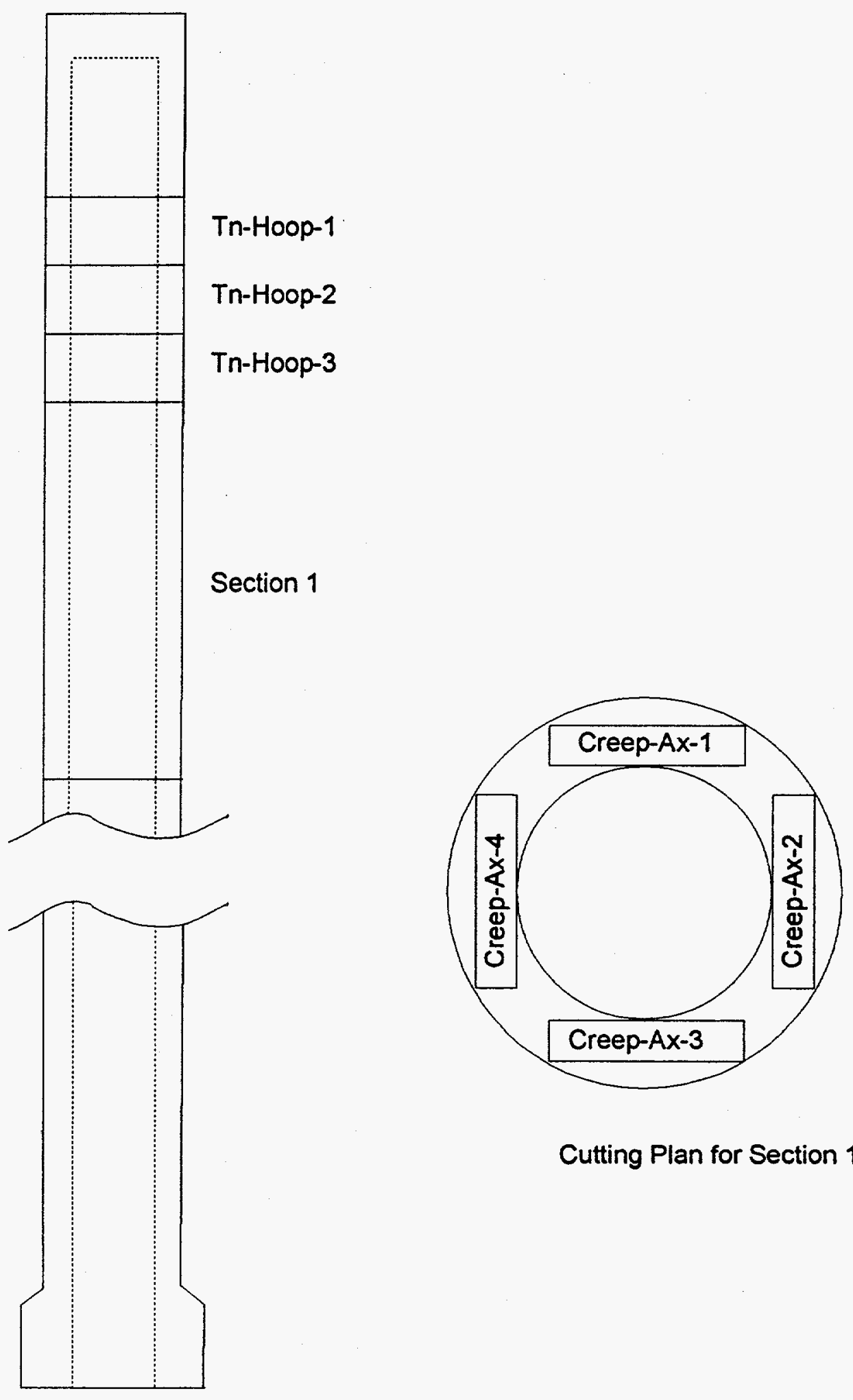

Cutting Plan for Section 1

Figure 18. Cutting plan for Refractron candle filter 2-469. 

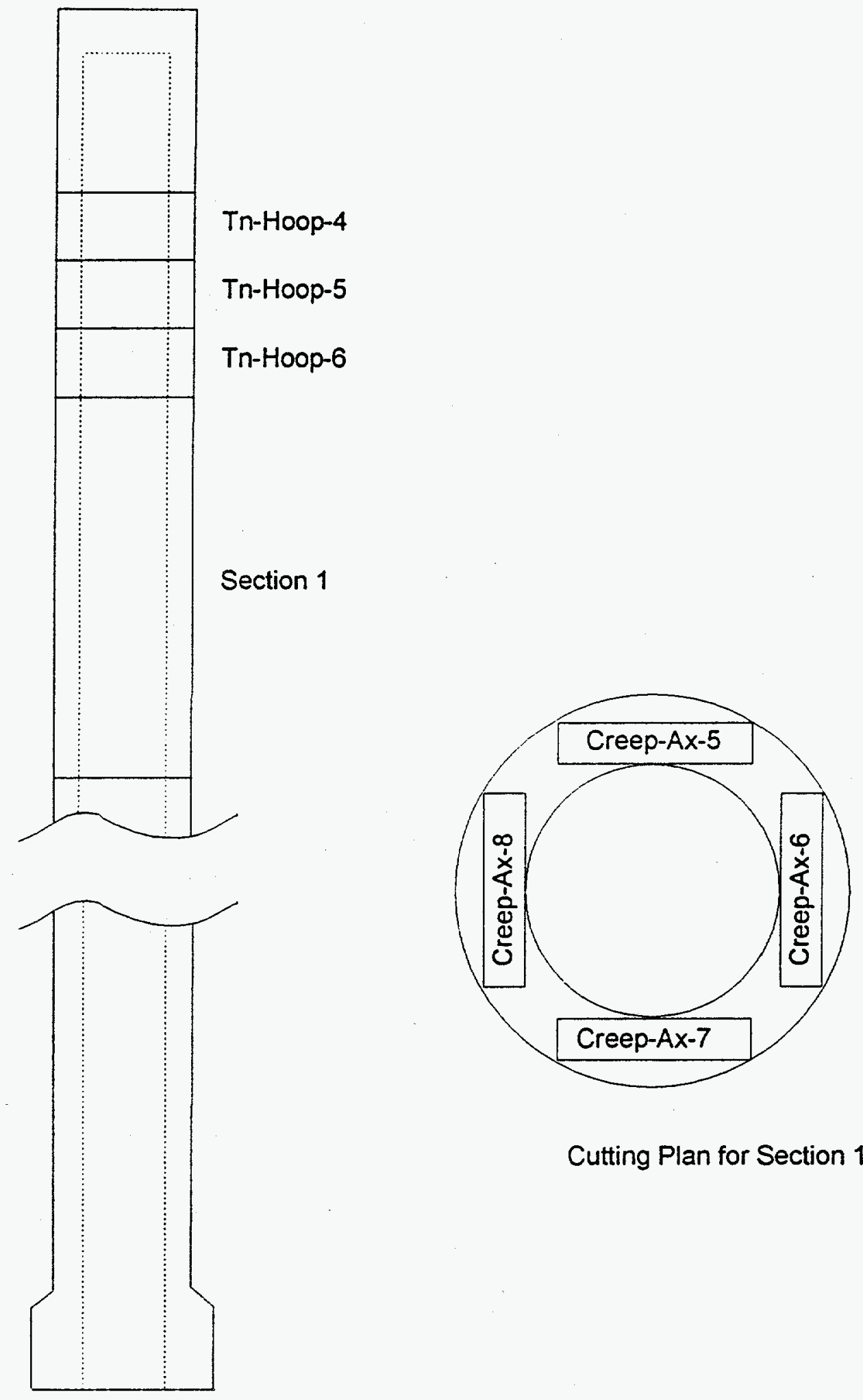

Cutting Plan for Section 1

Figure 19. Cutting plan for Refractron candle filter 4-471. 

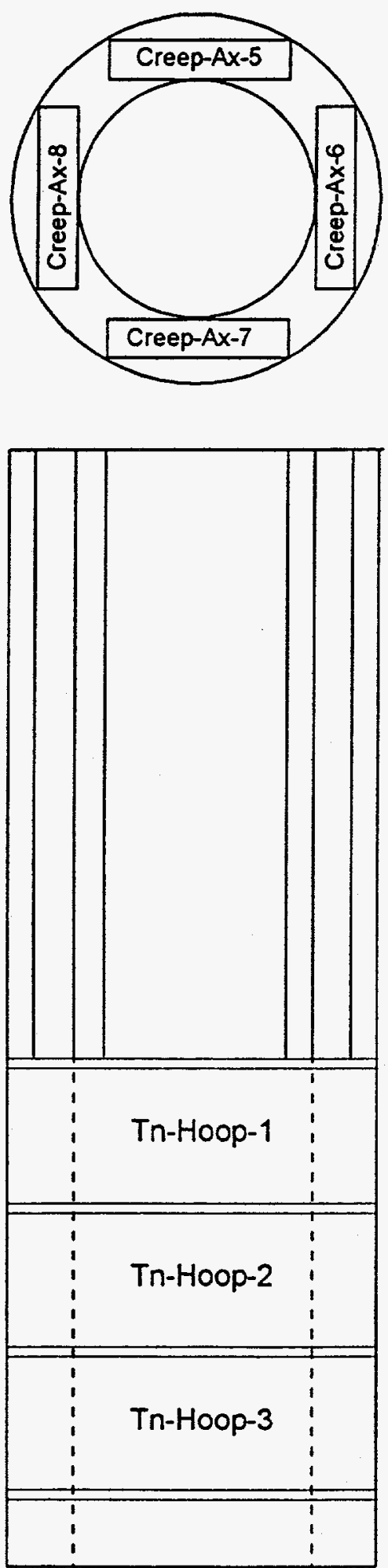

Final Specimen Dimensions (Inches):

Creep-Ax- $0.250 \times 0.9995 \times 7.00$

Tn-Hoop_as received i.d.x as received o.d. $\times 1.000$

Figure 20. Cutting plan for Schumacher candle filter S199/315E. 
specimens have been machined and testing of these specimens will follow testing of Refractron.

Table 20

Test Matrix for New Schumacher and Refractron Candle Filters

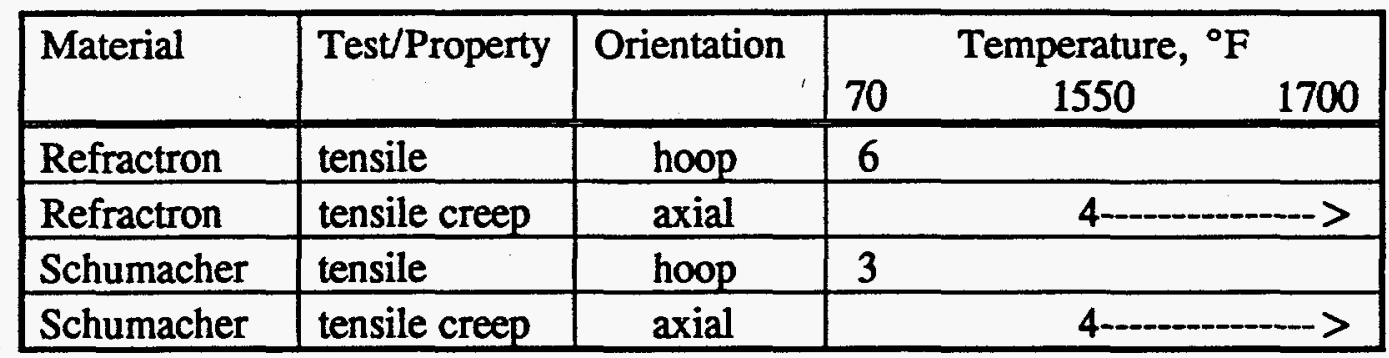

Table 21

Hoop Tensile Results for New Refractron Candle Filter Material

\begin{tabular}{|c|c|c|c|c|c|}
\hline $\begin{array}{c}\text { Candle } \\
\text { identification }\end{array}$ & $\begin{array}{c}\text { Specimen } \\
\text { number }\end{array}$ & $\begin{array}{c}\text { Test temperature, } \\
{ }^{\circ} \mathrm{F}\end{array}$ & $\begin{array}{c}\text { Specimen } \\
\text { ID, in. }\end{array}$ & $\begin{array}{c}\text { Specimen } \\
\text { OD, in. }\end{array}$ & $\begin{array}{c}\text { Ultimate tensile } \\
\text { strength, psi }\end{array}$ \\
\hline \hline $2-469$ & Tn-hoop-1 & 70 & 1.54 & 2.39 & 2000 \\
\hline $2-469$ & Tn-hoop-2 & 70 & 1.54 & 2.38 & 2100 \\
\hline $2-469$ & Tn-hoop-3 & 70 & 1.54 & 2.38 & 1980 \\
\hline $4-471$ & Tn-hoop-4 & 70 & 1.54 & 2.38 & 2190 \\
\hline $4-471$ & Tn-hoop-5 & 70 & 1.55 & 2.38 & 2470 \\
\hline $4-471$ & Tn-hoop-6 & 70 & 1.54 & 2.38 & 2040 \\
\hline
\end{tabular}

Average ultimate tensile strength $=2130 \mathrm{psi}$, standard deviation $=183 \mathrm{psi}, \mathrm{COV}=8.6 \%$.

Table 22

Hoop Tensile Results for New Schumacher Candle Filter Material

\begin{tabular}{|c|c|c|c|c|c|}
\hline $\begin{array}{c}\text { Candle } \\
\text { identification }\end{array}$ & $\begin{array}{c}\text { Specimen } \\
\text { number }\end{array}$ & $\begin{array}{c}\text { Test temperature, } \\
{ }^{\circ} \text { F }\end{array}$ & $\begin{array}{c}\text { Specimen } \\
\text { ID, in. }\end{array}$ & $\begin{array}{c}\text { Specimen } \\
\text { OD, in. }\end{array}$ & $\begin{array}{c}\text { Ultimate tensile } \\
\text { strength, psi }\end{array}$ \\
\hline S199/315E PT-20 & Tn-hoop-1 & 70 & 1.54 & 2.37 & 1740 \\
\hline S199/315E PT-20 & Tn-hoop-2 & 70 & 1.54 & 2.37 & 1720 \\
\hline S199/315E PT-20 & Tn-hoop-3 & 70 & 1.53 & 2.37 & 1620 \\
\hline
\end{tabular}

Average ultimate tensile strength $=1690 \mathrm{psi}$, standard deviation $=64 \mathrm{psi}$, COV $=3.8 \%$.

Mechanical and thermal testing of the new Refractron and Schumacher candle filter material is continuing. The test matrix used to evaluate the material is shown in Table 23 . 
Table 23

Test Matrix for Refractron and Schumacher Filter Materials

\begin{tabular}{|l|c|cccc|}
\hline \multicolumn{1}{|c|}{ Test Type } & Orientation & RT & $1600^{\circ} \mathrm{F}$ & $1700^{\circ} \mathrm{F}$ & $1800^{\circ} \mathrm{F}$ \\
\hline Tensile & Hoop & 6 & & 4 & 4 \\
Tensile Creep & Axial & 4 & 4 & 4 & \\
& Axial & & 4 & 4 & \\
Thermal Expansion & Hoop & 2 & & & \\
& Axial & 2 & & & \\
Microstructure & & & & & \\
\end{tabular}

Hoop and axial tensile results for the new Refractron material are given in Table 24. The average axial strength at room temperature was $1150 \mathrm{psi}$; the average hoop strength was 2130 psi. A plot of tensile strength versus temperature is given in Figure 21. Creep evaluations are in progress and no creep was detected after about 150 hours at $1550^{\circ} \mathrm{F}$. Testing will continue by increasing temperature and/or stress levels. Axial thermal expansion is summarized in Table 25 and Figure 22. 


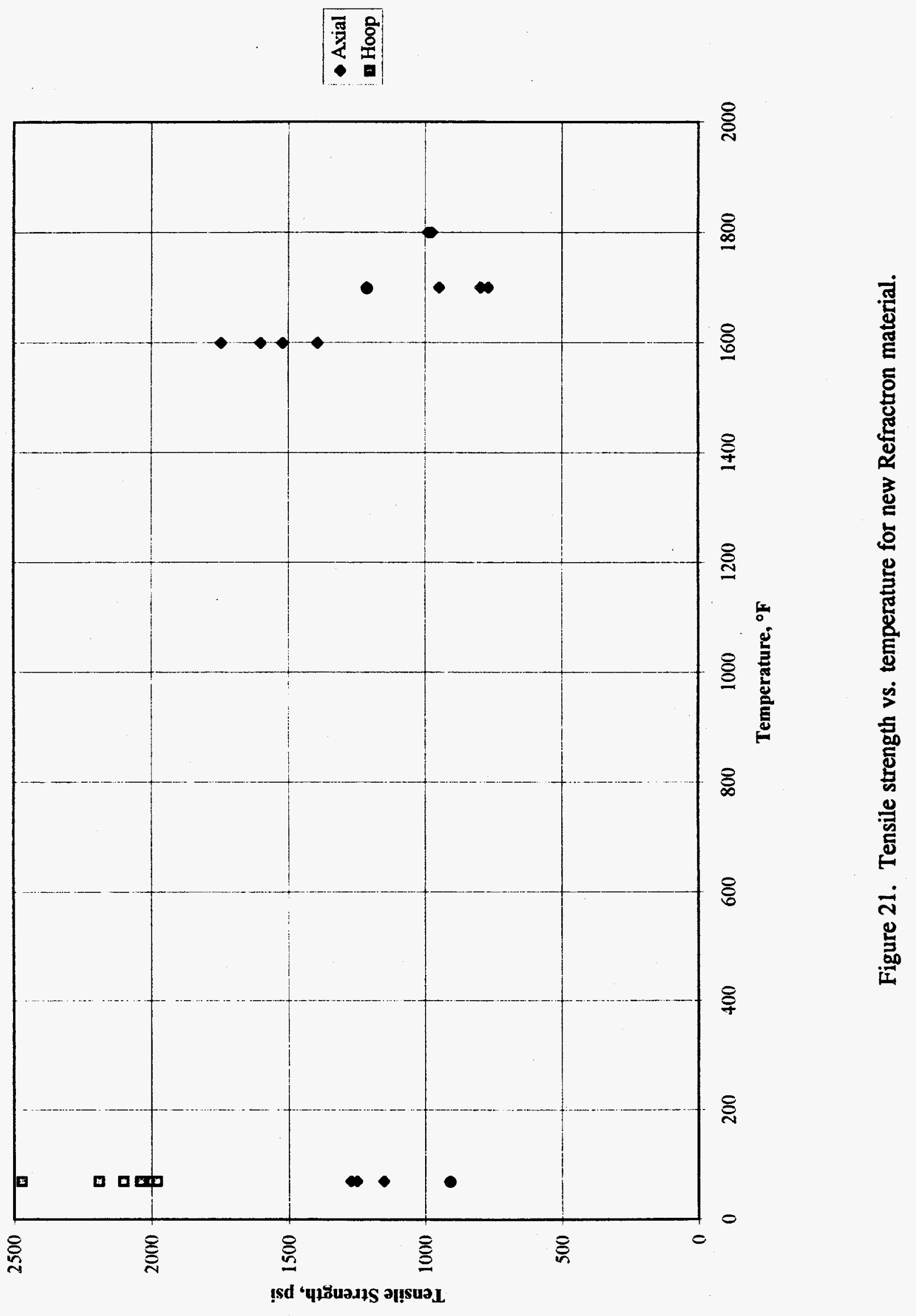




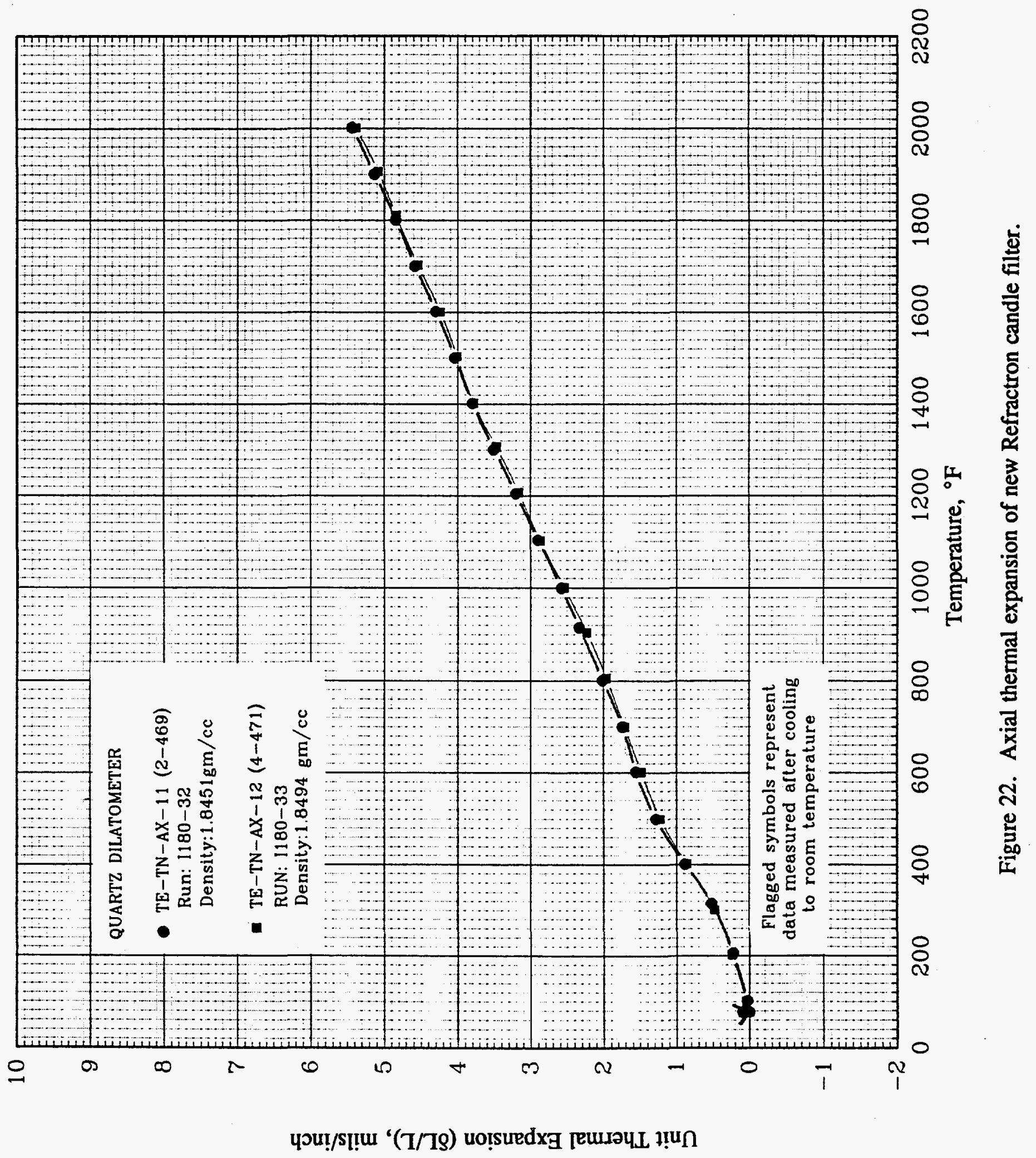


Table 24

Tensile Data for New Refractron Candle Material

\begin{tabular}{|c|c|c|c|c|c|c|}
\hline Candle & Specimen \# & Temp., ${ }^{\circ} \mathrm{F}$ & $\begin{array}{c}\text { Ultimate } \\
\text { strength, psi }\end{array}$ & $\begin{array}{c}\text { Modulus, } \\
\text { Msi }\end{array}$ & $\begin{array}{c}\text { Strain-to- } \\
\text { failure, in./in. }\end{array}$ & Remarks \\
\hline $4-471$ & TN-AX-12 & 70 & 1152 & 5.88 & 0.000196 & \\
\hline $4-471$ & TN-AX-17 & 70 & 1250 & 6.67 & 0.000187 & \\
\hline $2-469$ & TN-AX-5 & 70 & 910 & 4.82 & 0.000189 & \\
\hline $2-469$ & $\mathrm{TN}-\mathrm{AX}-11$ & 70 & 1272 & 5.06 & 0.000251 & \\
\hline $4-471$ & TN-AX-18 & 1600 & 1394 & 1.82 & 0.001300 & \\
\hline $4-471$ & $T N-A X-13$ & 1600 & 1746 & 1.68 & 0.001400 & \\
\hline $2-469$ & TN-AX-7 & 1600 & 1600 & 3.48 & 0.002250 & \\
\hline $4-471$ & TN-AX-21 & 1600 & 1520 & 2.72 & 0.001640 & \\
\hline $2-469$ & TN-AX-2 & 1700 & 768 & 1.79 & - & 1 \\
\hline $4-471$ & TN-AX-20 & 1700 & 796 & 2.77 & 0.000690 & \\
\hline $2-469$ & TN-AX-6 & 1700 & 948 & 2.45 & 0.000975 & \\
\hline $4-471$ & TN-AX-19 & 1700 & 1214 & 4.30 & 0.000925 & \\
\hline $2-469$ & TN-AX-10 & 1800 & 976 & 2.24 & 0.000600 & \\
\hline $4-471$ & TN-AX-14 & 1800 & 989 & 3.33 & 0.000400 & \\
\hline $2-469$ & TN-Hoop-1 & 70 & 2000 & - & - & 2 \\
\hline $2-469$ & TN-Hoop-2 & 70 & 2100 & $\cdots$ & - & 2 \\
\hline $2-469$ & TN-Hoop-3 & 70 & 1980 & - & - & 2 \\
\hline $4-471$ & TN-Hoop-4 & 70 & 2190 & -- & -- & 2 \\
\hline $4-471$ & TN-Hoop-5 & 70 & 2470 & - & - & 2 \\
\hline $4-471$ & TN-Hoop-6 & 70 & 2040 & - & - & 2 \\
\hline
\end{tabular}

1 Flags slipped during test

2 Load-time only 
Table 25

Axial Thermal Expansion for New Refractron Candle Material

\begin{tabular}{|c|c|c|}
\hline Filter \# & Temperature, ${ }^{\circ} \mathrm{F}$ & Unit Thermal Expansion, mils/inch \\
\hline . & \begin{tabular}{|l}
78 \\
102 \\
206 \\
315 \\
401 \\
500 \\
602 \\
700 \\
801 \\
915 \\
1000 \\
1104 \\
1205 \\
1301 \\
1402 \\
1501 \\
1602 \\
1700 \\
1801 \\
1901 \\
2002 \\
\end{tabular} & $\begin{array}{l}0.00 \\
0.03 \\
0.22 \\
0.51 \\
0.88 \\
1.28 \\
1.55 \\
1.74 \\
2.01 \\
2.33 \\
2.58 \\
2.90 \\
3.20 \\
3.50 \\
3.80 \\
4.04 \\
4.30 \\
4.58 \\
4.84 \\
5.13 \\
5.43\end{array}$ \\
\hline & 78 & 0.09 \\
\hline 4-471 & $\begin{array}{c}77 \\
101 \\
202 \\
301 \\
402 \\
500 \\
602 \\
700 \\
806 \\
905 \\
1001 \\
1102 \\
1207 \\
1307 \\
1402 \\
1503 \\
1601 \\
1702 \\
1811 \\
1907 \\
2001 \\
76\end{array}$ & $\begin{array}{l}0.00 \\
0.04 \\
0.23 \\
0.47 \\
0.86 \\
1.22 \\
1.48 \\
1.71 \\
1.96 \\
2.23 \\
2.54 \\
2.87 \\
3.16 \\
3.47 \\
3.78 \\
4.01 \\
4.24 \\
4.54 \\
4.84 \\
5.08 \\
5.38 \\
0.09\end{array}$ \\
\hline
\end{tabular}


New Schumacher filters were received and specimens are currently being machined according to the cutting plans given in Figures 23 and 24. When machining is complete, nondestructive density and ultrasonic velocity measurements will be made and then mechanical and thermal tests will commence. 

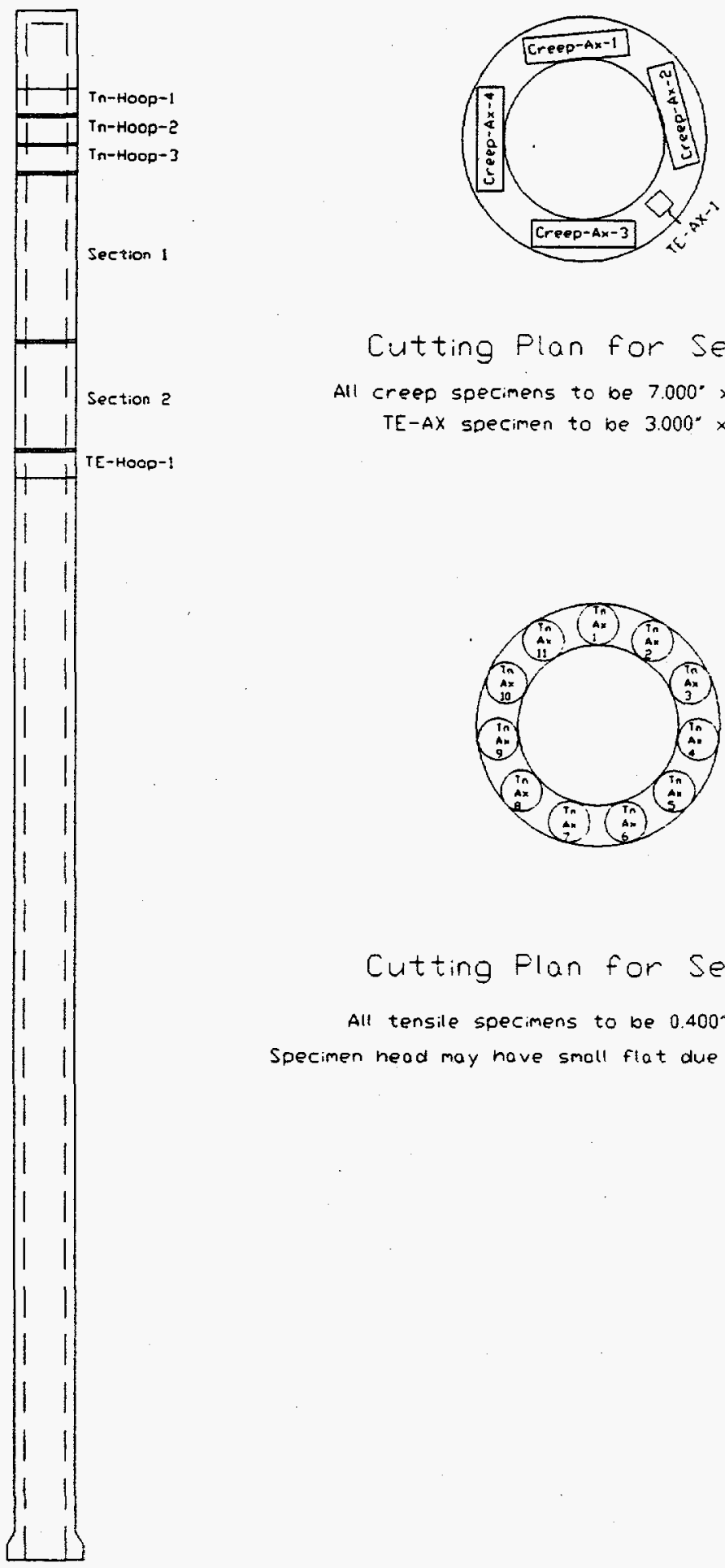

$$
\text { Cutting Plan for Section } 1
$$

All creep specimens to be $7.000^{\circ} \times 0.9995^{\circ} \times 0.250^{\circ}$

TE-AX specimen to be $3.000^{\circ} \times 0.375^{\circ} \times 0.375^{\circ}$

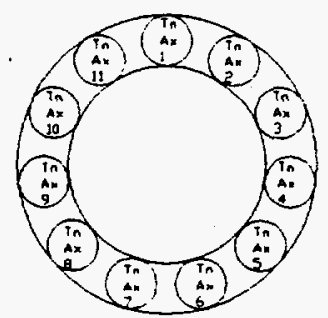

Cutting Plan for Section 2

All tensile specimens to be $0.400^{\prime \prime}$ dia $\times 410^{*}$

Specimen head may hove smoll flat due to insufficient wall thickness

Figure 23. Cutting plan for Schumacher candle 344E-295. 
TE-Hoop. Tn-Hoop specimens to be os-received ID and oD $\times 1.000^{\circ}$ thick
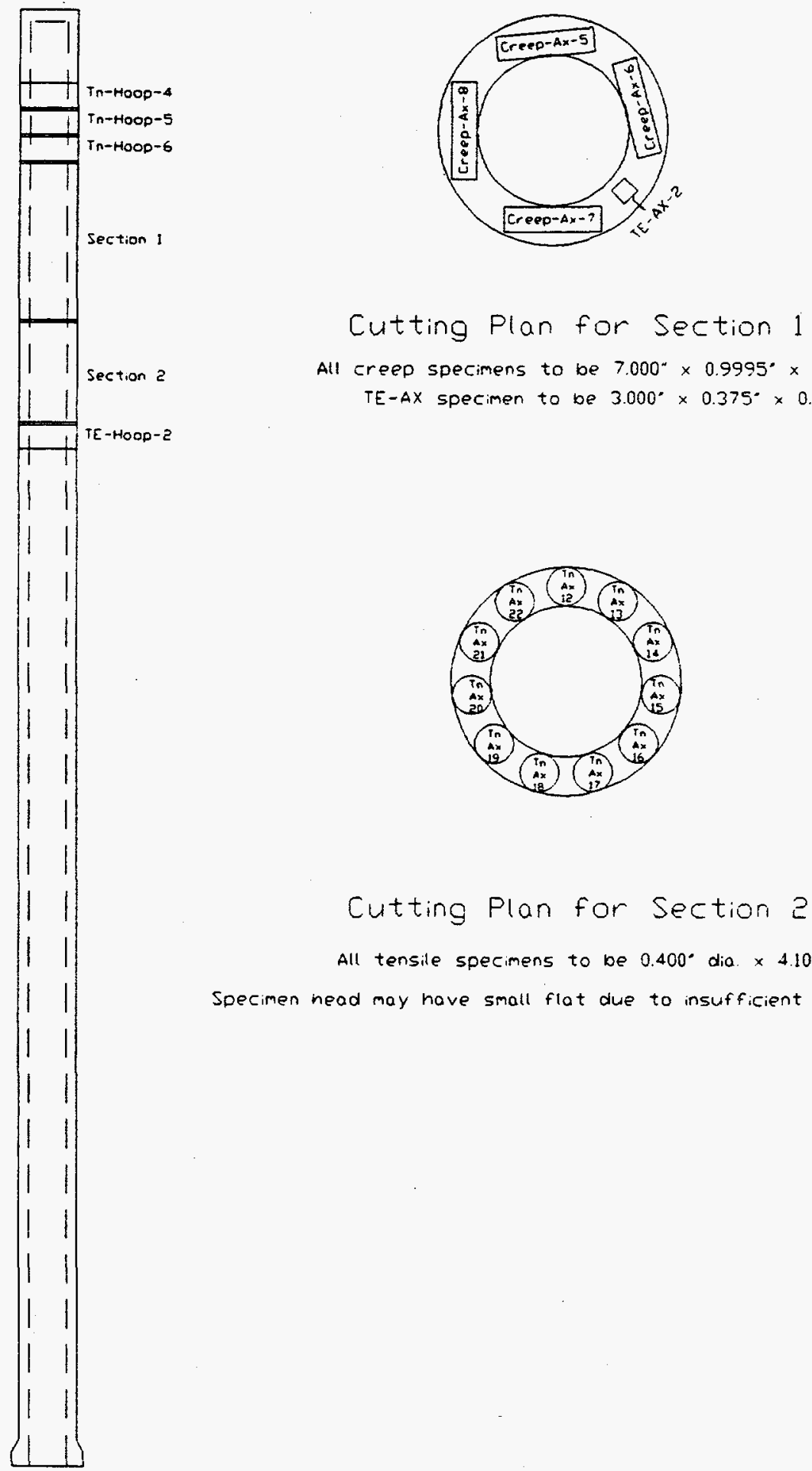

All creep specimens to be 7.000" $\times 0.9995^{\circ} \times 0.250^{*}$

TE-AX specimen to be $3.000^{\circ} \times 0.375^{\circ} \times 0.375^{\circ}$

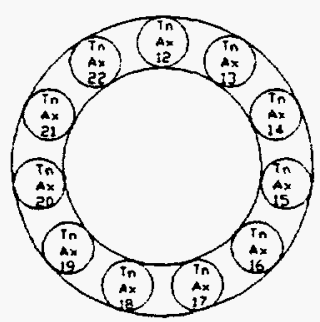

Cutting Plan for section ?

All tensile specimens to be $0.400^{\circ}$ dia $\times 4.10^{\circ}$

Specimen heod may have small flot due to insufficient wall thickness

Figure 24. Cutting plan for Schumacher candle 344E-309. 


\section{FUTURE WORK}

Our research plans include analyses of ashes that we expect to receive from General Electric's gasification facility in Schenectady, NY. We also plan to complete the design of a high-temperature test device intended to measure the uncompacted bulk porosity of aggregates of ash formed at temperatures commonly encountered in operating APFs. Additional plans include evaluation and selection of software for the presentation of the HGCU data base. Nondestructive density and ultrasonic velocity measurements will be made on the Schumacher filters that were recently received. Mechanical and thermal tests will follow these measurements. Creep testing of Refractron and Schumacher candle filter materials will continue. 


\section{REFERENCES}

1. Kozeny, J. Ber. Wein. Akad. 136a, 271 (1927)

2. Carman, P. C. "Fluid flow through granular beds," Trans. Inst. Chem. Engs. 15, 150 (1937).

3. Langmuir, I. "Report on Smokes and Filters," Section I. U.S. Office of Scientific Research and Development, No. 865, part IV (1942).

4. Davies, C.N., Air Filtration, Acedemic Press, New York, 1973, pp. 7-29.

5. O' Gorman, J.V. and P.L. Walker, Jr. "Thermal behavior of mineral fractions separated from selected American coals," Fuel 52, 71 (1973).

6. Wibberley, L.J. and T.F. Wall. "Alkali-ash reactions and deposit formation in pulverized-coal-fired boilers: experimental aspects of sodium silicate formation and the formation of deposits," Fuel 61, 93 (1982).

7. Helble, J.J., S. Srinivasachar, and A.A. Boni. "Factors influencing the transformation of minerals during pulverized coal combustion,” Prog. Energy Combust. Sci. 16, 267 (1990). 
NODULE POROSITY (WATER TECHINIQUE) - In this test, a nodule is selected, cleaned with a gentle jet of air, and weighed. Then water is allowed to soak very slowly into the nodule until the surface of the nodule glistens evenly. The fully wetted nodule is weighed, and the porosity of the nodule is calculated from the initial dry weight, the final wetted weight, and the true density of the ash particles. Determination of the porosity of a filter cake nodule provides a direct measurement of the porosity of the filter cake.

NODULE POROSITY (EPOXY TECHNIQUE) - In this test, a nodule is selected, cleaned with a gentle jet of air, and weighed. Then low-viscosity epoxy is allowed to soak slowly into the nodule until the surface of the nodule glistens evenly. The fully encapsulated nodule is baked to cure the epoxy, and its total volume is measured in a helium pycnometer. Nodule porosity is calculated from the initial dry weight, the final encapsulated volume, and the true density of the ash. Determination of the porosity of a filter cake nodule provides a direct measurement of the porosity of the filter cake. The cured, encapsulated nodule can be cut, machined, and prepared for further analyses, if desired.

STOKES' MASS MEAN DIAMETER - This technique uses a sedigraphic analyzer to provide a measurement of the fly ash size distribution based on aerodynamic classification of fly ash particles. The test procedure involves the suspension of a small amount of ash in a clear fluid. The particles in the fluid gradually settle out, first due to gravitational force alone, and then due to centrifugal force introduced by increasingly rapid rotation of the sample cell. The device combines photometrically-obtained particle concentration data with Stokes' law describing the settling of particles in a viscous medium to calculate the particle size distribution.

SPECIFIC SURFACE AREA - This measurement utilizes the Brunaeur-Emmett-Teller (BET) technique for determining the total surface area of a known mass of fly ash sample. Ashes that exhibit relatively high specific surface areas are usually highly cohesive, and form filter cakes with relatively high porosities.

UNCOMPACTED BULK POROSITY - This value expresses the porosity of a container of sifted ash. Ashes exhibiting a relatively high uncompacted bulk porosity value are generally highly cohesive.

DENSITY - This standard measurement is obtained with a helium pycnometer. The value obtained with this technique is the true density, or specific gravity of the ash particles in the sample tested. 
DRAG-EQUIVALENT DIAMETER - This quantity is not a measurement of physical size, but rather a fitted parameter ranking the characteristic specific gas-flow resistances of ashes at equal porosities. Increasing values of drag-equivalent diameter indicate a lower resistance to gas flow at a given porosity. Measurements of physical size generally correlate with this expression; however, the drag-equivalent diameter best expresses the fineness of an ash as it relates to its effect on specific gas-flow resistance. Ashes with smaller values of drag-equivalent diameter are generally more cohesive.

SPECIFIC GAS-FLOW RESISTANCE - This value is obtained by filtering air at a known flowrate through a simulated filter cake of known porosity in a laboratory test device while measuring the resistance to the air flow. When this measurement is made with the porosity of the simulated filter cake equal to the estimated characteristic filter cake porosity of the ash, the resistance is defined as the specific gas-flow resistance. This value is the resistance that this simulated filter cake (with an areal loading of $1.0 \mathrm{lb} / \mathrm{ft}^{2}$ ) exhibits for an air flow of $1.0 \mathrm{acfm} / \mathrm{ft}^{2}$.

TENSILE STRENGTH - This test measures the magnitude of the attractive forces between ash particles. An electrostatic tensiometer is used to apply a mechanical stress on a dust layer as an effect of an imposed electrostatic field. This electrostatic technique allows the measurement to be performed on uncompacted ash samples. 
PARTICULATE HOT GAS STREAM CLEANUP TECHNICAL ISSUES

\section{ANNUAL REPORT}

October 1994 - September 1995

SRI-ENV-95-899-8484-A1

Contract No. DE-AC21-94MC31160

December 19, 1995

Approved by

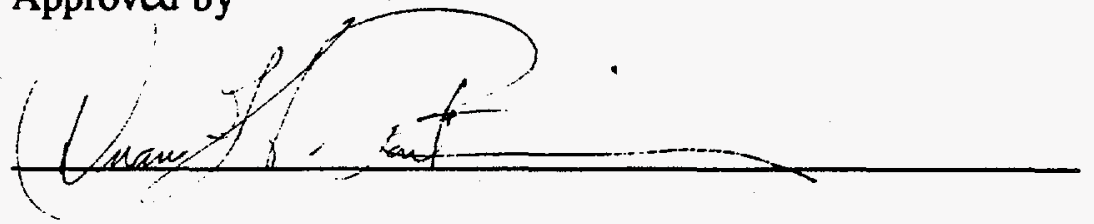

Duane H. Pontius, Director Particulate Sciences Department 